Karina de Barros Pellegrinelli

\title{
Existe associação entre a forma que os pais com TBI foram cuidados na sua infância e a forma como eles cuidam dos seus filhos na vida adulta?
}

\author{
Tese apresentada à Faculdade de Medicina da \\ Universidade de São Paulo para obtenção do título \\ de Doutor em Ciências \\ Programa de Psiquiatria \\ Orientador: Prof. Dr. Ricardo Alberto Moreno
}

(Versão corrigida. Resolução CoPGr 6018/11, de 1 de novembro de 2011.

A versão original está disponível na Biblioteca da FMUSP)

\section{São Paulo}


Dados Internacionais de Catalogação na Publicação (CIP)

Preparada pela Biblioteca da

Faculdade de Medicina da Universidade de São Paulo

Creprodução autorizada pelo autor

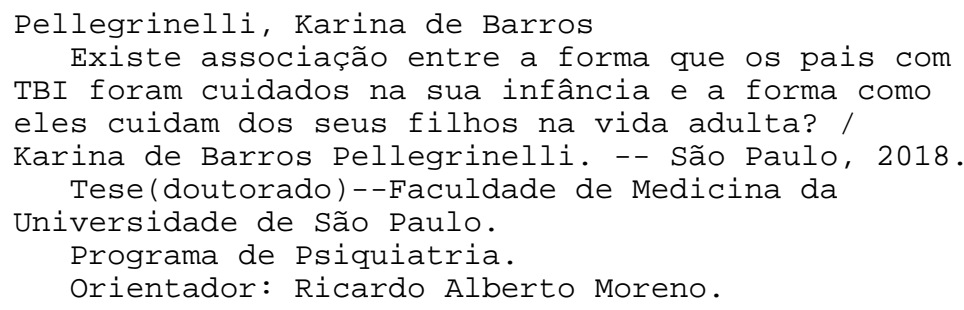

Descritores: 1.Transtorno bipolar 2.Cuidados parentais 3.Psicopatologia 4.Relações familiares 5.Comportamento infantil/psicologia 6. Relações paifilho

$\mathrm{USP} / \mathrm{FM} / \mathrm{DBD}-431 / 18$

Responsável: Erinalva da Conceição Batista, CRB-8 6755 


\section{Dedicatória}

Dedico este trabalho aos meus filhos Giulia Pellegrinelli Guedes e Luca Pellegrinelli Guedes, que são os maiores representantes do amor na minha vida. Ao meu marido Sergio Guedes, pelo amor, parceria e apoio incondicionais. E, claro, a todos os pacientes, que participaram e contribuíram para o desenvolvimento deste estudo e que, futuramente, poderão usufruir do tratamento baseado nas evidências levantadas. 


\section{Agradecimentos}

À psicóloga Daniele Soares Bio, pela inestimável contribuição por ter vislumbrado a oportunidade, ter apresentado a ideia de desenvolver este projeto de doutorado e ter dado todo o apoio necessário para seu desenvolvimento, sempre pronta para esclarecer uma dúvida e trocar ideias ou uma orientação.

À psicóloga Adriana Carneiro, por sua amizade, parceria, apoio, incentivo e cumplicidade durante o desenvolvimento deste projeto.

Ao Prof. Dr. Ricardo Alberto Moreno, por mais uma vez aceitar me orientar e pelas oportunidades proporcionadas de realização profissional a partir deste trabalho.

À toda equipe PROGRUDA e, principalmente, à Roberta Yamamoto, pelo apoio prestado sempre que necessário.

À estatística Rejane Rocha,do Departamento de Matemática e Estatística da Universidade Federal de São João del-Rei, pelo apoio estatístico e pela disposição inestimável em ajudar.

À toda a equipe do CAPS Del Rei/MG, por abrirem as portas para o desenvolvimento deste trabalho.

À toda a equipe do CAPS Oliveira/MG, pela imensurável ajuda em localizar os pacientes com o perfil para participar deste trabalho.

Aos estagiários da Faculdade de Psicologia da Universidade Federal de São João del-Rei,Philippe D. S. Reis, Lais Duarte, Poliana Inácio Pinto e Maria Fernanda Gusmão, pelo empenho e dedicação a este trabalho.

À Profa. Dra. Marina B. Bandeira, do Laboratório de Saúde Mental da Universidade Federal de São João del-Rei, pela importante parceria. 
À Fundação de Amparo à Pesquisa do Estado de São Paulo (FAPESP), pelo apoio financeiro concedido para desenvolvimento, realização e apresentação deste trabalho em eventos científicos extremamente relevantes no cenário mundial. PROCESSO FAPESP Nº 2015/164428. 


\section{NORMALIZAÇÃO ADOTADA}

Esta tese está de acordo com as seguintes normas, em vigor no momento desta publicação:

Referências: adaptado de International Committee of Medical Journals Editors (Vancouver).

Universidade de São Paulo. Faculdade de Medicina. Divisão de Biblioteca e Documentação. Guia de apresentação de dissertações, teses e monografias. Elaborado por Anneliese Carneiro da Cunha, Maria Julia de A. L. Freddi, Maria F. Crestana, Marinalva de Souza Aragão, Suely Campos Cardoso, Valéria Vilhena. 3a ed. São Paulo: Divisão de Biblioteca e Documentação; 2011.

Abreviaturas dos títulos dos periódicos de acordo com List of Journals Indexed in Index Medicus. 


\section{Sumário}

\section{LISTA DE ABREVIATURAS}

LISTA DE TABELAS

RESUMO

ABSTRACT

1 INTRODUÇÃO. . .1

1.1 Caracterização do cuidado parental de portadores de TB ................................3

1.2 Estudos com TB e EMBU ......................................................................

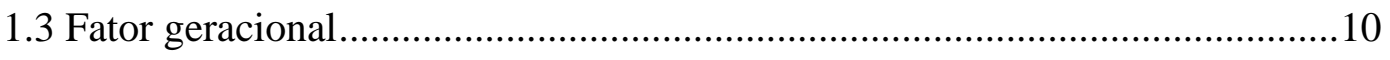

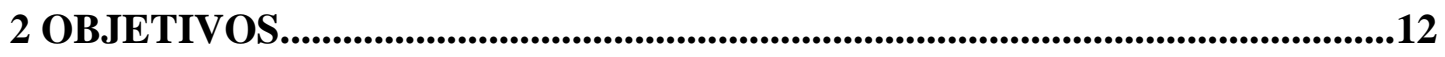

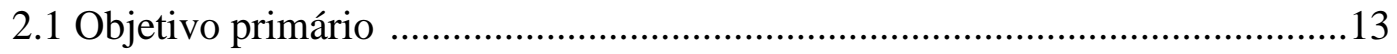

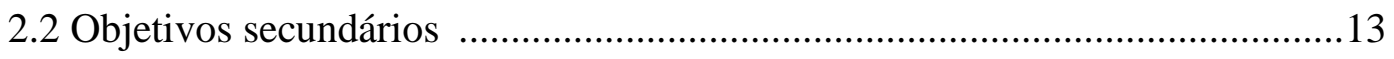

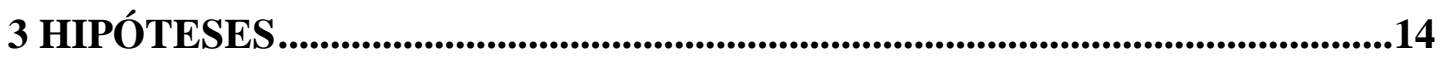

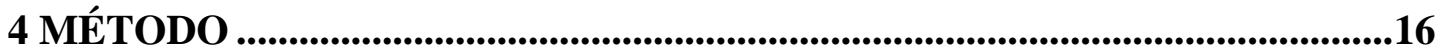

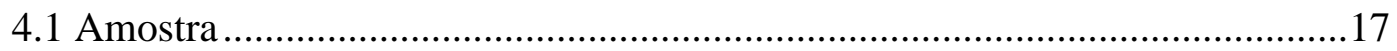

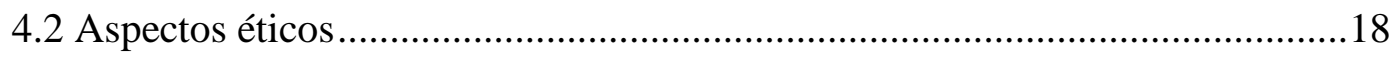

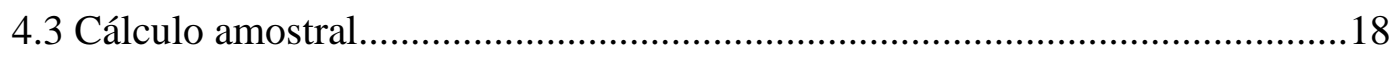

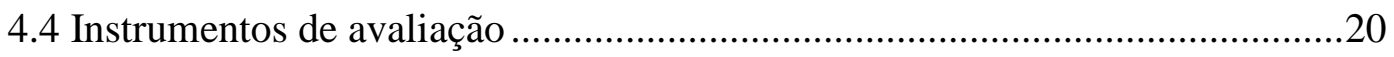

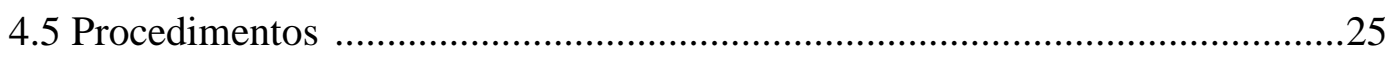

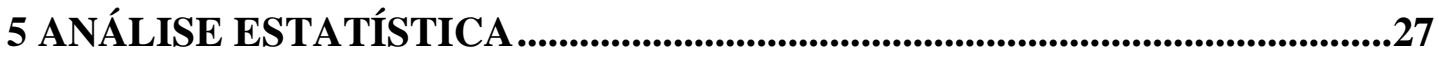

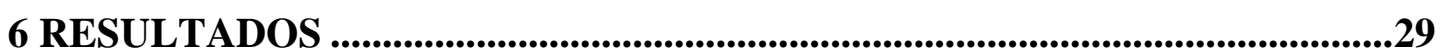

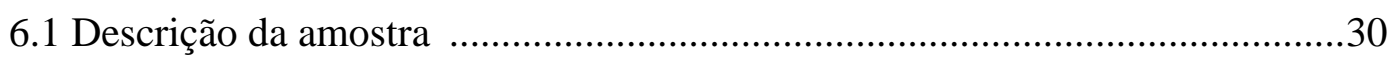

6.2 Resultados da análise de caracterização dos avós ...........................................40

6.3 Resultados da análise de caracterização dos filhos dos sujeitos da amostra....44

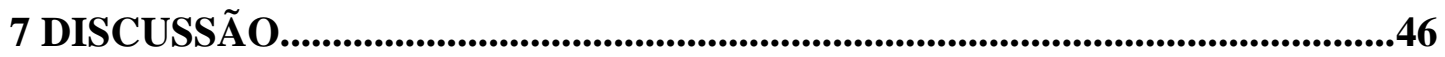

7.1 Cuidado recebido dos pais pelo sujeito......................................................47

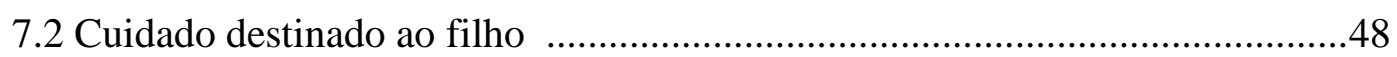

7.3 Associação entre o cuidado recebido e o cuidado destinado ao filho ..............49

7.4 Associação entre o cuidado recebido e o cuidado destinado ao filho do

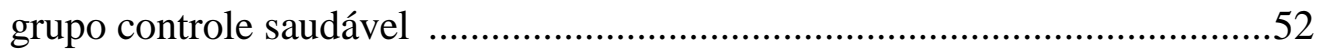

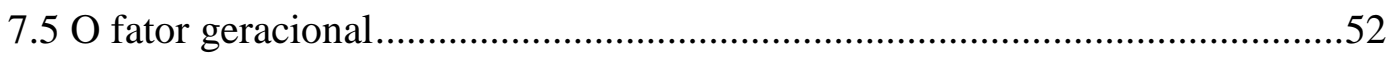




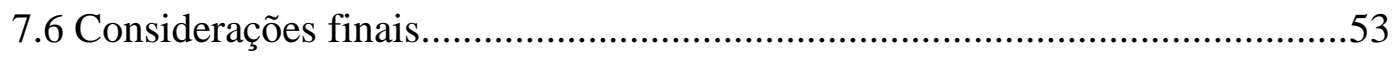

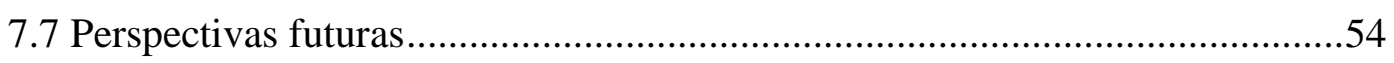

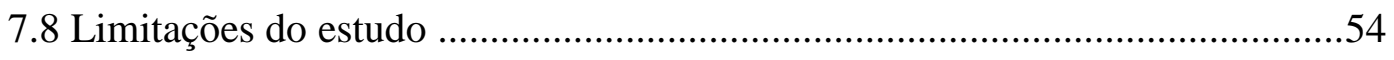

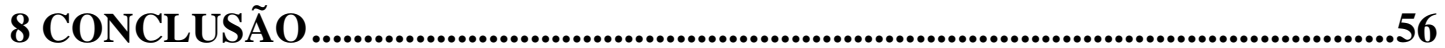

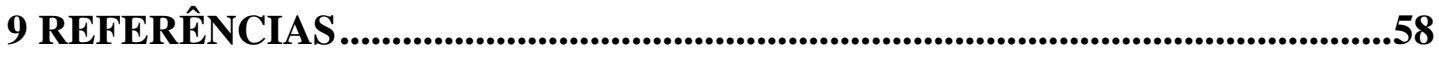

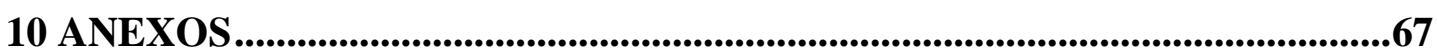




\section{Listas}

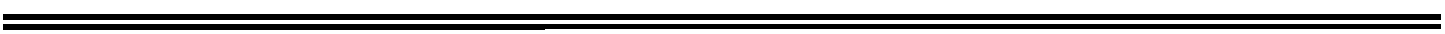

\begin{tabular}{|c|c|}
\hline \multicolumn{2}{|r|}{ ABREVIATURAS } \\
\hline $\mathrm{ABCL}$ & Adult Behaviour Checklist \\
\hline CBCL & Child Behaviour Checklist \\
\hline CHAOS & Confusion, Hubbub and Order Scale \\
\hline DSM-IV & $\begin{array}{l}\text { Diagnostic and Statistical Manual of Mental Disorders - Fourth } \\
\text { Edition }\end{array}$ \\
\hline $\mathrm{EE}$ & Emoção Expressa \\
\hline EMBU-P & $\begin{array}{l}\text { Egna Minnen Beträrran de Uppfostran } \\
\text { Escala de Lembranças sobre Práticas Parentais (versão pais) }\end{array}$ \\
\hline EMBU-S & $\begin{array}{l}\text { Egna Minnen Beträrran de Uppfostran } \\
\text { versão reduzida para adultos ( } \mathrm{S} \text { vem da palavra short) }\end{array}$ \\
\hline FACES II & Family and Cohesion Evaluation Scales II \\
\hline FES & Family Environment Scale \\
\hline HDRS & Hamilton Depression Rating Scale \\
\hline IPPA & Inventory of Parent and Peer Attachment \\
\hline KSP & Karolinska Scales of Personality \\
\hline MDQ & Mood Disorder Questionnaire \\
\hline NEO & Personality Inventory \\
\hline PBI & Parental Bonding Instrument \\
\hline PCR & Parent Child Report \\
\hline PRF & Parent Report Form \\
\hline PROGRUDA & Programa de Transtornos Afetivos \\
\hline PSS-R & $\begin{array}{l}\text { Psychosocial Schedule for School Age Children - Revised SCID } \\
\text { Structured Clinical Interview for }\end{array}$ \\
\hline SDQ & Strengths and Difficulties Questionnaire \\
\hline $\mathrm{TB}$ & Transtorno Bipolar \\
\hline TBI & Transtorno Bipolar do tipo I \\
\hline
\end{tabular}


TBII

TCLE

TDAH

TPB

UCLA

YSR

YMRS
Transtorno Bipolar do tipo II

Termo de Consentimento Livre e Esclarecido

Transtornos de Déficit de Atenção e Hiperatividade

Transtorno de Personalidade Borderline

Life Stress Interview

Youth Self-Report

Young Mania Rating Scale 


\section{TABELAS}

Tabela 1 - Caracterização de como os pacientes bipolares foram cuidados ...........5

Tabela 2 - $\quad$ Fator de exposição: variável Superproteção Materna (EMBU-S) ......19

Tabela 3 - Tabela de cálculo amostral utilizada para o estudo............................20

Tabela 4 - Variáveis sociodemográficas da amostra ..........................................31

Tabela 5 - $\quad$ Marcadores de gravidade e características clínicas.............................33

Tabela 6 - A influência do cuidado recebido no cuidado destinado aos filhos

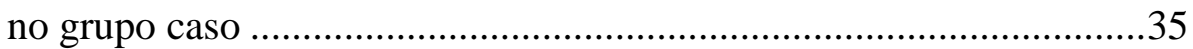

Tabela 7 - A influência do cuidado recebido no cuidado destinado aos filhos

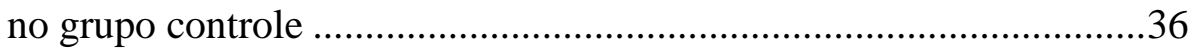

Tabela 8 - Caracterização do cuidado bipolar ........................................................37

Tabela 9 - Frequência de respostas quanto à pessoa que criou a amostra............40

Tabela 10 - Distribuição de frequência dos estilos parentais dos avós ...................41

Tabela 11 - Frequência de respostas da questão 9 da Escala de Responsividade ........................................................................42

Tabela 12 - Distribuição de frequência de idade e gênero dos filhos por grupo ...44

Tabela 13 - Comparação entre os grupos quanto às variáveis do $S D Q \ldots \ldots \ldots \ldots \ldots \ldots . . . . .45$

Tabela 14 - Distribuição de frequência dos avós diagnosticados ou não com TB e seu respectivo estilo parental do grupo TBI

Tabela 15 - Distribuição de frequência dos estilos parentais por idade dos avós do grupo TBI

Tabela 16 - Distribuição de frequência dos estilos parentais por idade dos avós do grupo controle

Tabela 17 - Distribuição de frequência dos estilos parentais por Embu-S do grupo TBI

Tabela 18 - Distribuição de frequência dos estilos parentais por Embu-S do grupo controle saudável 


\section{Resumo}

Pellegrinelli KB. Existe associação entre a forma que os pais com TBI foram cuidados na sua infância e a forma como eles cuidam dos seus filhos na vida adulta? [tese]. São Paulo: Faculdade de Medicina, Universidade de São Paulo; 2018.

Introdução: Nos últimos anos, têm crescido os estudos científicos focados em caracterizar o cuidado parental disfuncional como um possível fator associado ao risco de desenvolvimento de Transtorno Bipolar (TB) nos filhos e em incorporar esses resultados nas orientações para o cuidado parental nas diretrizes de psicoeducação. Objetivos: Verificar se existe associação entre o cuidado recebido durante a infância e o cuidado destinado aos filhos de pacientes bipolares. Caracterizar o cuidado parental bipolar destinado aos filhos e recebido durante a infância com foco em variáveis como: rejeição, superproteção e calor emocional. Método: Grupo experimental: 73 pacientes com filhos e TBI, eutímicos (YMRS $\leq 12, \mathrm{HAMD} \leq 7$ ), com idades entre 22 e 65 anos, atendidos no ambulatório de atenção terciária e num de atenção secundária foram avaliados. Grupo controle: 24 voluntários sadios do ponto de vista físico e mental, com idades entre 22 e 65 anos. Instrumentos de avaliação: SCID - CV, YMRS, HAM-D, EMBU-S (para acessar as memórias dos adultos sobre as práticas educativas dos seus pais), EMBU-P (para avaliar o relacionamento dos adultos com seus filhos). Resultados: Os dados indicam que houve associação entre a memória de calor emocional paterna e materna recebida durante a infância e o calor emocional destinado aos filhos $(\mathrm{p}=0,013 ; \mathrm{p}=0,013)$. Houve também associação entre a memória de superproteção materna e a superproteção destinada para o filho $(\mathrm{p}=0.003)$. Em relação aos dados de rejeição, não foram encontradas associações significativas ( $p>0.90)$. Os resultados nos mostraram que a memória de calor emocional materno foi menor no grupo TBI do que no controle saudável $(\mathrm{p}=0.036)$. Conclusão: Há uma associação da memória do calor emocional recebido do pai e da mãe com o calor emocional destinado à criança, da memória de superproteção materna e paterna, com a superproteção destinada ao filho. Além disso, os pacientes bipolares lembraram de terem recebido menos calor emocional de suas mães quando comparados aos do controle saudável.

Descritores: transtorno bipolar; cuidados parentais; psicopatologia; relações familiares; comportamento infantil/psicologia; relações pai-filho. 


\section{Abstract}

Pellegrinelli KB. The influence of child-rearing history in the parental care provided by bipolar [thesis]. São Paulo: "Faculdade de Medicina, Universidade de São Paulo"; 2018.

Introduction: In recent years there has been growing scientific studies focused on characterizing the dysfunctional parenting as a possible factor associated with the risk of Bipolar Disorder (BD) development and incorporating guidance for parental care in psychoeducation guidelines. Objectives: Check if there is an association between the care received during childhood and the care given to the children of bipolar patients. Characterize the bipolar parental care given to the children and received during childhood focusing on variables such as rejection, over protection and emotional warmth. Method: As experimental group: 73 patients with children and BDI euthymic $($ YMRS $\leq 12$, HAMD $\leq 7)$ aged between 22 and 65 years, treated at the tertiary care outpatient clinic and in a secondary care unit were evaluated. As control group: 24 healthy volunteers from the physical and mental point of view, aged between 22 and 65 years. Assessment tools: SCID - CV, YMRS, HAM-D, EMBU-S (to access adult memories of their parents rearing practices), EMBU-P (to assess adult's relationship with their children). Results: The data indicate that there was an association between the paternal and maternal emotional warmth memory received during childhood and the emotional warmth transmitted to the child ( $\mathrm{p}=0.013 ; \mathrm{p}=0.013$ ). There was also an association between the maternal overprotection memory and the overprotection for the child ( $\mathrm{p}=0.003)$. Regarding rejection data, no significant associations were found ( $p>0.90)$. The results also showed us that the maternal emotional warmth memory was lower in the BDI group than in the healthy control $(\mathrm{p}=0.036)$. Conclusion: There is an association between the memory of the emotional warmth received from the father and the mother in the emotional warmth destined to the child, between the memory of the overprotection received from the mother and the overprotection destined for the child. In addition, bipolar patients remember having received less emotional warmth from their mothers when compared with healthy control.

Descriptors: bipolar disorder; child rearing; psychopathology; family relations; child behavior/psychology; father-child relations. 
1 Introdução 


\section{INTRODUÇÃO}

Apesar de o Transtorno Bipolar (TB) ser altamente incapacitante e fortemente influenciado pelos fatores ambientais, há poucas décadas, eram raros os estudos que caracterizavam o cuidado parental e sua influência no desenvolvimento do TB nos filhos.

Em 1984, por exemplo, o estudo observacional longitudinal controlado, realizado por Gaensbauer et al. (1984), comparou sete bebês aos 12, 15 e 18 meses de idade, que tinham pelo menos um dos pais diagnosticados com Transtorno Bipolar do tipo I (TBI), com sete bebês filhos de pais sem diagnóstico pareados por idade, raça e condição socioeconômica. Apesar da limitação da amostra pequena, as diferenças entre os grupos ficaram evidentes. Os filhos de pais com TBI tiveram afetados muitos domínios: social, afetivo, funcionamento adaptativo pobre (cognitivo, afetivo e motivacional), capacidade de adaptação a novas situações, regulação das emoções, evitação proeminente e perturbação na qualidade do apego, bem como mais prováveis de apresentarem comportamentos agressivos. Além disso, os autores observaram que parecia haver relação entre ocrescimentoda gravidade da perturbação e o aumento da idade. Por isso, uma intervenção precoce está claramente indicada.

Embora as conclusões desse estudo devam ser provisórias por limitações evidentes (como natureza do estudo, ausência de medida para sintomatologia dos pais, ausência da caracterização do cuidado parental e amostra pequena), os resultados valem a pena serem lembrados quando se investigam cuidado parental bipolar e suas consequências.

Estudos têm focado no alto risco da prole (Mowbray et al., 2006; Goldstein et al., 2010), mas não levam em consideração a influência da psicopatologia dos pais no cuidado parental quando investigam o risco de fatores não genéticos como violência, abuso e trauma no desenvolvimento de TB (Etain et al., 2008; Alvarez et al., 2011) como se esses fatores fossem independentes da doença dos pais (Moreno et al., 2012). 
Caracterizar o cuidado parental disfuncional no TB pode ajudar a reforçar seu papel como fator ambiental e incorporar uma orientação de cuidados parentais para pais com TB em idade reprodutiva para os guidelines de psicoeducação (Moreno et al., 2012).

\subsection{Caracterização do cuidado parental de portadores de TB}

Em 2006, Alloy et al. fizeram uma revisão dos estudos publicados entre 1976 e 2006 (30 anos), que evidenciaram aspectos, os quais configuram o modelo de vulnerabilidade cognitiva ao estresse, que teria seu papel tanto no início quanto no curso do TB. Os aspectos que configuram esse modelo são: eventos de vida, vulnerabilidade cognitiva, combinação da vulnerabilidade cognitiva com o estresse e certas experiências do desenvolvimento (parentalidade pobre e maus-tratos). Vale ressaltar, aqui, apenas os estudos levantados, que caracterizam o cuidado parental bipolar e suas consequências.

Alguns desses estudos revisados caracterizaram o cuidado dos pais dos pacientes adolescentes bipolares. Exemplos disso são o estudo de Parker (1983), que comparou 50 bipolares e 50 controles "normais" (autoavaliação sobre pais e mães separadamente: Parental Bonding Instrument - PBI) e o de Geller et al. (2000), que comparou 93 bipolares, 81 Transtornos de Déficit de Atenção e Hiperatividade (TDAH) e 94 controles "normais" (entrevista para o jovem e suas mães: Psychosocial Schedule for School Age Children-Revised-PSS-R). Eles caracterizaram um cuidado parental pobre ou baixo calor emocional e alta superproteção, ou controle psicológico, que seria o "controle sem afeto/afeição". Outros estudos retrospectivos com adulto bipolar, como o de Rosenfarb et al. (1994), que compararam 106 unipolares, 25 bipolares e 25 controles "normais" (autoavaliação:Inventory of Parent and Peer Attachment-IPPA, Parent Child Report-PCR; projective: Family Circle Drawings), e o de Cooke et al. (1999), que compararam 56 pacientes TB e 21 controles "normais" (auto avaliação: Family Environment Scale - FES),reportaram que o baixo calor 
emocional materno predisse recaída mais rápida após recuperação de uma crise maníaca.

Já os estudos com emoção expressa (EE), que analisaram os pacientes bipolares e seus familiares, reportaram que aqueles pacientes com parentes com baixa EE (hostilidade, crítica, comentários intrusivos) tenderam a apresentar menos sintomas de humor em relação aos que tinham parentes com alta EE. EE alta predisse um curso pior do TB; ou seja, número maior de internação, sintomas e medicamentos adicionais, além de mais angústia (Miklowitz et al., 1988, 1995; Koenig et al., 1997; Simoneau et al., 1998; Rosenfarb et al., 2001).

Outros estudos sugeriram que maus-tratos na infância e parentalidade negativa podem contribuir para o risco de transtorno dos humores unipolar e bipolar por meio da contribuição para o modelo de vulnerabilidade cognitiva e vulnerabilidade cognitiva ao estresse. Eventos de vida também poderiam desencadear episódios de humor, principalmente naqueles que exibem estilos cognitivos desadaptativos (perfeccionismo, autocrítica, empenho excessivo para atingir uma meta) (Alloy et al., 2004, 2006).

O estudo recente de Muralidharan et al. (2015) buscou elucidar os mecanismos que levam a presença de criticismo, hostilidade e superenvolvimento emocional nas relações familiares predizer um funcionamento pobre no paciente com TB. Os resultados mostraram que a percepção de criticismo paterno foi associada com autocriticismo e perfeccionismo do filho portador de TB. Além disso, percepção de cuidado paterno baixo foi associada com baixo afeto positivo (reflete o quanto a pessoa está se sentindo entusiástica, ativa e alerta) e alto afeto negativo (dimensão geral da angústia e insatisfação). Esse estudo investigou 22 portadores de TB e 22 saudáveis com idades entre 18 e 40 anos. Os portadores de TB apresentaram níveis mais altos de autocriticismo e perfeccionismo.

No estudo comparativo entre cuidado parental recebido pelos 36 pacientes com TB, 59 com Esquizofrenia e 52 saudáveis, realizado por Gomes et al. (2015), ficou evidente o cuidado recebido: pobre ou baixo calor emocional e alta superproteção nos pacientes com TB quando comparados com os pacientes com Esquizofrenia e 
saudáveis. Esses achados foram condizentes com os resultados descritos em estudos anteriores já reportados aqui (Parker, 1983; Geller et al., 2000).

Já o estudo comparativo de regulação das estratégias emocionais entre 24 pais com diagnóstico de Transtorno Bipolar do tipo II (TBII) e 24 pais com diagnóstico de Transtorno de Personalidade Borderline (TPB) (Fletcher et al., 2014) mostrou que em ambos os grupos as relações paternas foram caracterizadas pela indiferença e que os cuidados parentais disfuncionais foram relacionados com estratégias de regulação da emoção desadaptativas.

A Tabela 1 apresenta o resumo da literatura da caracterização de como os pacientes bipolares foram cuidados na sua infância e adolescência.

Tabela 1 - Caracterização de como os pacientes bipolares foram cuidados

\begin{tabular}{|c|c|c|c|c|}
\hline Estudo & Grupos & $\begin{array}{l}\text { Escalas de } \\
\text { medida }\end{array}$ & $\begin{array}{l}\text { Caracterização do } \\
\text { cuidado recebido }\end{array}$ & $\begin{array}{c}\text { Fatores } \\
\text { associados aos } \\
\text { filhos } \\
\text { portadores de } \\
\text { TB }\end{array}$ \\
\hline $\begin{array}{l}\text { Muralidharan } \\
\text { et al., } 2015\end{array}$ & $\begin{array}{c}22 \text { TB } \\
\text { X } \\
22 \text { Saudável }\end{array}$ & $\begin{array}{c}\text { YA, PANAS, } \\
\text { Affective } \\
\text { Stroop Task } \\
\text { With Negative } \\
\text { Feedback, } \\
\text { DAS, DEQ, } \\
\text { PC, PBI e } \\
\text { FMSS }\end{array}$ & $\begin{array}{c}\uparrow \text { criticismo, } \\
\text { hostilidade, } \\
\text { superenvolvimento } \\
\text { emocional paterno, } \\
\downarrow \text { cuidado paterno }\end{array}$ & $\begin{array}{c}\uparrow \text { autocritica, } \\
\text { perfeccionismo } \\
\downarrow \text { Afeto positivo } \\
\uparrow \text { Afeto negativo }\end{array}$ \\
\hline $\begin{array}{l}\text { Reichart et } \\
\text { al., } \\
2007\end{array}$ & $\begin{array}{c}129 \text { filhos jovens } \\
\text { de pais com TB } \\
\text { X } \\
\text { 1.122 filhos jovens } \\
\text { da pop. geral }\end{array}$ & EMBU-S & & $\begin{array}{c}\text { Percebem: } \\
\uparrow \text { rejeição } \\
\text { paterna } \\
\downarrow \text { rejeição } \\
\text { materna } \\
\downarrow \text { superproteção }\end{array}$ \\
\hline $\begin{array}{c}\text { Gomes et al., } \\
2015\end{array}$ & $\begin{array}{c}36 \text { TB } \\
x \\
59 \text { Esquizo } \\
\text { x } \\
52 \text { Saudável }\end{array}$ & PBI & $\begin{array}{c}\downarrow \text { Cuidado parental } \\
\uparrow \text { Superproteção } \\
\downarrow \text { Calor emocional }\end{array}$ & \\
\hline $\begin{array}{c}\text { Fletcher et } \\
\text { al., } \\
2014\end{array}$ & $\begin{array}{c}24 \text { TBII } \\
\mathrm{X} \\
24 \mathrm{TPB}\end{array}$ & $\begin{array}{l}\text { CERQ, DERS, } \\
\text { MOPS. }\end{array}$ & $\begin{array}{l}\text { Ambos os grupos: } \\
\text { Relações paternas= } \\
\text { indiferença } \\
\text { Cuidados parentais } \\
\text { disfuncionais }\end{array}$ & $\begin{array}{l}\text { Estratégias de } \\
\text { regulação da } \\
\text { emoção } \\
\text { desadaptativas }\end{array}$ \\
\hline
\end{tabular}


O estudo inglês publicado por Barron et al. (2014) caracterizou o ambiente familiar de famílias bipolares em comparação com 23 famílias controles sem transtorno de humor. Os principais resultados confirmaram estudo anterior publicado por Gaensbauer et al. (1984), em que famílias bipolares apresentaram nível mais alto de conflito, de probabilidade de discutir e de desorganização, como também menor coesão, nível mais baixo de expressividade, orientação cultural/intelectual e orientação recreativa em relação às famílias controles. Nesse estudo, o número maior de filhos teve o mesmo efeito sobre os níveis de conflito como a presença de TB, enquanto a classe socioeconômica não foi fator tão importante no ambiente familiar. Nesse mesmo ano, Peay et al. (2014) avaliaram 266 pais bipolares (autorrelato). Os resultados mostraram associação entre monitoramento do humor dos filhos e aumento da percepção de controle sobre o bem-estar deles, e ainda enfrentamento ativo em relação ao risco dos filhos e enfrentamento ativo em relação à própria doença.

Os resultados do estudo prospectivo, que comparou 65 pais bipolares e 59 pais sem transtorno mental com seus filhos (Ostiguy et al., 2012), mostraram que alta neurose (traço da personalidade caracterizado pela propensão em vivenciar emoções negativas como raiva, tristeza, culpa e irritabilidade) e baixa amabilidade (ou agradabilidade) nos pais durante a primeira infância dos filhos (Personality Inventory - NEO-PI-R - NEO) predisseram funcionamento interpessoal pobre nos filhos (Life Stress Interview -UCLA) no final da adolescência e início da vida adulta (dez anos depois). Ainda, a externalização (agressão verbal ou física, destruição de objetos, mentira) e a internalização (retração social, mais sintomas depressivos, mais sintomas de ansiedade) dos problemas pelos filhos na metade da infância (Parent Report Form - PRF do Child Behaviour Checklist-CBCL) mediaram parcialmente a associação entre personalidade dos pais (NEO) e funcionamento interpessoal dos filhos (Life Stress Interview - UCLA). A associação entre a neurose dos pais e a internalização dos problemas pelos filhos foi mais forte entre pais bipolares. É interessante notar que os resultados sugerem uma transmissão entre gerações do risco por meio da alta neurose e da baixa amabilidade em pais que tiveram associação com problemas com filhos durante a infância média, fato que predisse pobre funcionamento dez anos depois.

O estudo conduzido online por Calam et al. (2012) observou que filhos de famílias cujos pais eram bipolares apresentavam mais dificuldades totais, tais como: 
problemas de conduta, hiperatividade, problemas de relacionamento com os colegas e sintomas emocionais), sendo esses filhos mais vulneráveis a doenças mentais. Os dados foram coletados com 48 pais bipolares e o estudo teve o objetivo de examinar relações entre humor dos pais, parentalidade, organização dos cuidadores de casa, organização emocional da criança e adequação do comportamento dos filhos em famílias de pais bipolares. A organização dos cuidadores de casa (Confusion, Hubbub and OrderScale-CHAOS) foi um forte preditor de dificuldades totais e sintomas emocionais (Strengths and Difficulties Questionnaire-SDQ). Ou seja, o alto nível de desorganização dos cuidadores de casa foi preditor de crianças com altos níveis de distúrbio.

Em uma análise qualitativa da perspectiva dos pais em relação ao TB do filho (Crowe et al., 2011), verificou-se que a maioria dos pais identificou o início dos sintomas depressivos em seu filho no início da adolescência, mas foi só no final da adolescência, ou mais tarde, que os pais notaram sintomas de mania. O início dos sintomas durante um período crucial do desenvolvimento teve impacto considerável no funcionamento social e ocupacional. Pais, muitas vezes, culpam a si mesmos pelo desenvolvimento do transtorno bipolar em seus filhos.

Os resultados do estudo comparativo realizado pelo PROGRUDA entre 34 mães TBI eutímicas e 106 controles sem TB (Moreno et al., 2012) mostraram que: mães com TBI foram menos propensas a estarem em uma união estável e viverem com o pai biológico dos filhos; $80 \%$ menos chance de fazer uso contínuo de contraceptivo; 97\% dos filhos de mães com TBI viveram com suas mães durante episódios; 33,3\% dos filhos foram expostos aos riscos, como abusos físico, sexual e psicológico, devido aos sintomas maternos (como: bater a ponto de machucar e os outros perceberem; dizer coisas que machucam ou ofendem, como: "você é estúpido", "preguiçoso", "feio"; ameaçar contar mentiras sobre ele ou machucar se não fizer algo sexual; tentar tocar ou fazer o filho tocar de maneira sexual, molestar), enquanto isso foi raro nos controles; tentativa de suicídio na presença do filho ocorreu apenas no grupo TB; e altos índices de utilização do seguro social ou aposentadoria. Ambos os grupos apresentaram alto índice de aborto e apenas $50 \%$ planejaram a gravidez, o que não caracteriza a mãe portadora de TB, mas são aspectos fundamentais de serem abordados na orientação de pais. 
O estudo recém-publicado por pesquisadores da universidade de Sidney na Austrália (Lau et al., 2018) teve como objetivo examinar a relação entre o ambiente familiar (Family and Cohesion Evaluation ScalesII - FACES-II; PBI)e o status de alto risco e psicopatologia nos filhos de pais bipolares (CBCL; Youth Self-Report - YSR; Adult Behaviour Checklist - $A B C L$ ) na perspectiva dos filhos e dos pais. Objetivou, também, testar se o ambiente familiar medeia a relação entre o status de risco bipolar e internalização e externalização de problemas. Para tal, participaram do estudo 90 filhos de pacientes bipolares e 56 filhos de controles saudáveis e seus pais. Apesar de os resultados terem apontado a não mediação do ambiente familiar entre o risco bipolar e problemas nos filhos, pais e filhos do grupo de alto risco (tem pelo menos um dos pais com TB) concordaram ao reportarem níveis mais altos de internalização e externalização dos problemas pelos filhos. O cuidado materno e paterno mais baixo reportado pelos filhos foi associado a internalização dos problemas pelos filhos. E o cuidado materno mais baixo foi associado à externalização dos problemas pelos filhos. Então, baixo calor parental foi associado à internalização e externalização dos problemas pelos filhos, como um fator de risco independente, em adição ao status de risco bipolar. Esses resultados foram coerentes com os encontrados por Ostiguy et al. (2012) relatados aqui. O relacionamento pais e filhos, portanto, merece atenção como alvo potencial para estratégias de prevenção com tais famílias.

Desse modo, os resultados dos estudos descritos que focam na influência mútua de exposições genéticas e não genéticas na etiologia dos transtornos mentais (Crowe et al., 2011; Calam et al., 2012; Moreno et al., 2012; Jones et al., 2013; Barron et al., 2014; Peay et al., 2014) são unânimes ao sugerirem a utilização de intervenções de base familiar com foco na psicoeducação (Pellegrinelli et al., 2012) adaptados para atender às necessidades parentais. As principais necessidades encontradas por esses estudos foram: melhorar a comunicação dentro das famílias; treinar habilidades para solução de problemas; tratar de questões de conflito, organização, expressividade, orientação de cuidado materno e paterno, relação pais e filhos; compreender a atribuição de causalidade e a importância da educação e do aconselhamento genético; e até fazer um controle da natalidade, evitando, assim, criar uma família muito numerosa com maior potencial de conflitos. 
Portanto, a psicopatologia do TB pode levar ao cuidado parental pobre (exposição a riscos, violência, abusos físico, sexual e psicológico) e a um ambiente familiar disfuncional (famílias numerosas, com altos níveis de conflito e desorganização, alta neurose e baixa amabilidade), que podem influenciar no desenvolvimento psicológico dos filhos, o que, por sua vez, pode influenciar no desenvolvimento de psicopatologias como o TB e, então, formar-se um ciclo vicioso (Miklowitz; Johnson, 2009). Dessa forma, os estudos descritos sugerem que o cuidado parental pobre e um ambiente familiar disfuncional poderiam estar associados aos fatores de risco para o desenvolvimento de TB (Schudlich et al., 2008).

1.2 Estudos com TB e EMBU (Egna Minnen Beträrran de Uppfostran - Escala de Lembranças sobre Práticas Parentais)

Quanto à avaliação de como pais portadores de TB cuidam dos seus filhos em relação às variáveis de rejeição, superproteção e calor emocional (avaliados pela escala EMBU - descrita no item Instrumentos de Avaliação), apenas três estudos foram encontrados.

Os dois primeiros estudos foram conduzidos por Perris et al. $(1983,1985) \mathrm{com}$ pacientes unipolares e bipolares deprimidos. O primeiro estudo, com 141 pacientes unipolares com idades entre 18 e 65 anos, avaliou as correlações entre práticas de criação parentais (EMBU) e características de personalidade parental (Karolinska Scales ofPersonality-KSP). É interessante notar que tipos de disciplina utilizados, como culpa e vergonha, apresentaram correlação significativa entre a agressão e correlação negativa e a socialização, e ainda que mulheres deprimidas classificaram suas mães como mais abusivas e homens deprimidos classificaram suas mães como mais superprotetoras. A classificação dos pais foi mais positiva comparada à da mãe apesar de não ter sido encontrada diferença significativa quanto ao gênero (pai e mãe). Já os resultados do segundo estudo, que comparou 54 bipolares e 52 unipolares, mostraram que o calor emocional foi menor nos portadores de TB em relação aos controles saudáveis. É importante ressaltar que, nesse estudo, a falta de calor 
emocional em práticas educativas dos pais pode ser uma variável crucial na patogênese de doenças depressivas. Vale destacar que esse resultado de baixo calor emocional parental no TB foi repetido em dois estudos posteriores já descritos aqui (Parker, 1983; Geller et al., 2000) e os estudos de Cooke et al. (1999) e Rosenfarb et al. (1994), também descritos, acrescentaram que o baixo calor emocional materno predisse recaída mais rápida após recuperação de uma crise maníaca.

O terceiro estudo, conduzido por Reichart et al. (2007), comparou a percepção de 129 jovens adultos, filhos de 80 pais bipolares e seus cônjuges, com a percepção de 1.122 jovens adultos da população em geral em relação à criação recebida dos pais. Em seguida, examinou as associações entre o comportamento de criação parental percebida e a psicopatologia parental e a psicopatologia na prole. Os resultados mostraram diferença entre a percepção dos filhos quanto aos cuidados materno e paterno recebidos no grupo de um dos pais bipolar comparado com o controle. Em geral, os filhos que cresceram em uma família com um dos pais bipolar perceberam: menos rejeição materna, mais calor emocional materno, menos calor emocional paterno e menos superproteção parental do que os adultos jovens da população em geral. Outro dado significativo é que os filhos portadores de TB perceberam maior rejeição parental do que os filhos sem psicopatologia. Ou seja, a percepção de rejeição parental foi relacionada à psicopatologia dos filhos. É interessante lembrar que pode existir um viés da percepção dos filhos, pois filhos saudáveis tendem a perceber melhor os pais.

\subsection{Fator geracional}

Vale destacar a importância do fator geracional no estilo parental de criação. Alterações culturais fundamentais ocorreram no último século. Dentre tais alterações, caracteriza-se "a transição do modelo tradicional (controlador, assimétrico e autoritário), para um dito 'moderno', mais centrado na criança, que valoriza a comunicação e a independência dos filhos" (Biasoli-Alves, Caldana, Silva, 1997). Estas autoras demonstraram em sua pesquisa que mães das décadas de 30-40 e 50- 60 
tinham suas atitudes e crenças sobre a educação dos filhos calcadas no sistema em que foram educadas e em conselhos de suas mães e sogras; enquanto que as das décadas de 70-80 apresentaram um padrão diferenciado, calcado na procura cientificista de orientação, com base em livros, artigos de revistas ou conselhos de pediatras e psicólogos (Weber, 2006). Ressaltamos que a amostra utilizada neste caso foi com sujeitos normais. Não sabemos se este padrão pode ser aplicado numa amostra clínica de pacientes TBI como utilizamos no presente estudo.

Considerando esses aspectos, o presente estudo visa a caracterizar o cuidado parental bipolar com os diferenciais de comparar a forma como os pais cuidam e foram cuidados; além de focar em aspectos como rejeição, suporte ou calor emocional e superproteção, com o intuito de proporcionar uma orientação familiar mais completa e eficiente tanto em termos preventivos como remediativos do TB. 
2 Objetivos

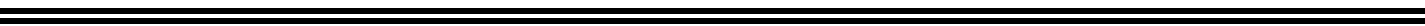




\section{OBJETIVOS}

\subsection{Objetivo primário}

Verificar se existe associação entre a forma como os pais com TBI foram cuidados durante sua infância e como eles cuidam dos seus filhos na vida adulta, focando nas variáveis: calor emocional, superproteção e rejeição.

\subsection{Objetivos secundários}

- Caracterizar o cuidado recebido por pacientes bipolares do tipo I durante a infância e o cuidado destinado aos seus filhos na vida adulta, comparando com o cuidado de pais saudáveis, segundo as variáveis: calor emocional, superproteção e rejeição.

- Identificar possíveis comportamentos dos pais portadores de TBI que possam funcionar como fatores de risco para o desenvolvimento de TB nos filhos, a partir da diferenciação do cuidado do grupo TBI com o cuidado do grupo controle saudável. Tais cuidados referentes ao calor emocional, superproteção e rejeição são descritos nas próprias perguntas das escalas de medida EMBU-S e EMBU-P. 
3 Hipóteses

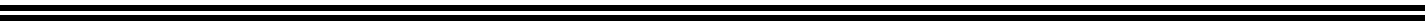




\section{HIPÓTESES}

- H1a - Existe associação da forma como os pais com TBI foram cuidados durante sua infância com a forma como eles cuidam dos seus filhos na vida adulta, focando nas variáveis: calor emocional, superproteção e rejeição.

- H1b-O cuidado recebido por pacientes bipolares do tipo I durante a infância e o cuidado destinado aos seus filhos diferem dos cuidados de pais saudáveis segundo as variáveis: calor emocional, superproteção e rejeição.

- H1c - Pais portadores de TBI apresentam possíveis comportamentos de risco para desenvolvimento de TB nos filhos. 
4 Método 


\section{MÉTODO}

\subsection{Amostra}

4.1.1 Grupo Caso: 73 pacientes diagnosticados com TBI em acompanhamento no ambulatório de atenção terciária do Programa Transtornos Afetivos (GRUDA) do IPqHC-FMUSP, no ambulatório de atenção secundária do Centro de Atenção Psicossocial das cidades de São João Del Rei e Oliveira - MG (CAPS Del Rei e CAPS Oliveira CAPS são instituições brasileiras destinadas a acolher pacientes com transtornos mentais, estimular sua integração social e familiar e apoiá-los em suas iniciativas de busca da autonomia, oferecendo-lhes atendimento médico e psicossocial) ou ainda em acompanhamento com médico psiquiatra em consultório particular.

\section{Critérios de inclusão}

- Idade entre 18 anos e 65 anos.

- Pelo menos um filho com mais de quatro anos de idade.

- Eutímico no momento da avaliação (YMRS $\leq 12$ e HAMD $\leq 7$ ).

\section{Critérios de exclusão}

- Presença de dependência de substâncias psicoativas e álcool no último mês (exceto nicotina e cafeína).

- Presença de transtorno mental orgânico, demência ou retardo mental.

4.1.2 Grupo Controle: 24 voluntários saudáveis do ponto de vista físico e mental.

\section{Critérios de inclusão}

- Idade entre 18 anos e 65 anos.

- Pelo menos um filho com mais de quatro anos de idade.

- Recrutados dos estudos LICAVAL, ARIQUELI e ESPECTGENE, e de escola privada situada próxima ao CAPS Del Rei. 


\section{Critérios de exclusão}

- Presença de diagnóstico psiquiátrico ao longo da vida segundo o DSM-IV e entrevista SCID-I/P (Del-Bem et al., 2001; First et al., 1997).

- Presença de condições clínicas agudas não estabilizadas.

- Presença de histórico de crises convulsivas ou problemas neurológicos.

- Presença de história familiar de $1^{\circ}$ grau de doenças psiquiátricas.

\subsection{Aspectos éticos}

Primeiramente, os sujeitos foram informados pela pesquisadora sobre os objetivos do estudo. A partir desses esclarecimentos, foi questionado ao sujeito sobre a concordância na participação da pesquisa. Os sujeitos somente participaram do estudo se houvesse compreensão, anuência e assinatura do consentimento livre e esclarecido (ANEXO A), seguindo o modelo solicitado pelo Comitê de Ética em Pesquisa do Hospital das Clínicas da Faculdade de Medicina da Universidade de São Paulo (HCFMUSP). O presente estudo foi aprovado pelo mesmo Comitê de Ética do HCFMUSP segundo o parecer número 1.215.099 de 02 de setembro de 2015 (ANEXO B).

\subsection{Cálculo amostral}

Trata-se de um estudo de caso-controle, cujo cálculo amostral foi feito com base no banco de dados proveniente dos estudos: "Eficácia e tolerabilidade da associação de lítio e ácido valpróico em comparação com a associação de lítio e carbamazepina no tratamento de pacientes bipolares tipo I jovens" (PROJETO LICAVAL - número do protocolo de pesquisa: 0820) (Campos et al., 2010) e 
"Eficácia e tolerabilidade da associação de lítio em doses baixas ou convencionais em pacientes bipolares tipo I jovens não respondedores ou respondedores parciais à monoterapia com Quetiapina" (PROJETO ARIQUELI- número: 8.637) (Missio et al., 2013). A amostra piloto consistiu em 22 pacientes bipolares (casos) e sete controles sem psicopatologia. Utilizou-se o fator de exposição à variável da escala EMBU-S Superproteção Materna, obtendo-se a Tabela 2 a seguir.

Tabela 2- Fator de exposição: variável Superproteção Materna (EMBU-S)

\begin{tabular}{cccc}
\hline \multirow{2}{*}{ Indivíduo } & \multicolumn{2}{c}{ EMBU-S } & \\
& Fator III - Superproteção - Mãe & Total \\
& Nunca/Às vezes & Frequentemente/Sempre & \\
\hline Caso & 2 & 20 & 22 \\
Controle & 2 & 4 & 6 \\
Total & 4 & 24 & 28 \\
\hline
\end{tabular}

Obs.: foi retirado um controle da amostra por falta de informação para variável EMBU-S Fator III - Superproteção- Mãe

A partir da Tabela 2, foram obtidas as seguintes medidas: a proporção de casos expostos ao Fator III - Superproteção - Mãe foi igual 0,9; a medida odds ratio (OR) igual a 5; e a proporção de número de controle por número de casos igual a 0,3 . O nível de significância do teste foi $\alpha=5 \%$. Foram calculados os tamanhos de amostra para diferentes porcentagens do poder do teste (1- $\beta$ ) (Tabela 3). 
Tabela 3 - Tabela de cálculo amostral utilizada para o estudo

\begin{tabular}{cccc}
\hline $\begin{array}{c}\text { Nível de } \\
\text { Significância }\end{array}$ & Poder do Teste & Número de Casos & Número de Controles \\
\hline $5 \%$ & $65 \%$ & 66 & 20 \\
$5 \%$ & $70 \%$ & 73 & 23 \\
$5 \%$ & $75 \%$ & 80 & 25 \\
$5 \%$ & $85 \%$ & 99 & 31 \\
$5 \%$ & $90 \%$ & 112 & 35 \\
$5 \%$ & $95 \%$ & 134 & 42 \\
$0.1 \%$ & $80 \%$ & 102 & 63 \\
$1 \%$ & $80 \%$ & 136 & 42 \\
$10 \%$ & $80 \%$ & 68 & 21 \\
\hline
\end{tabular}

A opção feita para este estudo foi utilizar o poder do teste de $70 \%$ por apresentar um poder razoável e uma amostra possível de ser obtida dentro do tempo estipulado para o projeto. Sendo assim, foi adotado o grupo caso com 73 pacientes bipolares e o grupo controle com 23 sujeitos saudáveis.

\subsection{Instrumentos de Avaliação (ANEXO C)}

a) Entrevista baseada no modelo da Associação Brasileira de Transtorno Bipolar, que tem como objetivo levantar dados sociodemográficos e características clínicas da doença.

b) Entrevista Clínica Estruturada para Transtornos do Eixo I do DSM-IV Edição para Pacientes - Versão 2.0 - SCID-I/P (First et al., 1997; Del-Bem et al., 2001), para confirmação diagnóstica.

c) Escala de Young para Avaliação da Mania - YMRS (Young et al., 1978; Vilela, 2000). 
d) Escala de Hamilton para Avaliação da Depressão (HDRS) (Hamilton, 1960; Moreno; Moreno, 2000).

e) Instrumentos de Avaliação das relações familiares.

A escala EMBU (Egna Minnen Beträrran de Uppfostran), de origem sueca, acessa as lembranças dos adultos sobre as práticas de criação de seus pais e foi publicada originalmente por Perris et al., em 1980, com 81 questões. A partir dessa escala, surgiram outras versões, dentre elas a EMBU-S e a EMBU-P, que foram utilizadas neste estudo.

1. EMBU-S - Versão reduzida para adultos ( $\mathrm{S}$ vem da palavra short): é recomendada como equivalente à EMBU original de 81 itens. Ela também acessa a memória de adultos sobre as práticas de criação de seus pais, mas é composta de apenas 23 perguntas. Para responder a esse questionário, é muito importante que o sujeito tente recordar o que sentia a respeito das atitudes que seus pais tinham com ele. Cada pergunta tem várias opções pontuadas de 1 a $4(1=$ Não, nunca; $2=\operatorname{Sim}$, às vezes; 3 $=$ Sim, frequentemente; 4 = Sim, sempre) e o sujeito deve escolher aquela que reflete melhor tanto o comportamento do seu pai como o de sua mãe na sua educação quando era criança. A escala foi validada para o português de Portugal por Canavarro em 1999 e para o português do Brasil por Kobarg et al. em 2010. Ela conta com três fatores:

- FATOR I - APOIO OU CALOR EMOCIONAL: é definido como uma série de comportamentos parentais, que geram no filho a sensação de conforto e a certeza de ser aprovado como pessoa pelos pais. Pontuação varia entre seis e 24. Quanto maior o número, maior o calor emocional.

- FATOR II - REJEIÇÃO: é compreendida como comportamentos com a intenção de mudar a vontade do filho, entendido como rejeição do filho como indivíduo. Pontuação varia entre sete e 28. Quanto maior o número, maior a rejeição.

- FATOR III - SUPERPROTEÇÃO: caracterizada pelo excessivo controle e preocupação dos pais, intrusão excessiva nas atividades dos filhos e altos níveis de imposição de regras rígidas. Por exemplo: o filho não poder realizar atividades que a maioria dos amigos realiza e está sujeito à 
obrigação de dar explicações por tudo o que fazem. Pontuação varia entre nove e 36. Quanto maior o número, maior a superproteção.

2. EMBU-P - Escala de Lembranças sobre Práticas Parentais-Versão para Pais sobre o relacionamento com seus filhos (Castro et al., 1997): esta escala é composta por 81 questões e é dividida em quatro fatores, os quais são exatamente os mesmos da EMBU-S (Calor Emocional, Rejeição e Superproteção) com o acréscimo do Fator Favorecimento (caracterizado pelo favorecimento de um filho em relação aos outros).

- FATOR I - CALOR EMOCIONAL: pontuação varia entre 16 e 48. Quanto menor o número, maior o calor emocional.

- FATOR II - REJEIÇÃO: pontuação varia entre 13 e 39. Quanto maior o número, menor a rejeição.

- FATOR III - SUPERPROTEÇÃO/TENTATIVA DE CONTROLE: pontuação varia entre 19 e 57. Quanto maior o número, menor a superproteção e maior a autonomia).

- FATOR IV - FAVORECIMENTO: pontuação varia entre três e nove (quando não tem irmão=0). Quanto maior o número, menor o favorecimento.

Conforme foi descrito, as escalas EMBU-P e EMBU-S acessam lembranças do estilo parental. É interessante pensar que essas lembranças podem não corresponder à prática, mas sim à percepção de cada sujeito (pai, mãe, filhos). No estudo realizado por Aluja et al. (2006), foi comparada a percepção do estilo parental de 134 adolescentes (EMBU-A) com a percepção dos seus pais (EMBU-P). O resultado mostrou uma diferença significativa no fator Favorecimento, e não nos outros três fatores. Ou seja, podem existir diferenças nas percepções de cada sujeito sobre uma mesma situação, independente da presença da psicopatologia.

3. Responsividade e Exigência: são duas escalas para avaliar estilos parentais validadas no Brasil para adolescentes por Costa et al. (2000), que se basearam nas usadas por Lamborn et al. (1991). Neste estudo, tem a finalidade de corrigir uma limitação importante: práticas parentais seriam avaliadas por 
instrumentos muito similares (EMBU-P e EMBU-S) e com o mesmo respondedor. Espera-se, portanto, uma correlação entre ambos os escores, que pode se dever exclusivamente em função de vieses na resposta (como mostrou o estudo realizado por Widom et al. em 2015). Então, essas escalas foram respondidas pelo pai ou mãe do sujeito da pesquisa, chamados de avós para se evitar confusão. Portanto, foram incluídas informações fornecidas pelos avós a respeito da relação com seu filho na fase em que estava sendo criado (mesma informação fornecida pela EMBU-S).

Todas as 16 questões são avaliadas por meio de um sistema Likert de três pontos. Para viabilizar a aplicação do instrumento aos pais, a adaptação foi feita na construção das frases. Portanto, os pais respondem sobre seus próprios comportamentos na época quando criaram seus filhos (e não o filho adolescente como na escala original). Essa adaptação, também, foi feita pelo estudo de Weber et al. (2004).

Estilo parental é a manifestação dos pais em direção aos filhos, que caracteriza a natureza da interação. É o clima emocional, que perpassa as atitudes dos pais, o qual influencia em diversos aspectos no desenvolvimento dos filhos, tais como: ajustamento psicossocial, psicopatologia e desempenho escolar. Pode, ainda, determinar o estilo que os filhos vão adotar futuramente (Weber et al., 2004).

A escala Exigência avalia o quanto os pais monitoram e supervisionam o filho. Ela está ligada ao controle, limites e regras. Já a escala Responsividade avalia o quanto os pais respondem às necessidades do filho e o quanto o filho percebe os pais como amorosos, responsivos e envolvidos. Está ligada ao calor emocional e ao desenvolvimento da autonomia. Favorece autoconceito positivo, autoconfiança e bemestar no filho.

A classificação dos estilos parentais adotada por este estudo foi descrita por Weber et al. (2004) da seguinte forma:

- Estilo Autoritativo: é aquele que apresenta escores altos de exigência e de responsividade. Filhos de pais autoritativos apresentam melhor desempenho escolar, competência social e psicológica. 
- Estilo Negligente-permissivo: é aquele que apresenta escores baixos em exigência e responsividade. Filhos de pais negligentes apresentam baixo rendimento escolar, mais sintomas depressivos, baixa autoestima, problemas afetivos e comportamentais, alto índice de estresse e podem ter atraso no desenvolvimento.

- Estilo Autoritário: é aquele que apresenta escore baixo em responsividade e alto em exigência. Filhos de pais autoritários apresentam comportamento de externalização (agressão verbal ou física, destruição de objetos, mentira) e de internalização (retração social, mais sintomas depressivos, mais sintomas de ansiedade), bem como tendência para desempenho escolar moderado, pouca habilidade social e baixa autoestima. Filhas educadas por mãe autoritária tendem a adotar o mesmo estilo na criação dos seus filhos.

- Estilo Indulgente-permissivo: é o daqueles pais que apresentam escore alto em responsividade e baixo em exigência. São mais tolerantes, com disposição para perdoar. Filhos de pais indulgente-permissivos apresentam características positivas e negativas.

4. Questionário de Transtornos de Humor: o Mood Disorder Questionnaire (MDQ) é um questionário de autoavaliação para TBI e II, com questões relacionadas à hipomania, validadas para uso na prática psiquiátrica e na população em geral. Consiste em 13 perguntas (sim / não) avaliando humor, autoconfiança, energia, sociabilidade, interesse em sexo e outros comportamentos. Duas perguntas adicionais exploram a concomitância dos sintomas durante um determinado período de tempo, bem como a gravidade dos sintomas pelo comprometimento funcional. A incapacidade é classificada de "Sem consequências" até "Conseqüências severas". O MDQ é considerado positivo quando indivíduos respondem "sim" a pelo menos sete dos 13 itens, têm pelo menos dois sintomas que ocorrem simultaneamente e são pelo menos moderadamente impactados. A versão brasileira do MDQ foi validada por Soares et al. (2010). O MDQ foi incluído neste estudo para confirmação do diagnóstico de TB dos avós.

5. Questionário de Capacidades e Dificuldades: o Strengths and Difficulties Questionnaire (SDQ) é uma medida de psicopatologia breve e útil, 
aplicável à população de quatro a 16 anos. Os critérios de pontuação e interpretação estão disponíveis no ANEXO D. Embora tenha sido publicado apenas em 1997, já se encontra disponível em mais de 40 idiomas, incluindo a versão validada em português (Fleitlich et al., 2000), e está disponível via internet no site www.sdqinfo.com. Foi incluído neste estudo por se considerar fundamental avaliar as características individuais dos filhos, uma vez que essas características influenciam os cuidados parentais e podem ser específicas para cada um dos filhos, porque características diferentes tendem a provocar comportamentos diferentes nos pais (Klahr; Burt, 2014).

\subsection{Procedimentos}

Este é um projeto de conveniência, que utilizou parte das amostras de pacientes bipolares e saudáveis dos projetos: LICAVAL - número do protocolo de pesquisa: 0820 (Campos et al., 2010) e ARIQUELI - número: 8637 (Missio et al., 2013). A metodologia utilizada em ambos os projetos foi semelhante em relação ao recrutamento dos pacientes, caracterização da amostra, critérios de inclusão e exclusão, e instrumentos de confirmação diagnóstica e sintomatológica entre outros. Em ambos os projetos, os pacientes foram incluídos em fase de mania/hipomania ou depressão, e foi iniciado o tratamento medicamentoso proposto. Após o início do tratamento, eles foram avaliados quanto à gravidade dos sintomas a cada retorno por um avaliador cego ao tratamento. Quando foi constatada a eutimia, os pacientes foram encaminhados para as avaliações do projeto de pesquisa aqui proposto. A importância de recrutar pacientes em dois estudos com metodologia semelhante está no fato de se conseguir garantir a homogeneidade da amostra em termos do adequado balanceamento entre casos e controles.

A outra parte da amostra de pacientes bipolares utilizada por este estudo, como já descrito no item Grupo Caso, foi proveniente dos CAPS Del Rei e Oliveira-MG e de consultórios de médicos psiquiatras particulares da cidade de São João del-Rei MG. 
A importância de recrutar pacientes TBI em 3 tipos de serviços diferentes (atenção secundária-CAPS, atenção terciária-ambulatório GRUDA e ainda em consultórios particulares de médicos psiquiatras), é que temos uma amostra mais próxima da realidade, ou seja, do que encontramos no mundo real; e este é um diferencial da metodologia utilizada no presente estudo.

Os sujeitos sem patologia psiquiátrica foram recrutados em parte juntamente ao projeto: "Estudo de associação de Polimorfismos de Nucleotídeo Único e Expressão Gênica de GAD1 com Espectroscopia por Ressonância Magnética de Glutamato/GABA no Transtorno Bipolar tipo I" (PROJETO ESPECTGENE número: 0703) e a outra parte foi recrutada no grupo de pais de uma escola particular em São João Del Rei - MG.

Os sujeitos foram avaliados clinicamente por um psiquiatra ou psicólogo especializado em transtornos do humor, com treinamento específico tanto para a aplicação dos instrumentos diagnóstico e sintomatológico quanto para o preenchimento dos critérios de inclusão e exclusão. Na sequência, foram esclarecidos os objetivos e procedimentos da pesquisa e os pacientes receberam o Termo de Consentimento Livre e Esclarecido (TCLE). Após assinatura deste, os sujeitos foram submetidos aos instrumentos já descritos em um único encontro com duração aproximada de duas horas. Os instrumentos foram aplicados por um psicólogo treinado. 
5 Análise Estatística

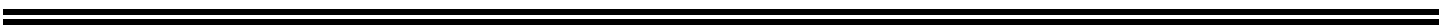




\section{ANÁLISE ESTATÍSTICA}

Primeiramente, foram construídas tabelas descritivas contendo as médias e distribuição de frequência para a análise exploratória das variáveis sociodemográficas e das características clínicas.

Posteriormente, a comparação da distribuição das médias foi feita utilizando o TESTE ANOVA (Zar, 2010). A associação das variáveis categóricas foi investigada por meio de testes de Qui-quadrado (Zar, 2010) e exato de Fisher (Zar, 2010). O teste Kruskal-Wallis test by ranks (Zar, 2010) foi utilizado para verificar se houve diferença entre os resultados do grupo caso (TBI) e do controle saudável.

As análises foram conduzidas utilizando-se os softwares KNIME (2007) e o R (2007) para Microsoft Windows 10 (https://www.microsoft.com/pt-br/windows) com nível de significância de $5 \%$. 


\section{Resultados}




\section{RESULTADOS}

\subsection{Descrição da amostra}

$\mathrm{Na}$ Tabela 3, encontram-se as variáveis sociodemográficas da amostra. O grupo caso (n=73) apresentou em média 46.2 anos de idade (mínimo 35 e máximo 57 anos) e o grupo controle (n=23) 40,1 anos de idade (mínimo 30,1 e máximo 50,1). Quanto à escolaridade, o grupo caso apresentou 11,3 anos de estudo (mínimo 7 e máximo 16) e o controle 15,2 anos de estudo (mínimo 9,4 e máximo 21). Essas diferenças foram estaticamente significativas com o p=0,021 e 0,002, respectivamente. A média do número de filhos foi 2 (mínimo 1 e máximo 3) e não houve diferença entre os grupos $(\mathrm{p}=0,167)$. A maior parte da amostra foi do gênero feminino, $82,2 \%$ do caso, e $91,7 \%$ do controle. Não houve diferença significativa entre os grupos $(p=0,265)$.

Quanto à etnia, a maior parte foi branca, 71,2\% do caso e 94,4\% do controle, sem diferença significativa entre os grupos $(p=0,135)$. Em relação ao estado civil, a amostra se distribuiu da seguinte forma: a maior parte era casada, 46,6\% do caso e $62,5 \%$ do controle, seguida de divorciada (27,4\% do caso e $33,3 \%$ do controle), solteira ( $15 \%$ do caso e $4,2 \%$ do controle) e viúva ( $11 \%$ do caso e $0 \%$ do controle) sem diferença entre os grupos $(\mathrm{p}=0,319)$.

Quanto à renda familiar, 82,1\% do grupo caso apresentaram uma renda familiar mensal entre 0 e 5 salários mínimos, enquanto o grupo controle apresentou apenas $38,9 \%$, tendo suas rendas mais distribuídas entre as categorias. Nesse caso, foi encontrada diferença significativa entre os grupos $(p=0,005)$. Por meio destes resultados apresentados na Tabela 4, pode-se concluir que os grupos são homogêneos de acordo com as variáveis sociodemográficas com exceção da idade, anos de escolaridade e renda familiar. 
Tabela 4 - Variáveis sociodemográficas da amostra

\begin{tabular}{|c|c|c|c|c|}
\hline & & $\begin{array}{c}\text { Grupo Caso } \\
\text { TBI } \\
\mathbf{n}=73\end{array}$ & $\begin{array}{c}\text { Grupo Controle } \\
\text { Saudável } \\
\text { n=24 }\end{array}$ & $\mathbf{P}$ \\
\hline \multicolumn{2}{|c|}{$\begin{array}{l}\text { Idade* } \\
\text { Média (Desvio padrão) }\end{array}$} & $46.2(11.1)$ & $40.1(10.0)$ & 0,021 \\
\hline \multicolumn{2}{|c|}{$\begin{array}{l}\text { Anos de Escolaridade* } \\
\text { Média (Desvio padrão) }\end{array}$} & $11.3(4.5)$ & $15.2(5.8)$ & 0,002 \\
\hline \multicolumn{2}{|c|}{$\begin{array}{l}\mathbf{N}^{\mathbf{o}} \text { de Filhos* } \\
\text { Média (Desvio padrão) }\end{array}$} & $2.0(1.0)$ & $1.7(0.8)$ & 0,167 \\
\hline $\begin{array}{l}\text { Gênero** } \\
(\%)\end{array}$ & $\begin{array}{l}\text { Feminino } \\
\text { Masculino }\end{array}$ & $\begin{array}{l}82.2 \\
17.8\end{array}$ & $\begin{array}{c}91.7 \\
8.3\end{array}$ & 0,265 \\
\hline $\begin{array}{l}\text { Etnia } * * * \\
(\%)\end{array}$ & $\begin{array}{c}\text { Branco } \\
\text { Negro e mulato } \\
\text { Asiático }\end{array}$ & $\begin{array}{c}71.2 \\
27.3 \\
1.5\end{array}$ & $\begin{array}{c}94.4 \\
5.6 \\
0.0\end{array}$ & 0,135 \\
\hline $\begin{array}{l}\text { Estado Civil }{ }^{* * *} \\
(\%)\end{array}$ & $\begin{array}{c}\text { Casado } \\
\text { Divorciado } \\
\text { Solteiro } \\
\text { Viúvo }\end{array}$ & $\begin{array}{c}46.6 \\
27.4 \\
15 \\
11\end{array}$ & $\begin{array}{c}62.5 \\
33.3 \\
4.2 \\
0.0\end{array}$ & 0,319 \\
\hline $\begin{array}{l}\text { Renda } \\
\text { Familiar*** } \\
(\%)\end{array}$ & $\begin{array}{c}1 \text { a } 5 \text { salários } \\
6 \text { a } 10 \text { salários } \\
11 \text { a } 15 \text { salários } \\
16 \text { a } 20 \text { salários } \\
\text { acima de } 20 \text { salários }\end{array}$ & $\begin{array}{c}82.1 \\
14.3 \\
0.0 \\
0.0 \\
3.6\end{array}$ & $\begin{array}{c}5.6 \\
11.1 \\
11.1\end{array}$ & 0,005 \\
\hline
\end{tabular}

*ANOVA **Qui-Quadrado ***Teste exato de Fisher 
Na Tabela 5, encontra-se a distribuição de frequência dos marcadores de gravidade e características clínicas do TB. Identificou-se que 50\% do grupo caso tiveram o início da doença antes do nascimento do filho, 58,8\% de antes do nascimento até cinco anos depois do nascimento do filho e $82,3 \%$ de antes do nascimento até dez anos depois do nascimento do filho. Ou seja, a maior parte dos filhos destes pacientes TBI teve durante sua criação, infância e adolescência, um dos progenitores com TBI.

Além disso, 53,2\% dos pacientes do grupo caso TBI tiveram o início da doença até os 25 anos de idade e 53,1\% tiveram mais de dez episódios anteriores. Observouse, também, a média de 23 anos de tempo da doença (mínimo 9 e máximo 36); ou seja, tempo transcorrido do primeiro episódio até o momento da avaliação. Em relação aos sintomas de mania e de depressão no momento da avaliação, a média os escores da YMRS foi 3,6 (mínimo 1,3 e máximo 6) e da HDRS foi 4,9 (mínimo 3 e máximo 7). 
Tabela 4- Marcadores de gravidade e características clínicas

\begin{tabular}{|c|c|c|}
\hline \multirow{6}{*}{$\begin{array}{l}\text { Início da doença em } \\
\text { relação ao nascimento } \\
\text { do filho } \\
\text { n(\%) }\end{array}$} & Antes do nascimento do filho & $17(50)$ \\
\hline & 1 a 5 anos depois do nascimento do filho & $3(8.8)$ \\
\hline & 6 a 10 anos depois do nascimento do filho & $8(23.5)$ \\
\hline & 11 a 15 anos depois do nascimento do filho & $2(5.8)$ \\
\hline & 16 a 20 anos depois do nascimento do filho & $3(8.8)$ \\
\hline & Mais de 20 anos depois do nascimento filho & $1(3)$ \\
\hline \multirow{4}{*}{$\begin{array}{l}\text { Idade de início da } \\
\text { doença } \\
\text { n(\%) }\end{array}$} & 5 a 15 & $10(21,3)$ \\
\hline & 16 a 25 & $15(31,9)$ \\
\hline & 26 a 40 & $15(31,9)$ \\
\hline & $>40$ & $7(14,9)$ \\
\hline \multirow{3}{*}{$\begin{array}{l}\text { Número de episódios } \\
\text { anteriores } \\
\text { n(\%) }\end{array}$} & até 5 & $11(34.4)$ \\
\hline & 6 a 10 & $4(12, .5)$ \\
\hline & $>10$ & $17(53,1)$ \\
\hline \multicolumn{3}{|l|}{ Tempo de doença } \\
\hline $\begin{array}{l}\text { média (desvio padrão) } \\
\text { mediana }\end{array}$ & $22,7(13,7)$ & 21 \\
\hline \multicolumn{3}{|l|}{ HDRS-21 } \\
\hline $\begin{array}{l}\text { média (desvio padrão) } \\
\text { mediana }\end{array}$ & $4,5(2,8)$ & 5 \\
\hline \multicolumn{3}{|l|}{ YOUNG } \\
\hline $\begin{array}{l}\text { média (desvio padrão) } \\
\text { mediana }\end{array}$ & $3,3(3,2)$ & 3 \\
\hline
\end{tabular}




\section{- $\quad$ Resultados das escalas de medida}

Na Tabela 5, encontram-se os resultados da comparação das variáveis avaliadas (calor emocional, superproteção e rejeição) quanto ao cuidado recebido pelo paciente TBI durante sua infância e adolescência (EMBU-S) e ao cuidado destinado ao filho na vida adulta (EMBU-P).

Observou-se que, quando o paciente tem a lembrança de ter recebido alto calor emocional paterno e materno, ele destinou alto calor emocional para seus filhos. Isso ocorreu em $100 \%$ dos casos. E quando o paciente tem a lembrança de ter recebido médio ou baixo calor emocional, 74,5\% destinaram alto calor emocional para seu filho e 25,5\% reproduziram o que receberam, destinando médio ou baixo calor emocional para seu filho. A influência do calor emocional recebido no calor emocional destinado ao filho foi significativa na amostra de pacientes bipolares $(\mathrm{p}=0,013)$.

Quanto à superproteção, daqueles pacientes que têm a lembrança de terem recebido baixa superproteção paterna, 69\% destinaram para seus filhos superproteção média ou alta e apenas 31\% reproduziram a baixa superproteção. Daqueles pacientes que têm a lembrança de terem recebido média ou alta superproteção paterna, $87 \%$ reproduziram média ou alta superproteção e apenas $13 \%$ destinaram baixa superproteção. Apesar de os dados mostrarem uma tendência à associação entre a memória de superproteção recebida paterna e a superproteção destinada ao filho, essa associação não foi significativa $(\mathrm{p}=0,08)$. Já daqueles que lembram terem recebido baixa superproteção materna, $57 \%$ destinaram ao filho média ou alta superproteção e 43\% reproduziram a baixa superproteção. Daqueles que lembram terem recebido superproteção materna média e alta, $91 \%$ reproduziram a superproteção média e alta destinada ao seu filho e apenas $9 \%$ destinaram baixa superproteção. A influência da superproteção materna recebida na superproteção destinada ao filho foi significativa na amostra de pacientes bipolares $(\mathrm{p}=0,003)$.

Quanto à rejeição, apesar de não terem sido encontradas associações significativas $(\mathrm{p}>0,90)$, observou-se que, daqueles que têm a lembrança de terem recebido baixa rejeição do pai e da mãe, $80 \%$ destinaram ao filho baixa rejeição e apenas $20 \%$ destinram ao filho rejeição média e alta. Mesmo daqueles que têm a 
lembrança de terem recebido rejeição média ou alta, a maioria $(85 \% / 83 \%)$ também criou seu filho com baixa rejeição e apenas $15 \% / 17 \%$ reproduziram com rejeição média e alta.

Tabela 6- A influência do cuidado recebido no cuidado destinado aos filhos no grupo caso

\section{Calor Emocional}

\begin{tabular}{ccc}
\hline Pai & \multicolumn{2}{c}{ EMBU-P } \\
\hline EMBU-S & Alto & Médio/Baixo \\
\hline Alto & $21(100 \%)$ & $0(0 \%)$ \\
Médio/Baixo & $35(74 \%)$ & $12(26 \%)$ \\
\hline $\mathrm{p}=0.01$ Teste Exato de Fisher (2-tail)
\end{tabular}

\section{Superproteção}

\begin{tabular}{ccc}
\hline Pai & \multicolumn{2}{c}{ EMBU-P } \\
\hline EMBU-S & Baixo & Médio/Alto \\
\hline Baixo & $9(31 \%)$ & $20(69 \%)$ \\
Médio/Alto & $5(13 \%)$ & $34(87 \%)$ \\
\hline p=0.08 Teste Exato de Fisher (2-tail)
\end{tabular}

\section{Rejeição}

\begin{tabular}{ccc}
\hline Pai & \multicolumn{2}{c}{ EMBU-P } \\
\hline EMBU-S & Baixo & Médio/Alto \\
\hline Baixo & $44(80 \%)$ & $11(20 \%)$ \\
Médio/Alto & $11(84.6 \%)$ & $2(15.4 \%)$ \\
\hline p>0.90 Teste Exato de Fisher (2-tail)
\end{tabular}

\begin{tabular}{ccc}
\hline Mãe & \multicolumn{2}{c}{ EMBU-P } \\
\hline EMBU-S & Alto & Médio/Baixo \\
\hline Alto & $20(100 \%)$ & $0(0 \%)$ \\
Médio/Baixo & $36(75 \%)$ & $12(25 \%)$ \\
\hline p=0.013 Teste Exato de Fisher (2-tail)
\end{tabular}

\begin{tabular}{ccc}
\hline Mãe & \multicolumn{2}{c}{ EMBU-P } \\
\hline EMBU-S & Baixo & Médio/Alto \\
\hline Baixo & $10(43 \%)$ & $13(57 \%)$ \\
Médio/Alto & $4(9 \%)$ & $41(91 \%)$ \\
\hline p=0.003 Teste Exato de Fisher (2-tail)
\end{tabular}

\begin{tabular}{ccc}
\hline Mãe & \multicolumn{2}{c}{ EMBU-P } \\
\hline EMBU-S & Baixo & Médio/Alto \\
\hline Baixo & $45(80.3 \%)$ & $11(19.7 \%)$ \\
Médio/Alto & $10(83.3 \%)$ & $2(16.7 \%)$ \\
\hline p $>0.90$ Teste Exato de Fisher (2-tail)
\end{tabular}

Na Tabela 7, encontram-se os resultados da comparação das variáveis avaliadas (calor emocional, superproteção e rejeição) quanto ao cuidado recebido pelo sujeito saudável durante sua infância e adolescência (EMBU-S) e ao cuidado destinado ao filho na vida adulta (EMBU-P).

Observou-se que, diferente do grupo caso, no grupo controle não foi encontrada associação significativa entre a lembrança do calor emocional recebido paterno ( $p=0.61)$ e materno $(p=0.57)$ e o calor emocional destinado ao filho. Também, não foi 
encontrada associação significativa entre a lembrança de superproteção recebida paterna $(\mathrm{p}=0.10)$ e materna $(\mathrm{p}=0.10)$ e a superproteção destinada ao filho. O mesmo ocorreu em relação à lembrança de rejeição recebida paterna $(\mathrm{p}=0.72)$ e materna $(\mathrm{p}=0.95)$ e a rejeição destinada ao filho. Apesar disso, observou-se, nos percentuais que, independente do grupo e do cuidado recebido, a maioria dos pais dessa amostra destinou alto calor emocional para seu filho, superproteção média ou alta e rejeição baixa.

Tabela 7 - A influência do cuidado recebido no cuidado destinado aos filhos no grupo controle

\section{Calor Emocional}

\begin{tabular}{lcc}
\hline Pai & \multicolumn{2}{c}{ EMBU-P } \\
\hline EMBU-S & Alto & Médio/Baixo \\
\hline Alto & $10(83.3 \%)$ & $2(16.7 \%)$ \\
Médio/Baixo & $11(91.7 \%)$ & $1(8.7 \%)$ \\
\hline
\end{tabular}

p=0.61 Teste Exato de Fisher (2-tail)

\section{Overprotection}

\begin{tabular}{lcc}
\hline Pai & \multicolumn{2}{c}{ EMBU-P } \\
\hline EMBU-S & Baixo & Médio/Alto \\
\hline Baixo & $2(25 \%)$ & $6(75 \%)$ \\
Médio/Alto & $0(0 \%)$ & $16(100 \%)$ \\
\hline
\end{tabular}

$\mathrm{p}=0.10$ Teste Exato de Fisher (2-tail)

\begin{tabular}{lcc}
\hline Mãe & \multicolumn{2}{c}{ EMBU-P } \\
\hline EMBU-S & Alto & Médio/Baixo \\
\hline Alto & $9(81.8 \%)$ & $2(18.2 \%)$ \\
Médio/Baixo & $12(92.3 \%)$ & $1(7.7 \%)$ \\
\hline p=0.57 Teste Exato de Fisher (2-tail)
\end{tabular}

\begin{tabular}{lcc}
\hline Mãe & \multicolumn{2}{c}{ EMBU-P } \\
\hline EMBU-S & Baixo & Médio/Alto \\
\hline Baixo & $2(25 \%)$ & $6(75 \%)$ \\
Médio/Alto & $0(0 \%)$ & $16(100 \%)$ \\
\hline
\end{tabular}

$\mathrm{p}=0.10$ Teste Exato de Fisher (2-tail)

\section{Rejeição}

\begin{tabular}{|c|c|c|c|c|c|}
\hline \multirow{2}{*}{$\begin{array}{l}\text { Pai } \\
\text { EMBU-S }\end{array}$} & \multicolumn{2}{|c|}{ EMBU-P } & \multirow{2}{*}{$\begin{array}{l}\text { Mãe } \\
\text { EMBU-S }\end{array}$} & \multicolumn{2}{|c|}{ EMBU-P } \\
\hline & Baixo & Médio/Alto & & Baixo & Médio/Alto \\
\hline Baixo & $16(88.9 \%)$ & $2(11.1 \%)$ & Baixo & $18(85.7 \%)$ & $3(14.3 \%)$ \\
\hline Médio/Alto & $5(83.3 \%)$ & $1(16.7 \%)$ & Médio/Alto & $3(100 \%)$ & $0(0 \%)$ \\
\hline
\end{tabular}


$\mathrm{Na}$ Tabela 8, encontra-se a comparação dos grupos caso (TBI) e controle (saudável). Mediante a diferença entre eles, pode-se caracterizar o cuidado bipolar recebido (EMBU-S) e destinado aos filhos (EMBU-P). Observou-se que foi encontrada diferença estatisticamente significativa na lembrança de calor emocional materno, que foi menor no grupo TBI do que no controle saudável ( $\mathrm{p}=0,036)$. Quanto ao calor emocional destinado ao filho, embora não significativo, tendeu a ser menor no grupo TBI do que no grupo saudável $(\mathrm{p}=0,08)$. Foi encontrada também uma tendência tanto para a lembrança de rejeição materna ter sido maior no grupo TBI do que no grupo saudável $(\mathrm{p}=0.068)$ quanto para a superproteção destinada ao filho ter sido menor no grupo TBI do que no grupo saudável ( $\mathrm{p}=0,097)$. Nas demais variáveis avaliadas, não foram entradas diferenças significativas ou tendências.

Tabela 8 - Caracterização do cuidado bipolar

\begin{tabular}{llcc}
\hline Grupo & Variáveis & Mediana & P \\
\hline TBI & Rejeição & 34 & 0,40 \\
Controle Saudável & Rejeição & 35,5 & \\
\hline TBI & Lembrança de rejeição paterna & 10 & 0,39 \\
Controle Saudável & Lembrança de rejeição paterna & 10 & \\
\hline TBI & Lembrança de rejeição materna & 11 & 0,068 \\
Controle Saudável & Lembrança de rejeição materna & 9 & \\
\hline TBI & Calor emocional & 21 & 0,08 \\
Controle Saudável & Calor emocional & 20 & 0,58 \\
\hline TBI & Lembrança de calor emocional paterno & 14 & \\
Controle Saudável & Lembrança de calor emocional paterno & 14,6 & \\
\hline TBI & Lembrança de calor emocional materno & 14 & 0,036 \\
Controle Saudável & Lembrança de calor emocional materno & 15 & \\
\hline TBI & Superproteção & 40 & 0,097 \\
Controle Saudável & Superproteção & 36 & 0,066 \\
\hline TBI & Lembrança de superproteção paterna & 19 & 0,64 \\
Controle Saudável & Lembrança de superproteção paterna & 19 & \\
\hline TBI & Lembrança de superproteção materna & 18 & \\
Controle Saudável & Lembrança de superproteção materna & 18 & \\
\hline Krat & & & \\
\hline
\end{tabular}

Kruskal-Wallis test by ranks 
A partir desses resultados encontrados na Tabela 9, pode-se identificar possíveis comportamentos de risco para o desenvolvimento de psicopatologia como o TB pela identificação dos comportamentos parentais relacionados às variáveis avaliadas.

Quanto à variável calor emocional (comportamentos parentais que geram nos filhos a sensação de conforto e a certeza de serem aprovados como pessoa pelos pais), encontram-se a lembrança de ter recebido menor calor emocional materno $(\mathrm{p}=0.036)$ e a tendência a ter destinado menos calor emocional aos filhos $(\mathrm{p}=0.08)$, ambas no grupo TBI. Esses resultados estão relacionados aos seguintes comportamentos parentais:

- Deixar de elogiar o filho ou elogiar raramente.

- Se o filho fizer uma "arte", ele não poder consertar a situação pedindolhes desculpas.

- Não tentar tornar a adolescência do filho estimulante, interessante, instrutiva (por exemplo: dando-lhe bons livros para ler, incentivando-o a sair para passear, levando-o a clubes).

- Deixar de encorajar ou confortar o filho quando ele precisa.

- Não demonstrar com palavras e gestos que gostam do filho.

- Ausência de calor e ternura entre os pais e filhos.

- Não ficar orgulhoso quando o filho obtém êxito em alguma coisa pela qual havia se empenhado.

Quanto à variável rejeição (comportamentos dos pais com a intenção de mudar a vontade do filho, entendidos como rejeição do filho como indivíduo), encontra-se uma tendência à lembrança de a rejeição materna ter sido maior no grupo TBI $(\mathrm{p}=0,06)$. Esses resultados estão relacionados aos seguintes comportamentos parentais:

- Ficar aborrecido com o filho e não lhe dizer o motivo.

- Bater no filho mais do que ele merece.

- Criticar o filho na frente dos outros dizendo que ele é preguiçoso e inútil. 
- Tratar o filho como "ovelha negra" ou como "bode expiatório" da família.

- Tratar o filho de um modo que ele sinta que os pais gostam mais de seus irmãos do que dele.

- Tratar o filho de um modo que o faça sentir-se envergonhado.

- Castigar com severidade mesmo por coisas sem importância.

- Desejar que o seu filho fosse diferente em algum aspecto.

Quanto à variável superproteção (comportamentos parentais caracterizados por excessiva preocupação indutora de estresse, intrusão nas atividades dos filhos, altos níveis de padrão de realização, imposição de regras rígidas), encontra-se uma tendência a destinar menos superproteção ao filho no grupo TBI do que no controle saudável $(\mathrm{p}=0,09)$. Esses resultados estão relacionados aos seguintes comportamentos parentais contrários aos de superproteção que lembram negligência:

- Não ter preocupação com o filho.

- Não cobrar.

- Não impor regras. 


\subsection{Resultados da análise de caracterização dos avós}

Na Tabela 9, encontra-se a frequência de respostas quanto a quem criou os sujeitos da amostra (casos e controles). Observou-se a seguinte distribuição: a maior parte da amostra foi criada pelos pais biológicos (avós) com ou sem ajuda de outros parentes $69,2 \%$ do grupo TBI e $86,4 \%$ do grupo controle saudável. Períodos com parentes diferentes corresponderam a 16,9\% do grupo TBI e 4,5\% do grupo saudável. Mãe biológica com ou sem a ajuda de outros parentes correspondeu a 10,8\% do grupo TBI e 9,1\% do grupo controle saudável. Pais adotivos (avós) só foram encontrados no grupo TBI $3,1 \%$.

Tabela 9 - Frequência de respostas quanto à pessoa que criou a amostra

\begin{tabular}{lcc}
\hline & $\begin{array}{c}\text { Grupo Caso } \\
\text { TBI } \\
(\mathbf{n = 7 3})\end{array}$ & $\begin{array}{c}\text { Grupo Controle } \\
\text { Saudável } \\
(\mathbf{n = 2 4})\end{array}$ \\
\hline Pais biológicos com ou sem outros parentes & $69,2 \%$ & $86,4 \%$ \\
Períodos com parentes diferentes & $16,9 \%$ & $4,5 \%$ \\
Mãe biológica com ou sem outros parentes & $10,8 \%$ & $9,1 \%$ \\
Pais adotivos & $3,1 \%$ & 0 \\
\hline
\end{tabular}


Na Tabela 10, encontram-se idade, gênero e estilos parentais dos avós (pais dos sujeitos) segundo os próprios avós. Esse último foi resultado das escalas de Responsividade e Exigência. Dessa subanálise, participaram 17 avós do grupo caso e cinco avós do grupo controle. Devido à impossibilidade de contatar os demais avós (falecimento, não concordância em participar da pesquisa ou telefone não encontrado), o $n$ foi baixo, o que impossibilitou fazer um teste de significância estatística. Portanto, a subanálise dessa amostra foi descritiva.

Observou-se que a imensa maioria dos avós em ambos os grupos era do gênero feminino ( $94 \%$ no grupo TBI e 100\% no controle saudável) e apresentou em média a idade de 72,3 anos $(\mathrm{dp}=18,15)$ no grupo TBI e de 73,1 $(\mathrm{dp}=9,1)$ no grupo controle saudável. Os avós do grupo TBI apresentaram a seguinte distribuição de estilos parentais: $35 \%$ estilo parental negligente, 23,5\% autoritativo, 23,5\% autoritário e $17,7 \%$ indulgente. Já os avós do grupo controle saudável apresentaram a seguinte distribuição: $60 \%$ autoritativo, $20 \%$ indulgente e $20 \%$ negligente.

Tabela 10 - Distribuição de frequência dos estilos parentais dos avós

\begin{tabular}{lccc}
\hline Variáveis & & $\begin{array}{c}\text { Caso } \\
\text { TBI } \\
\mathbf{n = 1 7}\end{array}$ & $\begin{array}{c}\text { Controle } \\
\text { Saudável } \\
\mathbf{n = 5}\end{array}$ \\
\hline Idade & Média(dp) & $72,3(18,15)$ & $73,1(9,1)$ \\
\hline Gênero & Masculino & $6 \% 1$ & -- \\
& Feminino & $94 \% 16$ & $100 \% 5$ \\
\hline Estilo Autoritativo & $\boldsymbol{\%} / \mathbf{n}$ & $23,53 \% 4$ & $60 \% 3$ \\
Estilo Autoritário & $\boldsymbol{\%} / \mathbf{n}$ & $23,53 \% 4$ & $0 \% 0$ \\
Estilo Indulgente & $\boldsymbol{\%} / \mathbf{n}$ & $17,65 \% 3$ & $20 \% 1$ \\
Estilo Negligente & $\boldsymbol{\%} / \mathbf{n}$ & $35,29 \% 6$ & $20 \% 1$ \\
\hline
\end{tabular}


Vale lembrar que a função desta análise é avaliar a mesma relação avós e sujeitos, mas utilizando outro instrumento e outro sujeito para se evitar o viés do mesmo sujeito na mesma avaliação. Conforme descrito, o estilo parental que produz os resultados mais desejáveis nos filhos, melhor desempenho escolar, competência social e psicológica é o estilo autoritativo responsável por apenas $23,53 \%$ dos avós do grupo TBI. A soma dos demais estilos foi responsável pela grande maioria dos avós $(76,47 \%)$, sendo que o estilo que teve a maior porcentagem dos avós do TBI foi o estilo negligente $(35,29 \%)$. Esse resultado de $35 \%$ de os avós TBI exigirem pouco e terem responsividade baixa é condizente com o resultado encontrado neste estudo de que, daqueles que lembraram terem recebido baixa superproteção materna, $43 \%$ reproduziram esse cuidado destinando à baixa superproteção para seus filhos ( $\mathrm{p}=0,003)$. Já no grupo controle saudável, mais da metade dos avós (60\%) apresentaram o estilo autoritativo.

Os resultados das tabulações cruzadas mostraram que houve diferença estatisticamente significativa entre as variáveis Grupo e a questão 9 da escala de Responsividade ( $\mathrm{p}=0,024$; Teste Exato de Fisher), que pergunta se os pais incentivam o filho a pensar de forma independente durante a sua infância e adolescência. $\mathrm{Na}$ Tabela 11, encontra-se a frequência dessas respostas por grupo.

Tabela 11 - Frequência de respostas da questão 9 da Escala de Responsividade

\begin{tabular}{lcc}
\hline $\begin{array}{l}\text { Respostas da questão 9 da } \\
\text { escala de Responsividade }\end{array}$ & $\begin{array}{c}\text { Grupo Caso } \\
\text { TBI } \\
(\mathbf{n = 7 3})\end{array}$ & $\begin{array}{c}\text { Grupo Controle 1 } \\
\text { Saudável } \\
(\mathbf{n = 2 4})\end{array}$ \\
\hline Geralmente & $\mathbf{4 7 \%}$ & $\mathbf{1 0 0 \%}$ \\
Às vezes & $\mathbf{4 1 , 2 \%}$ & $0 \%$ \\
Quase nunca & $\mathbf{1 1 , 8 \%}$ & $0 \%$ \\
\hline
\end{tabular}


Os resultados da Tabela 11 indicaram que 100\% dos avós do grupo controle saudável responderam que, geralmente, incentivaram o filho a pensar de forma independente. Já os avós do grupo TBI, em sua maioria, respondeu geralmente (47\%), seguido de às vezes $(41,2 \%)$ e minoritariamente quase nunca $(11,8 \%)$. Ou seja, em relação à promoção de autonomia no filho, os escores foram melhores no grupo saudável e piores no grupo TBI. Resultados que, de certa forma, foram coerentes com a visão dos sujeitos TBI, dos quais se lembram terem recebido superproteção baixa materna, $43 \%$ reproduziram esse cuidado destinando à baixa superproteção para seu filho ( $\mathrm{p}=0,003)$. Além disso, os sujeitos TBI lembram de terem recebido menos calor emocional do que o controle saudável $(\mathrm{p}=0.036)$ e maior rejeição materna (tendência, $\mathrm{p}=0,06)$.

No ANEXO E, encontram-se a análise descritiva da presença ou não de TB nos avós do grupo TBI e seus estilos parentais. No ANEXO F, encontra-se a análise descritiva do estilo parental por idade dos avós do grupo TBI e controle saudável, visando ao aspecto geracional. E, finalmente, no ANEXO G, encontra-se a análise descritiva dos estilos parentais dos avós (visão dos avós) por cuidado recebido dos pais (visão do sujeito); ou seja, visões diferentes (avô e sujeito) sobre a mesma relação (como o sujeito foi criado na infância e adolescência) no grupo TBI e no controle saudável. Dessa subanálise, conforme destacado anteriormente, participaram apenas 17 avós do grupo caso e cinco avós do grupo controle. Devido à impossibilidade de contatar os demais avós, o $n$ foi baixo, o que impossibilitou fazer um teste de significância estatística. 


\subsection{Resultados da análise de caracterização dos filhos dos sujeitos da amostra (grupo caso e grupo controle)}

Na Tabela 12, encontra-se a distribuição de frequência da idade e do gênero dos filhos dos sujeitos por grupo. Observou-se que houve diferença significativa entre os grupos quanto à média de idade dos filhos avaliados pelo SDQ $(\mathrm{p}=0,01)$. No grupo TBI, a média de idade dos filhos e o dp foram maiores $(20,6 \mathrm{dp}=10,1)$ em comparação ao grupo controle saudável $(13,6 \mathrm{dp}=6,5)$. Quanto ao gênero dos filhos avaliados pelo SDQ, não houve diferença entre os grupos $(\mathrm{p}=0,85)$. No grupo TBI, $51 \%$ foram do gênero masculino e $49 \%$ do gênero feminino. No grupo controle saudável, $46 \%$ foram do gênero masculino e $54 \%$ do gênero feminino.

Tabela 12 - Distribuição de frequência de idade e gênero dos filhos por grupo

\begin{tabular}{cccc}
\hline & Grupo Caso TBI & Grupo Controle Saudável & $\mathbf{P}^{*}$ \\
\hline Idade média(dp) & $20.6(10.1)$ & $13.56(6.5)$ & 0.01 \\
Masculino & $37(51 \%)$ & $11(46 \%)$ & \\
\hline Total & $73(100 \%)$ & $24(100 \%)$ & \\
\hline
\end{tabular}

Qui-quadrado* 
Na Tabela 13, encontra-se a comparação entre os grupos quanto às variáveis do SDQ. Apesar de não ter sido encontrada diferença estatisticamente significativa entre os grupos em todas as variáveis avaliadas, na variável problemas de conduta, o grupo TBI apresentou um escore médio maior $(2,08)$ do que o grupo controle saudável $(1,50)$ e saiu da faixa considerada normal (0-2) em direção à faixa limítrofe (3). Ou seja, os filhos dos pacientes TBI apresentaram mais problemas de conduta em relação ao grupo controle saudável.

Tabela 13 - Comparação entre os grupos quanto às variáveis do $S D Q$

\begin{tabular}{lccc}
\hline & $\begin{array}{c}\text { Grupo TB I } \\
(\mathbf{n = 7 3})\end{array}$ & $\begin{array}{c}\text { Grupo Controle } \\
\text { Saudável } \\
(\mathbf{n = 2 4})\end{array}$ & $\boldsymbol{P}^{*}$ \\
\hline Dificuldades totais & $9,27 \pm 6,93$ & $6,64 \pm 3,75$ & 0,162 \\
Comportamento Prossocial & $8,31 \pm 2,12$ & $8,43 \pm 1,55$ & 0,737 \\
Hiperatividade & $3,17 \pm 2,86$ & $1,93 \pm 14,49$ & 0,442 \\
Sintomas Emocionais & $2,65 \pm 2,11$ & $2,07 \pm 1,77$ & 0,407 \\
Problemas de conduta & $\mathbf{2 , 0 8} \pm 2,52$ & $1,5 \pm 1,6$ & 0,521 \\
Problemas com colegas & $1,46 \pm 1,57$ & $1,14 \pm 1,23$ & 0,623 \\
\hline
\end{tabular}

*ANOVA 


\section{DISCUSSÃO}

A presente pesquisa é um estudo caso controle, em que reportamos a influência encontrada da forma como os pais com TBI foram cuidados durante sua infância e como eles cuidam dos seus filhos na vida adulta. Caracterizam-se, também, o cuidado recebido por pacientes bipolares do tipo I durante a infância e o cuidado destinado aos seus filhos na vida adulta comparando-os com o cuidado de pais saudáveis. A partir da caracterização desse cuidado, pôde-se identificar comportamentos parentais que podem estar associados ao desenvolvimento de TB nos filhos, lembrando-se que as variáveis avaliadas foram: calor emocional, superproteção e rejeição. Os resultados do presente trabalho serão discutidos nesta ordem: 1) Cuidado recebido dos pais pelo sujeito; 2) Cuidado destinado ao filho; 3) Associação entre o cuidado recebido e o cuidado destinado ao filho do grupo caso TBI; 4) Associação entre o cuidado recebido e o cuidado destinado ao filho do grupo controle saudável; 5) O fator geracional; 6) Considerações finais; 7) Perspectivas futuras; 8) Limitações do estudo.

\subsection{Cuidado recebido dos pais pelo sujeito}

Os resultados apontaram que os sujeitos TBI lembram terem recebido menos calor emocional materno quando comparados ao grupo controle saudável. Essa diferença foi significativa $(\mathrm{p}=0.036)$. O resultado de baixo calor emocional parental no TB foi condizente com os resultados encontrados em estudos anteriores (Parker, 1983; Geller et al., 2000; Gomes et al., 2015). Outros estudos acrescentaram que o baixo calor emocional materno predisse recaída mais rápida após recuperação de uma crise maníaca (Rosenfarb et al., 1994; Cooke et al., 1999). Além disso, o baixo calor parental também foi associado à internalização e externalização dos problemas pelos filhos, como um fator de risco independente, em adição ao status de risco bipolar (Lau et al., 2018). Esses resultados também foram coerentes com os encontrados anteriormente 
por Ostiguy et al. (2012), que mostraram que a associação entre a neurose dos pais e a internalização dos problemas pelos filhos foi mais forte entre pais bipolares. É interessante notar que os resultados sugerem uma transmissão entre gerações do risco por meio da alta neurose e baixa amabilidade em pais que tiveram associação com problemas com filhos durante a infância média, fato que predisse pobre funcionamento dez anos depois.

Quanto à lembrança de rejeição materna, apesar de não significativa, os resultados apontaram uma tendência de ter sido maior no grupo TBI quando comparado ao grupo controle saudável $(\mathrm{p}=0,06)$. Nos achados deste estudo, foram condizentes com os resultados encontrados por Reichart et al. (2007), que avaliaram a percepção dos filhos (bipolares x não bipolares) em relação à criação que tiveram dos pais (bipolares x população geral), e concluíram que filhos bipolares percebem mais rejeição parental do que filhos sem psicopatologia. Nesse caso, a percepção de rejeição parental foi relacionada à psicopatologia dos filhos. É interessante lembrar que pode existir um viés da percepção dos filhos, pois filhos saudáveis tendem a perceber melhor os pais.

\subsection{Cuidado destinado ao filho}

Quanto ao calor emocional dedicado aos filhos, apesar de não significativo, os resultados apontaram uma tendência de ser menor no grupo TBI em comparação ao controle saudável $(\mathrm{p}=0,08)$. Nos achados deste estudo, foram condizentes com os encontrados por Perris et al. (1985), que avaliaram pacientes unipolares e bipolares deprimidos e concluíram que o calor emocional dedicado ao filho portador de TB foi menor quando comparado ao controle saudável. É importante ressaltar que, neste estudo, a falta de calor emocional em práticas educativas dos pais pode ser uma variável crucial na patogênese de doenças depressivas. É fundamental considerar ainda, que, neste estudo, os pacientes avaliados estavam deprimidos, o que, também, pode favorecer a existência um viés da percepção da relação pais e filhos pela própria sintomatologia depressiva. 
No que se refere à superproteção dedicada aos filhos, apesar de não significativa, resultados apontaram uma tendência de ser menor no grupo TBI em comparação ao controle saudável ( $\mathrm{p}=0.09)$. Nos resultados deste estudo, nesse caso, foram divergentes dos descritos nos estudos de Geller et al. (2000), Gomes et al. (2015) e Parker (1983), que concluíram que a superproteção destinada ao filho foi maior no grupo TB quando comparado ao grupo controle saudável. Eles foram convergentes com os resultados encontrados por Reichart et al. (2007) de superproteção parental menor em relação aos adultos jovens da população em geral. Uma observação do avaliador feita durante as avaliações deste estudo mostrou que muitos pais TBI apresentaram comportamentos contrários aos de superproteção, que lembram mais negligência, como, por exemplo: não ter preocupação alguma com o filho, não cobrar, não impor regras e não estar atento às necessidades do filho; um estilo de criação mais “solto". Essa observação pode elucidar que essa diferença de resultados dos estudos e, talvez, caracterizar um pouco melhor a amostra avaliada neste estudo.

\subsection{Associação entre o cuidado recebido e o cuidado destinado ao filho}

Quanto à associação do calor emocional recebido e destinado ao filho, os resultados deste estudo mostraram que, quando o paciente tem a lembrança de ter recebido alto calor emocional paterno e materno, ele destina alto calor emocional para seus filhos. Isso ocorreu em $100 \%$ dos casos. Vale ressaltar que, mesmo daqueles pacientes que têm a lembrança de terem recebido médio ou baixo calor emocional, $74,5 \%$ destinaram alto calor emocional para seu filho e apenas $25,5 \%$ reproduziram o que receberam, destinando médio ou baixo calor emocional para seu filho. E os outros $74,5 \%$, que modificaram o que receberam, transformando o calor emocional médio ou baixo recebido em calor emocional alto destinado ao filho, parecem ter procurado melhorar os cuidados recebidos dos seus pais. O calor emocional alto é compatível com os estilos parentais de alta responsividade (estar atento às necessidades do filho): autoritativo e indulgente-permissivo. $O$ autoritativo é aquele que tem alta responsividade e alta exigência (monitora, supervisiona, dá limites, impõe regras e 
controle). Filhos de pais autoritativos apresentam melhor desempenho escolar e competências social e psicológica em relação aos demais estilos. O indulgentepermissivo é aquele pai que apresenta alta responsividade e baixa em exigência, é mais tolerante e tem disposição para perdoar. Filhos de pais indulgente-permissivos apresentam características positivas e negativas. Portanto, calor emocional alto aumenta a chance de obter melhores resultados nos filhos. Associação entre o calor emocional recebido e o calor emocional destinado ao filho foi significativa na amostra de pacientes bipolares $(\mathrm{p}=0.013)$.

Quanto à associação da superproteção recebida e destinada ao filho, daqueles pacientes que têm a lembrança de terem recebido baixa superproteção paterna, 69\% destinaram para seus filhos superproteção média ou alta e apenas $31 \%$ reproduziram a baixa superproteção. Daqueles pacientes que têm a lembrança de terem recebido média ou alta superproteção paterna, $87 \%$ reproduziram média ou alta superproteção e apenas $13 \%$ destinaram baixa superproteção. Os dados mostraram uma tendência à associação entre a memória de superproteção recebida paterna e a superproteção destinada ao filho $(\mathrm{p}=0,08)$.

Daqueles que lembram terem recebido baixa superproteção materna, 57\% destinaram ao filho média ou alta superproteção e $43 \%$ reproduziram a baixa superproteção. Daqueles que lembram terem recebido superproteção materna média e alta, $91 \%$ reproduziram a superproteção média e alta destinada ao seu filho e apenas 9\% destinaram baixa superproteção. A influência da superproteção materna recebida na superproteção destinada ao filho foi significativa na amostra de pacientes bipolares $(\mathrm{p}=0,003)$. Quanto à superproteção, vale ressaltar que os extremos, alto e baixo, que seriam representados pelos estilos parentais autoritário (de alta exigência e baixa responsividade) e negligência (de baixa exigência e baixa responsividade), respectivamente, podem trazer resultados não saudáveis na prole como por exemplo: filhos de pais negligentes apresentam baixo rendimento escolar, mais sintomas depressivos, baixa autoestima, problemas afetivos e comportamentais, alto índice de estresse e podem ter atraso no desenvolvimento. Filhos de pais autoritários apresentam comportamento de externalização (agressão verbal ou física, destruição de objetos, mentira) e de internalização (retração social, mais sintomas depressivos, mais sintomas de ansiedade), bem como tendência para desempenho escolar moderado, pouca 
habilidade social e baixa autoestima. Filhas educadas por mãe autoritária tendem a adotar o mesmo estilo na criação dos seus filhos (Weber, 2004).

Quadro comparativo: Resumo dos nossos resultados x literatura

A lembrança do calor emocinal materno foi menor no grupo TBI $(p=0,036)$.

O calor emocional dedicado aos filhos tendeu a ser menor no grupo TBI em comparação ao controle saudável $(p=0,08)$.

A lembrança de rejeição materna tendeu a ser maior no grupo TBI $(p=0,06)$

A superproteção dedicada aos filhos tendeu a ser menor no grupo TBI em comparaçăo ao controle saudável $(\mathrm{p}=0,09)$
Dados condizentes com os encontrados por Parker (1983). Geller et al. (2000) e Gomes et al. (2015) de baixo calor emocional parental no TB.

Dados condizentes com os encontrados por Perris et al. (1985) que concluiu que o calor emocional dedicado ao filho foi menor.

Dados divergentes com os encontrados por Reichart et al. (2007) que concluiu que filhos pais bipolares percebem rejeição materna menor.

Dados divergentes dos encontrados por Gomes et al. (2015), Geller et al. (2000) e Parker (1983) que concluiram que a superproteção destinada ao filho foi maior.

Dados coerente com os resultados encontrados por Reichart et al. (2007) de uma percepção dos filhos de terem recebido uma de superproteção parental menor. 


\subsection{Associação entre o cuidado recebido e o cuidado destinado ao filho do grupo controle saudável}

Apesar de não ter sido encontrada associação significativa entre os cuidados recebidos durante a infância e adolescência e os cuidados destinados aos filhos no grupo controle saudável, observou-se nos percentuais que, independente do grupo e do cuidado recebido, a maioria dos pais desta amostra destinou alto calor emocional para seu filho, superproteção média ou alta e rejeição baixa.

\section{$7.5 \mathrm{O}$ fator geracional}

Aqui cabe uma breve reflexão a partir de estudos que ajudam a elucidar a influência do fator geracional no cuidado dos filhos. Pais trazem para sua forma de cuidar as estratégias desenvolvidas pela sua experiência de serem filhos, tendendo, pois, a repetir o modelo parental aprendido. Entretanto, isto nem sempre ocorre. Existem pessoas que quebram os padrões. Algumas mães que lembram terem se sentido rejeitadas ao invés de aceitas durante a sua infância podem se tornar mais responsivas com seus próprios filhos, demonstrando que uma diferenciação pode otimizar as estratégias maternas. Alterações culturais fundamentais ocorreram ao longo do último século. Dentre tais alterações, caracteriza-se "a transição do modelo tradicional (controlador, assimétrico e autoritário), para um dito 'moderno', mais centrado na criança, que valoriza a comunicação e a independência dos filhos" (Biasoli-Alves, Caldana, Silva, 1997). Estas autoras demonstraram em sua pesquisa que mães das décadas de 30-40 e 50-60 tinham suas atitudes e crenças sobre a educação dos filhos calcadas no sistema em que foram educadas e em conselhos de suas mães e sogras; enquanto que as das décadas de 70-80 apresentaram um padrão diferenciado, calcado na procura cientificista de orientação, com base em livros, artigos de revistas ou conselhos de pediatras e psicólogos (Weber, 2006). Estes achados são coerentes e ajudam na compreensão dos resultados deste estudo, ou seja, os pais que 
transformaram a criação recebida, em algo melhor para seus filhos, o fizeram provavelmente também por uma orientação cientificista cultural. Ressaltamos que a amostra utilizada neste caso foi com sujeitos normais. Não sabemos até o momento, se este padrão pode ser aplicado numa amostra clínica de pacientes TBI como utilizamos no presente estudo.

No entanto, observou-se nos resultados da amostra, grupos caso e controle, que, mesmo aquele pai que recebeu cuidados parentais potencialmente danosos para seu desenvolvimento, a maioria fez diferente e melhor em relação ao seu filho. Este achado vem de encontro aos padrões atuais de criação, mais pautado na ciência e orientação de profissionais da saúde especializados e menos na criação recebida.

\subsection{Considerações finais}

O presente estudo identificou de forma inédita no nosso entender, a associação entre o cuidado recebido pelo paciente TBI durante sua infância e o cuidado destinado ao seu filho na vida adulta. A associação entre o calor emocional recebido do pai e da mãe na infância e o destinado ao filho na vida adulta foi significativo $(\mathrm{p}=0,013)$ e ocorreu da seguinte forma: aqueles pacientes TBI que lembram terem recebido alto calor emocional dos seus pais, todos reproduziram o alto calor emocional na vida adulta com seus filhos (100\%); já aqueles pacientes TBI que lembram terem recebido calor emocional médio ou baixo dos pais, $75 \%$ destinaram um calor emocional alto para seus filhos e apenas $25 \%$ reproduziram o calor emocional médio e baixo (potencialmente prejudicial a prole).A associação entre a superproteção recebida da mãe na infância e a superproteção destinada ao seu filho na vida adulta também foi significativa $(\mathrm{p}=0,003)$ e ocorreu da seguinte forma: aqueles pacientes TBI que lembram terem recebido superproteção média ou alta, $91 \%$ reproduziram superproteção média ou alta e apenas $9 \%$ transformaram em superproteção baixa (potencialmente prejudicial a prole). Já aqueles que lembram terem recebido superproteção baixa, 57\% destinaram superproteção média ou alta para seus filhos e 
43\% reproduziram a superproteção baixa recebida (potencialmente prejudicial a prole).

O resultado de baixa superproteção surpreendeu, pois foi diferente do que foi publicado até o momento na literatura e trouxe uma contribuição nova para o tema. Vale lembrar que a baixa superproteção também pode ser maléfica para a prole (baixo rendimento escolar, mais sintomas depressivos, baixa autoestima, problemas afetivos e comportamentais, alto índice de estresse, podem ter atraso no desenvolvimento, comportamento de externalização [agressão verbal ou física, destruição de objetos, mentira] e de internalização [retração social, mais sintomas depressivos, mais sintomas de ansiedade], bem como tendência para desempenho escolar moderado, pouca habilidade social e baixa autoestima) e foi identificada como uma característica dos pacientes com TBI que participaram deste estudo.

\subsection{Perspectivas futuras}

Para o futuro próximo temos a perceptiva de investigar modelos de intervenção psicoeducativos focados na relação pais e filhos, estilo parental e práticas educativas de criação que possam contemplar as necessidades levantadas neste estudo. É sabido que o autor David Miklowitz tem muitos estudos e livros publicados na área da psicoeducação para o TB focada na família de uma forma geral e não focada especificamente nesta relação pais e filhos e suas consequências (Miklowitz, 1997; $2005 ; 2007$; 2014).

\subsection{Limitações do estudo}

A primeira limitação foi a dificuldade em encontrar sujeitos saudáveis disponíveis com o mesmo nível socioeconômico (previsível pelas características e 
consequências do próprio TB) e a mesma faixa etária dos sujeitos TBI. Além disso, sujeitos saudáveis com um nível socioeconômico melhor são mais propensos a entenderem e a se disponibilizarem a participar da pesquisa.

A segunda limitação foram os dados terem sido extraídos de lembranças e percepções subjetivas do passado (limitação da própria escala EMBU). E a terceira limitação foi o $n$ reduzido de pais disponíveis, o que impossibilitou uma subanálise mais detalhada dos resultados com utilização de testes estatísticos. 
8 Conclusão

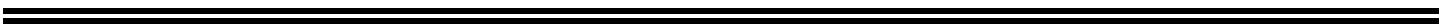




\section{CONCLUSÃO}

O presente estudo fornece evidência de forma inédita de que há associação entre a lembrança do calor emocional recebido do pai e/ou da mãe no calor emocional destinado ao filho; da lembrança da superproteção recebida da mãe na superproteção destinada ao filho; e uma tendência de a superproteção recebida do pai influenciar a superproteção destinada ao filho. Além disso, os pacientes bipolares lembram-se de terem recebido menos calor emocional de suas mães quando comparados ao controle saudável. Eles tenderam à lembrança de terem recebido mais rejeição da mãe e a dar menos calor emocional e menos superproteção aos seus filhos. Este estudo, também, identificou comportamentos parentais, que podem estar associados ao desenvolvimento de TB nos filhos.

O presente estudo também serviu para identificar famílias com padrão disfuncional parental. Sugerimos que estes resultados possam contribuir com a psicoeducação tanto para prevenção primária, focada nos filhos dos pacientes TBI (pessoas em risco), quanto nos serviços de atenção secundários e terciários com o foco no paciente e seus familiares. A psicoeducação poderia beneficiar aqueles pacientes que por algum motivo (gravidade da doença, falta de informação, consciência, treinamento de comunicação ou reforço social) destinam um cuidado potencialmente danoso para sua prole. 


\section{Referências}




\section{REFERÊNCIAS}

American Psychiatry Association [APA]. Manual Diagnóstico e Estatístico de Transtornos Mentais - DSM-IV. 4a ed. Porto Alegre: Artes Médicas; 1995.

American Psychiatry Association [APA]. Manual Diagnóstico e Estatístico de Transtornos Mentais - DSM-IV. 4a ed. Porto Alegre: Artes Médicas; 2003.

Alloy LB, Abramson LY, Gibb BE, Crossfield AG, Pieracci AM, Spasojevic J, et al. Developmental antecedents of cognitive vulnerability to depression: Review of findings from the Cognitive Vulnerability to Depression (CVD) Project. Journal of Cognitive Psychotherapy: An International Quarterly. 2004;18:115-33.

Alloy LB, Abramson LY, Smith JM, Gibb BE, Neeren AM. Role of parenting and maltreatment histories in unipolar and bipolar mood disorders: Mediation by cognitive vulnerability to depression. Clin Child Fam Psychol Rev. 2006;9:23-64.

Aluja A, Barrio V del, Garcia LF. Do parents and adolescents differ in their perceptions of rearing styles? Analysis of the EMBU versions for parents and adolescents. Scand J Psychol. 2006;47(2):103-8.

Alvarez MJ, Roura P, Osés A, Foguet Q, Solá J, Arrufat FX. Prevalence and clinical impact of childhood trauma in patients with severe mental disorder. J Nerv Ment Dis. 2011;199:156-61.

Barron E, Sharma A, Le Couteur J, Rushton S, Close A, Kelly T, Grunze H, Nicol Ferrier I, Le Couteur A. Family environment of bipolar families: a UK study. J Affect Disord. 2014;522(5):152-4.

Biasoli-Alves ZMM, Caldana RHL, Silva MHGFD. Práticas de educação da criança na família: a emergência do saber técnico científico. Revista Brasileira de Crescimento e Desenvolvimento Humano. 1997;7:49-62. 
Canavarro M. Relações afectivas e saúde mental. Coimbra: Quarteto Editora; 1999.

Calam R, Jones S, Sanders MR, Dempsey R, Sadhnani V. Parenting and the emotional and behavioural adjustment (adequação) of young children in families with a parent with bipolar disorder. Behav Cogn Psychother. 2012;40(4):425-37.

Campos RN, Costa LF, Bio DS, Souza MG de, Garcia CR, Demétrio FN, Moreno DH, Moreno RA. LICAVAL: Combination therapy in acute and maintenance treatment of bipolar disorder. Trials. 2010;23(11):72.

Castro J, Pablo J, Gómes J, Arrindell WA, Toro J. Assessing rearing behaviour from the perspective of the parents: a new form of the EMBU. Social Psychiatry and Psychiatric Epidemiology. 1997;32(4):230-5.

Cooke RG, Young LT, Mohri L, Blake P, Joffe RT. Family-of-origin characteristics in bipolar disorder: A controlled study. Can J Psychiatry, 1999;44:379-81.

Costa FT, Teixeira MAP, Gomes WB. Responsividade e Exigência: Duas escalas para avaliar estilos parentais. Psicologia: Reflexão e Crítica, 2000;13(3):465-73.

Crowe M, Wilson L, Inder M. Patients' reports of the factors influencing medication adherence in bipolar disorder - An integrative review of the literature. Int J Nurs Stud. 2011;48(7):894-903.

Del-Bem CM, Vilela JA, Crippa JA, Hallak JE, Labate CM, Zuardi AW. Confiabilidade da "Entrevista Clínica Estruturada para o DSM-IV - Versão Clínica traduzida para o português. Rev Bras Psiquiatr. 2001;23(3):156-9.

Etain B, Henry C, Bellibier F, Mathieu G, Leboyer M. Beyond genetics: Childhood affective trauma in bipolar disorder. Bipolar Disord. 2008;10:867-76. 
First MB, Gibbon M, Spitzer RL, Williams JBW, Benjamin LS. Structured Clinical Interview for DSM-IV Axis II Personality Disorders, (SCID-II). Washington, D.C.: American Psychiatric Press, Inc; 1997.

Fleitlich B, Cortázar PG, Goodman R. Questionário de capacidades e dificuldades (SDQ) / Strengths and difficulties questionnaire (SDQ). Infanto Rev Neuropsiquiatr Infanc Adolesc. 2000;8(1):44-50.

Fletcher K, Paterson A, McClure G. Emotion regulation strategies in bipolar II disorder and borderline personality disorder: Differences and relationships with perceived parental style. J Affect Disord. 2014;157:52-9.

Gaensbauer TJ, Harmon RJ, Cutrun L, McKnew DH. Social and affective development in infants with a manic-depressive parent. Am J Psychiatr. 1984;141:223-9.

Geller B, Bolhofner K, Craney JL, Williams M, Delbello MP, Gundersen K. Psychosocial functioning in prepubertal and early adolescent bipolar disorder phenotype. J Am Acad Child Adolesc Psychiatry, 2000;39:1543-8.

Goldstein BI, Shamseddeen W, Axelson DA, Kalas C, Monk K, Brent DA, Kupfer DJ, Birmaher B. Clinical, demographic and familial correlates of bipolar spectrum disorders among offspring of parents with bipolar disorder. J Am Acad Child Adolesc Psychiatry. 2010;49:388-96.

Gomes FG, Passos IC, Krolow AC, Reckziegel R, Vasconcelos-Moreno MP, Spanemberg L, Belmonte-de-Abreu P, Kapczinski F, Kauer-Sant'Anna M. Differences in parental bonding between schizophrenia and bipolar disorder: Evidence of prodromal symptoms? Schizophr Res. 2015;165(2-3):134-7.

Hamilton M. Rating scale for depression. J Neurol Neurosurg Psychiatry. 1960;23:56-62. 
Jones S, Calam R, Sanders M, Diggle PJ, Dempsey R, Sadhnani V. A pilot web based positive parenting intervention to help bipolar parents to improve perceived parenting skills and child outcomes. Behav Cogn Psychother. 2013;42(3):283-96.

Klahr AM, Burt SA. Elucidating the etiology of individual differences in parenting: A meta-analysis of behavioral genetic research. Psychol Bull. 2014;140(2):544-86.

KNIME. Chair for Bioinformatics and Information Mining at the University of Konstanz: Germany; 2007. Disponível em: http://www.knime.org.

Kobarg APR, Vieira V, Vieira ML. Validação da Escala de Lembranças sobre Práticas Parentais (EMBU). Avaliação Psicológica. 2010;9(1):77-85.

Koenig JE, Sachs-Ericsson N, Miklowitz DJ. How do psychiatric patients experience interactions with their relatives? Journal of Family Psychology. 1997;11:251-6.

Lamborn SD, Mounts NS, Steinberg L, Dornbusch SM. Patterns of competence and adjustment among adolescents from authoritative, authoritarian, indulgent, and neglectful families. Child Development. 1991;62:1049-65.

Lau P, Hawes DJ, Hunt C, Frankland A, Roberts G, Wright A, Costa DSJ, Mitchell PB. Family environment and psychopathology in offspring of parents with bipolar disorder. J Affect Disord. 2018;226(15):12-20.

Miklowitz DJ, Goldstein MJ, Nuechterlein KH, Snyder KS, Mintz J. Family factors and the course of bipolar affective disorder. Arch Gen Psychiatry. 1988;45(3):22531.

Miklowitz DJ, Goldstein MJ, Nuechterlein KH. Verbal interactions in the families of schizophrenic and bipolar affective patients. J Abnorm Psychol. 1995;104(2):268-76. 
Miklowitz DJ, Johnson SL. Social and familial factors in the course of bipolar disorder: basic processes and relevant interventions. Clinical Psychologist. 2009;16:281-96.

Miklowitz DJ. Bipolar disorder: a family-focused treatment approach. $2^{\mathrm{a}}$ ed. New York/London: The Guilford Press; 1997.

Miklowitz DJ. The bipolar disorder survival guide. $2^{\mathrm{a}}$ ed. New York/London: The Guilford Press; 2005.

Miklowitz DJ. The bipolar teen: what you can do to help your child and your family. New York/London: The Guilford Press; 2007.

Miklowitz DJ. Clinician's guide to bipolar disorder. New York/London: The Guilford Press; 2014.

Missio G, Moreno DH, Fernandes F, Bio DS, Soeiro-de-Souza MG, Rodrigues dos Santos D Jr., David DP, Costa LF, Demétrio FN, Moreno RA. The ARIQUELI study: Potentiation of quetiapine in bipolar I nonresponders with lithium versus aripiprazole. Trials. 2013;14(1):190.

Moreno DH, Bio DS, Petresco S, Petresco D, Gutt EK, Soeiro-de-Souza MG, Moreno RA. Burden of maternal bipolar disorder on at risk offspring: A controlled study on family planning and maternal care. J Affect Disord. 2012;143:172-8.

Moreno RA, Moreno DH. Escalas para avaliação para depressão de Hamilton (HAM-D) e Montgomerry-Asberg (MADRS). In: Clarisse G, Laura HSG, Andrade WZ. (Eds.). Escalas de avaliação clínica em psiquiatria e psicofarmacologia. São Paulo: Lemos Editorial; 2000. p. 71-88.

Mowbray CT, Bybee D, Oyserman D, MacFarlane P, Bowersox N. Psychosocial outcomes for adult children of parents with severe mental illnesses: demographic and clinical history predictors. Health Soc Work. 2006;31:99-108. 
Muralidharan A, Kotwicki RJ, Cowperthwait C, Craighead WE. Parental relationships and behavioral approach system dysregulation in young adults with bipolar disorder. J ClinPsychol. 2015;71(4):387-401.

Ostiguy CS, Ellenbogen MA, Hodgins S. Personality of parents with bipolar disorder and interpersonal functioning among their offspring: a prospective 10-year study. Dev Psychopathol. 2012;24(2):573-87.

Parker G. Parental "affectionless control” as an antecedent to adult depression. Arch Gen Psychiatry. 1983;34:138-47.

Pellegrinelli KB de, Costa LFO de, Silva KID, Dias VV, Roso MC, Bandeira M, Colom F, Moreno RA. Efficacy of Psychoeducation on simptomatic and functional recovery in bipolar disorder. Acta Psychiatr Scand. 2013;127(2):153-8.

Perris C, Eisemann M, Ericsson U, von Knorring L, Perris H. Parental rearing behaviour and personality characteristics of depressed patients. Arch Psychiatr Nervenkr. 1983;233(2):77-88.

Perris C, Jacobson L, Linndström H, Knorring Lvon, Perris H. Development of a new inventory for assessing memories of parental rearing behavior. Acta Psychiatr Scand. 1980;61:265-74.

Perris C, Maj M, Perris H, Eisemann M. Perceived parental rearing behaviour in unipolar and bipolar depressed patients. A verification study in an Italian sample. Acta Psychiatr Scand. 1985;72(2):172-5.

R: A Language and Environment for Statistical Cumputing R Development Core Team. Vienna, Austria; 2007. Disponível em: http://www.R-project.org:

Reichart CG, van der Ende J, Hillegers MH, Wals M, Bongers IL, Nolen WA, Ormel J, Verhulst FC. Perceived parental rearing of bipolar offspring. Acta Psychiatr Scand. 2007;115(1):21-8. 
Rosenfarb IS, Becker J, Khan A. Perceptions of parental and peer attachments by women with mood disorders. J Abnorm Psychol. 1994;103:637-44.

Rosenfarb IS, Miklowitz DJ, Goldstein MJ, Harmon L, Nuechterlein KH, Rea MM. Family transactions and relapse in bipolar disorder. Fam Process. 2001;40:5-14.

Schudlich TDR, Youngstron EA, Calabrese JR, Findling RL. The role of family functioning in bipolar disorder in families. J Abnorm Child Psychol. 2008;36:849-63.

SimoneauTL, Miklowitz DJ, Saleem R. Expressed emotion and interactional patterns in the families of bipolar patients. J Abnorm Psychol. 1998;107(3),497-507.

Soares OT, Moreno DH, Moura EC de, Angst J, Moreno RA. Reliability and validity of a Brazilian version of the Hypomania Checklist (HCL-32) compared to the Mood Disorder Questionnaire (MDQ). Revista Brasileira de Psiquiatria. 2010;32(4):41623.

Vilela JAA. Estudo da confiabilidade e validade de uma versão modificada da Young Mania Rating Scale. Dissertação de Mestrado. Ribeirão Preto: Faculdade de Medicina de Ribeirão Preto, Universidade de São Paulo; 2000.

Weber LND, Prado PM, Viezzer AP, Brandengurg OJ. Identificação de estilos parentais: O ponto de vista dos pais e dos filhos. Psicologia: Reflexão e Crítica. 2004;17(3):323-31.

Widom CS, Czaja SJ, Du Mont KA. Intergenerational transmission of child abuse and neglect: Real or detection bias? Science. 2015;347(6229):1480-5.

Young RC, Biggs JT, Ziegler VE, Meyer DA. A rating scale for mania: reliability, validity and sensitivity. Br J Psychiatry. 1978;133:429-35.

Zar JH. Biostatistical analysis. 5th ed. Upper Saddle River, NJ: Prentice-Hall/Pearson; 2010. 
Zhang TY, Hellstrom IC, Bagot RC, Wen X, Diorio J, Meaney MJ. Maternal care and DNA methylation of a glutamic acid decarbosylase one promoter in rat hippocampus. J Neurosci. 2010;30:13130-7. 
10 Anexos

ב 


\section{ANEXOS}

ANEXO A - Termo de Consentimento Livre e Esclarecido

HOSPITAL DAS CLÍNICAS DA FACULDADE DE MEDICINA DA UNIVERSIDADE DE SÃO PAULO- HCFMUSP

TERMO DE CONSENTIMENTO LIVRE E ESCLARECIDO

DADOS DE IDENTIFICAÇÃO DO SUJEITO DA PESQUISA OU RESPONSÁVEL LEGAL

1. NOME:

DOCUMENTO DE IDENTIDADE $\mathrm{N}^{\circ}$ SEXO: $\mathrm{M} \square \mathrm{F} \square$

DATA NASCIMENTO /..........................

$\mathrm{N}^{\mathrm{o}}$ APTO

ENDEREÇO CIDADE

BAIRRO

CEP. .TELEFONE: DDD (

2. RESPONSÁVEL LEGAL

NATUREZA (grau de parentesco, tutor, curador etc.)

DOCUMENTO DE IDENTIDADE: SEXO: $\mathrm{M} \square \mathrm{F} \square$ DATA NASCIMENTO: .$/$ .............

ENDEREÇO: $\mathrm{N}^{\mathrm{o}}$ APTO:

BAIRRO: CIDADE:

CEP: TELEFONE: DDD

\section{DADOS SOBRE A PESQUISA}

TÍTULO DO PROTOCOLO DE PESQUISA:

"A Influência da Criação Recebida da Infância no Cuidado Parental de Pais Bipolares" PESQUISADOR: Dr. Ricardo Alberto Moreno. CARGO/FUNÇÃO: Professor, Coordenador de Psiquiatria. INSCRIÇÃO CONSELHO REGIONAL: No 48.1554. UNIDADE DO HCFMUSP: IPq AVALIAÇÃO DO RISCO DA PESQUISA:

$\begin{array}{ll}\text { RISCO MÍNIMO: X } & \text { RISCO MÉDIO: } \square \\ \text { RISCO BAIXO: } \quad \square & \text { RISCO MAIOR: } \square\end{array}$

DURAÇÃO DA PESQUISA: 33 MESES 


\section{Continuação ANEXO A}

\section{HOSPITAL DAS CLÍNICAS DA FACULDADE DE MEDICINA DA UNIVERSIDADE DE SÃO PAULO- HCFMUSP}

Justificativa e os objetivos da pesquisa -Predisposição biológica e hereditariedade no Transtorno Bipolar (TB) são universalmente aceitos. Porém, evidências experimentais apontam que o ambiente familiar e a interação pais e filhos influenciam nas funções fisiológicas, no comportamento dos filhos e na expressão do gene, que permanece estável nos estágios de vida e fornece base para plasticidade fenotípica. Estudos com TB mostraram que a diminuição do nível do cuidado parental pode influenciar diretamente o desenvolvimento psicológico, que, por sua vez, pode influenciar no desenvolvimento de psicopatologias dessas crianças. E, assim, forma-se um ciclo vicioso. Diante disso, nos últimos anos, vêm crescendo estudos científicos com enfoque na caracterização do cuidado parental disfuncional como fator de risco e na incorporação de uma orientação de cuidados parentais para os guidelines de psicoeducação. O presente estudo tem com o objetivo investigar se existe relação entre a forma como os pais foram criados e a forma como eles criam seus filhos, com enfoque em variáveis como rejeição, superproteção e suporte emocional, além de caracterizar o cuidado bipolar e não bipolar.

Procedimentos que serão utilizados e propósitos, incluindo a identificação dos procedimentos que são experimentais - Este estudo consiste em entrevista para confirmação diagnóstica e sintomatológica e preenchimento de escalas autoaplicáveis em uma única ocasião. A seleção dos pacientes e a avaliação clínica são coordenadas pelo Dr. Ricardo Alberto Moreno e a avaliação do comportamento parental pela psicóloga Karina de Barros Pellegrinelli. Se você decidir participar, será preenchida uma ficha de histórico e avaliação clínica e serão entregues as escalas autoaplicáveis para preenchimento. Os procedimentos irão durar o equivalente a uma hora. É preciso chegar 20 minutos antes do agendamento.

Desconfortos e riscos esperados - Os desconfortos e riscos esperados são mínimos e decorrentes apenas do cansaço decorrente das respostas às escalas.

Benefícios que poderão ser obtidos - "Não há benefício direto para o participante". Trata-se de um estudo experimental testando a existência da associação entre a forma como o adulto foi cuidado e a forma como ele cuida dos seus filhos, além de caracterizar o cuidado bipolar e não bipolar.

Procedimentos alternativos que possam ser vantajosos para o indivíduo-É possível, mas não garantido, que os pacientes com Transtorno Bipolar possam beneficiar-se dos resultados deste estudo no futuro, bem como seus familiares. Por meio dessa caracterização da associação entre a forma como fui cuidado e a forma que cuido, e da caracterização do cuidado parental bipolar e não bipolar, pretende-se contribuir para a melhor compreensão do Transtorno Bipolar, bem como para o desenvolvimento de novas estratégias de diagnóstico e tratamento.

Garantia de acesso em qualquer etapa do estudo -Você terá acesso aos profissionais responsáveis pela pesquisa para esclarecimento de eventuais dúvidas. O principal investigador é o DR. RICARDO ALBERTO MORENO, que pode ser encontrado no endereço: Programa Transtornos Afetivos do Instituto de Psiquiatria, Hospital das Clínicas da Faculdade de Medicina da Universidade de São Paulo - Gruda HC FMUSP, $\underline{3^{\circ} \text { andar do Prédio de }}$ Psiquiatria, sala 3, tel.: 3069-6648 ou no celular 8511-2277. E-mail: gruda@ hcnet.usp.br. Se você tiver alguma consideração ou dúvida sobre a Ética da Pesquisa, entre em contato com o Comitê de Ética em Pesquisa (CEP) - Rua Ovídio Pires de Campos, 225 - $5^{\circ}$ andar - tel.: 3069-6442 ramais 16, 17, 18 ou 20, FAX: 3069-6442 ramal 26 - E-mail: cappesq@hcnet.usp.br 


\section{Continuação ANEXO A \\ HOSPITAL DAS CLÍNICAS DA FACULDADE DE MEDICINA DA UNIVERSIDADE DE SÃO PAULO- HCFMUSP}

É garantida a liberdade da retirada de consentimento a qualquer momento e deixar de participar do estudo sem qualquer prejuízo à continuidade de seu tratamento na Instituição.

Direito de confidencialidade: as informações obtidas serão analisadas em conjunto com outros pacientes, não sendo divulgada a identificação de nenhum paciente. Direito de ser mantido atualizado sobre os resultados parciais das pesquisas, quando em estudos abertos, ou de resultados que sejam do conhecimento dos pesquisadores.

Despesas e compensações: não há despesas pessoais para o participante em qualquer fase do estudo. Também, não há compensação financeira relacionada à sua participação.

Compromisso do pesquisador de utilizar os dados e o material coletado somente para esta pesquisa: acredito ter sido suficientemente informado a respeito das informações que li ou que foram lidas para mim, descrevendo o estudo "A influência do comportamento dos pais no desenvolvimento de Transtorno Bipolar nos filhos".

Eu discuti com o médico avaliador clínico do estudo sobre a minha decisão em participar deste estudo. Ficaram claros para mim quais são os propósitos do estudo, os procedimentos a serem realizados, seus desconfortos e riscos, as garantias de confidencialidade e de esclarecimentos permanentes. Ficou claro também que minha participação é isenta de despesas. Concordo voluntariamente em participar deste estudo e conceder o uso dos meus dados clínicos, sabendo que poderei retirar o meu consentimento a qualquer momento, antes ou durante o mesmo, sem penalidades ou prejuízo ou perda de qualquer benefício que eu possa ter adquirido, ou no meu atendimento neste Serviço.

Declaro que obtive de forma apropriada e voluntária o Consentimento Livre e Esclarecido deste paciente ou representante legal para a participação neste estudo.

Data _ _ _ I 


\title{
ANEXO B - Aprovação do Comitê de Ética
}

\author{
Hospital das Clinicas da FMU̦s
}

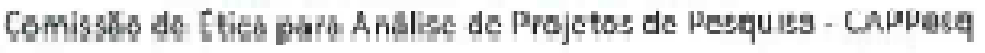

\section{PROJETO DE PESQUISA}

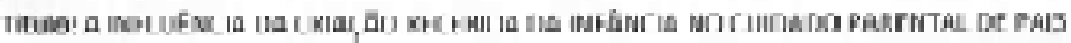
IIPQLARES.

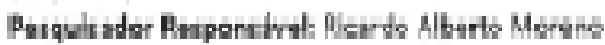

iprurgnirucu

Pinalidade Acadênnha tousunadu

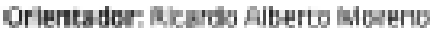

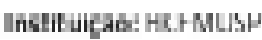

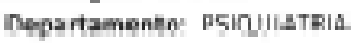

\section{PARFCFR CONSUIRSTANCIADO DO CEP}

Ine gistro on -line: 12054

Nümero do Parecer: 1215099

Data da Relatoria: 02/09/2015

Apresentachlo do Prajeto: Estudo de doutorado que pretende imvestigar a hipcte se de que o ambiente familiar, e a interaçăo pais e fihos podem influenciar as funçises fsiologicas, o comportamento dos fillhos e a eupre ssäo do gene do Transtomo Bipolar. SerJo avala dos 73 pacientes com Transtorno: Bipolar I (TTB) com idade entre $\mathbf{1 8}$ e $\mathbf{4 0}$ anos e com fillwos. Serdo vilicedos dois grupos como controle cam iflades entret8 of 40 anos: 73 pacientes com dagnostico de outra transtorno mental grave e, 23 voluntários sadios do ponta de vista mental s firiog:

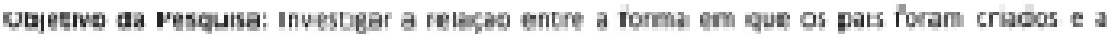
forma que eles criam seus fil hos com enfoque em variaveis como: rejeiça, super proteçãd, e ituporte emocional.

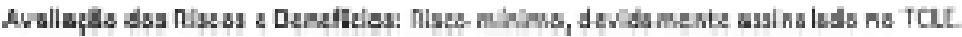

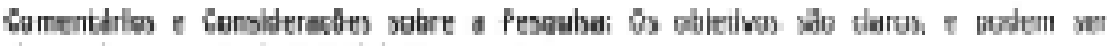
alcancados dor meno da metoodiaga droporta.

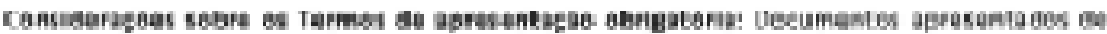
Horms sdoqusds.

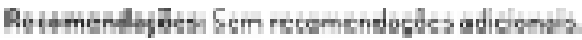

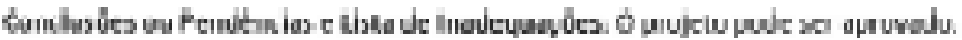

3ituacao do marecer: Anrovado.

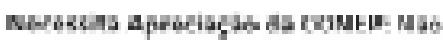

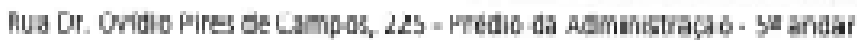

LEP US403-010- S3o Paulo - 5P.

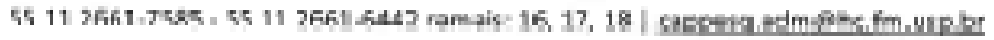




\section{Continuação ANEXO B}

\section{Hospital das Clínicas da FMUSP}

Comissa de Etica para Análise de Projetos de Pesquisa - CAPPesq

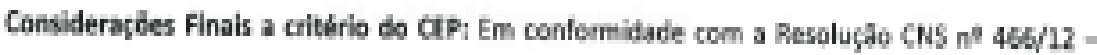

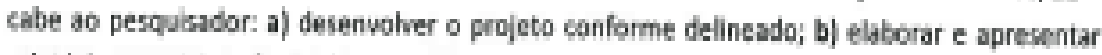

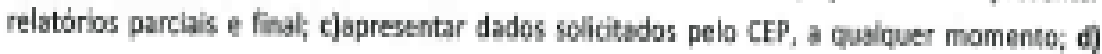

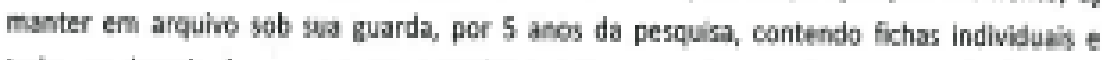

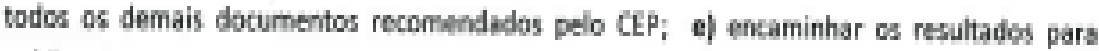

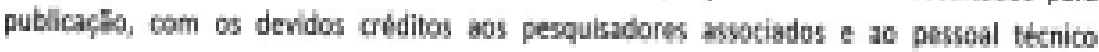

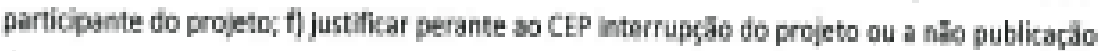
dos resultados.

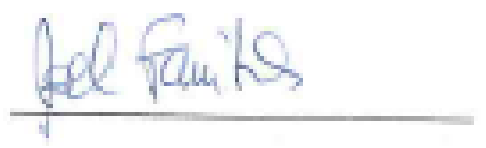

Prot, Dr, Joel Fointuch

Vice - Coordenador Comisuóo de tilco para Andilse de Projetos de Pesquina - CAPPesq 


\section{ANEXO C - Caderno dos Instrumentos de Avaliação Utilizados no Estudo}

> ENTREVISTA ABTB (DADOS SOCIODEMOGRÁFICOS, CARACTERÍSTICAS CLÍNICAS DA DOENÇA-QUANDO HOUVER).

NOME

GENERO RAÇA

IDADE ANOS DE ESTUDO

ESTADO CIVIL $\mathrm{N}^{\circ}$ DE FILHOS

TELEFONES

CONTATO DO PAI OU DA MÃE:

RENDA FAMILIAR: 1 a $5 \mathrm{SM}(\quad$ ), 6 a $10($ ), 11 a 15( ), 16 a 20( ), mais de 20( ). TIPO DO PRIMEIRO EPISÓDIO: MANIA ( ) DEPRESSÃO ( ) $\mathrm{N}^{\circ}$ DE CRISES DE MANIA $\mathrm{N}^{\circ}$ CRISES DE DEPRESSÃO

IDADE DX (RECEBEU O DIAGNÓSTICO) IDADE $1^{\circ}$ EPISÓDIO

TEMPO DE DOENÇA (ANOS DO PRIMEIRO EPISÓDIO ATÉ HOJE)

SINTOMAS PSICÓTICOS ECT SUICÍDIO

SCID (ANEXAR FOLHAS DE RESPOSTA)

$>$ HAM-17 (QUANDO BIPOLARES) (ANEXAR FOLHAS DE RESPOSTA)

$>$ YOUNG (QUANDO BIPOLARES) (ANEXAR FOLHAS DE RESPOSTA)

$>$ EMBU-P (AUTOAPLICÁVEL)

$>$ EMBU-S (AUTOAPLICÁVEL)

$>$ SDQ (AUTOAPLICÁVEL)

$>$ RESPONSIVIDADE E EXIGÊNCIA (RESPONDIDAS PELO PAI ou MÃE DO SUJEITO/AVÓS)

$>$ MDQ (RESPONDIDO PELO PAI ou MÃE DO SUJEITO/AVÓS) 


\section{SIGH-D-17 e YMRS}

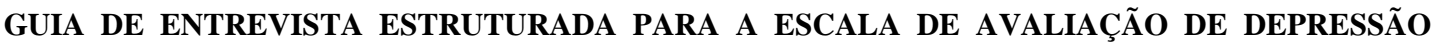 HAMILTON}

Structured Interview Guide for the Hamilton Depression Rating Scale - SIGH-D

Introdução: Gostaria de lhe fazer algumas perguntas sobre a última semana. Como você tem se sentido nesta última semana? Você tem trabalhado? SE NÃO: Por que não?

1. Como tem estado seu humor na última semana? Você tem se sentido para baixo ou deprimido? Triste? Sem esperança? Na última semana, com que frequência você se sentiu (a palavra usada pelo paciente)? Todos os dias? O dia inteiro? Você tem chorado?

HUMOR DEPRIMIDO (tristeza, desesperança, desamparo, inutilidade)

0 - ausente

1- sentimentos relatados apenas ao ser inquirido

2- sentimentos relatados espontaneamente, com palavras

3- comunica os sentimentos não com palavras, isto é, com a expressão facial, a postura, a voz e a tendência ao choro

4- sentimentos deduzidos da comunicação verbal e não verbal do paciente

Se pontuou de 1-4, pergunte: há quanto tempo você tem se sentido desta maneira?

2. Você tem se sentido especialmente autocrítico nesta última semana, sentindo que fez coisas erradas ou decepcionou outras pessoas? SE SIM: quais foram esses pensamentos?

Você tem se sentido culpado em relação a coisas que fez ou não fez? Você tem pensado que, de alguma forma, você é responsável pela sua depressão? Você sente que está sendo punido ficando doente? SENTIMENTOS DE CULPA:

0 - ausente

1- autorrecriminação; sente que decepcionou os outros

2- ideias de culpa ou ruminação sobre erros passados ou más ações

3- a doença atual é um castigo. Delírio de culpa

4- ouve vozes de acusação ou denúncia e/ou tem alucinações visuais ameaçadoras

3. Nesta última semana, você teve pensamentos de que não vale a pena viver ou que você estaria melhor morto, ou pensamentos de se machucar ou até de se matar? SE SIM: o que você tem pensado sobre isso? Você já se machucou?

SUICÍDIO:

0 - ausente

1- sente que a vida não vale a pena

2- deseja estar morto ou pensa na possibilidade de sua própria morte 
3- ideias ou gestos suicidas

4- tentativa de suicídio (qualquer tentativa séria marcar 4)

4. Como tem sido seu sono na última semana? Você teve alguma dificuldade em iniciar o sono? Após se deitar, quanto tempo leva para conseguir dormir? Em quantas noites nesta última semana você teve problemas para iniciar o sono?

\section{INSÔNIA INICIAL:}

0- sem dificuldade para conciliar o sono

1- queixa-se de dificuldade ocasional para conciliar o sono, isto é, mais de meia hora

2- queixa-se de dificuldade para conciliar o sono todas as noites

5. Durante esta última semana, você tem acordado no meio da noite? SE SIM: você sai da cama? O que você faz? (somente vai ao banheiro?) Quando você volta para a cama, você volta a dormir logo? Você sente que seu sono é agitado ou perturbado em algumas noites?

\section{INSÔNIA INTERMEDIÁRIA}

0- sem dificuldade

1- o paciente se queixa de inquietude e perturbação durante a noite

2- acorda à noite - qualquer saída da cama marcar 2 (exceto para urinar)

6. A que horas você tem acordado pela manhã na última semana? Se cedo: acorda com despertador ou sozinho? A que horas você normalmente acorda (ou seja, antes de ficar deprimido)?

INSÔNIA TARDIA:

0- sem dificuldade

1- acorda de madrugada, mas volta a dormir

2- incapaz de voltar a conciliar o sono se deixar a cama

7. Como você tem passado seu tempo na última semana (quando não está no trabalho)? Você se sente interessado em fazer (estas atividades) ou você tem que se esforçar? Você parou de fazer atividades que costumava fazer? (SE SIM: Porquê?

Há alguma coisa que você aguarda ansiosamente? No seguimento:

Seu interesse voltou ao normal? TRABALHO E ATIVIDADES:

0- sem dificuldades

1- pensamentos e sentimentos de incapacidade, fadiga ou fraqueza, relacionados a atividades: trabalho ou passatempos

2- perda de interesse por atividades (passatempos ou trabalho), quer diretamente relatada pelo paciente, quer indiretamente por desatenção, indecisão ou vacilação (sente que precisa se esforçar para o trabalho ou atividade)

3- diminuição do tempo gasto em atividades ou queda de produtividade. No hospital, marcar 3 se o paciente passar ao menos 3 horas ao dia em atividades externas (trabalho hospitalar ou passatempos) 
4- parou de trabalhar devido à doença atual no hospital, marcar 4 se o paciente não se ocupar de outras atividades além de pequenas tarefas do leito, ou for incapaz de realizá-las sem ajuda

8. Avaliação baseada na observação durante a entrevista:

RETARDO (Identificação do pensamento e fala; dificuldade de concentração; diminuição da atividade motora):

0 - pensamento e fala normais

1- leve retardo à entrevista

2- retardo óbvio à entrevista

3- entrevista difícil

4- estupor completo

9. Avaliação baseada na observação durante a entrevista AGITAÇÃO:

0- nenhuma

1- inquietude

2- brinca com as mãos, com os cabelos etc.

3- mexe-se, não consegue sentar quieto

4- torce as mãos, rói as unhas, puxa os cabelos, morde os lábios

10. Você tem se sentido especialmente tenso ou irritado nesta última semana? Você tem estado preocupado com coisas pouco importantes com as quais normalmente não se preocuparia? SE SIM:

Como o que, por exemplo?

\section{ANSIEDADE PSÍQUICA:}

0- sem dificuldade

1- tensão e irritabilidade subjetivas

2- preocupação com trivialidades

3- atitude apreensiva aparente no rosto ou na fala

4- medos expressos sem serem inquiridos

11.Na última semana, você sofreu de alguns dos seguintes sintomas físicos? Leia a lista, parando após cada sintoma para resposta. O quanto estes sintomas o incomodaram na última semana? Quão intensos eles foram? Quanto tempo ou com que frequência 'você os teve? Nota: não considerar se claramente relacionados à medicação (por exemplo, boca seca e imipramina)

\section{ANSIEDADE SOMÁTICA}

Concomitantes fisiológicos da ansiedade, tais como:

Gastrintestinais: boca seca, flatulência, indigestão, diarreia, cólicas, eructações 
Cardiovasculares: palpitações, cefaleias

Respiratórios: hiperventilação, suspiros

Frequência urinária

Sudorese

0 - ausente

1- leve

2- moderada

3- grave

4- incapacitante

12. Como tem estado seu apetite nesta última semana? (Como se compara ao seu apetite habitual?) Você tem tido que se esforçar a comer? As outras pessoas têm que insistir para você comer?

SINTOMAS SOMÁTICOS GASTRINTESTINAIS.

0 - nenhum

1- perda de apetite, mas alimenta-se voluntariamente. Sensações de peso no abdome

2- dificuldade de comer se não insistirem. Solicita ou exige laxativos ou medicações para os intestinos ou para sintomas digestivos

13. Como tem estado sua "energia" nesta última semana?

Você se sente cansado o tempo todo? Nesta última semana, você teve dor nas costas, dor de cabeça ou dor muscular? Nesta última semana, você tem sentido um peso nos membros, costas ou cabeça?

\section{SINTOMAS SOMÁTICOS EM GERAL}

0 - nenhum

1- peso nos membros, nas costas ou na cabeça. Dores nas costas, cefaleia, mialgias. Perda de energia e cansaço

2- qualquer sintoma bem caracterizado e nítido, marcar 2

14. Como tem estado seu interesse em sexo nesta semana? (não estou the perguntando sobre performance, mas sobre seu interesse por sexo - o quanto você tem pensado nisso? Houve alguma mudança em seu interesse por sexo (em relação à época em que você não estava deprimido)? Isso é algo em que você tem pensado muito? Se não, isso é pouco habitual para você?

\section{SINTOMAS GENITAIS}

Sintomas como perda de libido, distúrbios menstruais

0 - ausentes

1- leves

2- intensos 
15. Na última semana, o quanto seus pensamentos têm focalizado na sua saúde física ou no funcionamento de seu corpo (comparado ao seu pensamento habitual?) Você se queixa muito de sintomas físicos? Você tem se deparado com situações em que você pede ajuda para fazer coisas que poderia fazer sozinho? Se sim: como o que, por exemplo? Com que frequência isto tem ocorrido?

\section{HIPOCONDRIA}

0 - ausente

1- auto-observação aumentada (com relação ao corpo)

2- preocupação com a saúde

3- queixas frequentes, pedidos de ajuda etc.

4- ideias delirantes hipocondríacas

16. Você perdeu algum peso desde que essa (DEPRESSÃO) começou? Se sim: quanto? Se incerto: você acha que suas roupas estão mais folgadas? No seguimento: você voltou a ganhar algum peso?

\section{PERDA DE PESO}

0- sem perda de peso ou com perda de peso NÃO causada pela doença atual

1- perda de peso provavelmente causada pela doença atual. Perda de menos de meio quilo.

2- perda de peso definitivamente causada pela doença atual. Perda de meio quilo ou mais

17. Avaliação baseada na observação CRÍTICA

0- reconhece que está deprimido e doente

1- reconhece a doença mas atribui a causa à má alimentação, ao clima, ao excesso de trabalho, a vírus, à necessidade de repouso etc.

2- nega estar doente 


\section{YMRS - YOUNG MANIA RATING SCALE - Entrevista}

Tradução, adaptação, modificação e elaboração de catálogo de definições de sintomas com roteiro de entrevista semiestruturada por Vilela (2000)

Guia para avaliação dos itens - a proposta de cada item é avaliar a gravidade da anormalidade no paciente. Quando vários sintomas são fornecidos para um grau específico de gravidade, a presença de apenas um dos sintomas é suficiente para a pontuação. Os sintomas são fornecidos como guias. Pode-se ignorá-los se isso for necessário para indicar gravidade, embora isso deva ser a exceção, e não a regra. Pontuação entre os escores fornecidos (ponto inteiro ou meio ponto) é possível e incentivada após aquisição de experiência com a escala, isso é particularmente útil quando a gravidade de um item específico em um paciente não segue a sequência indicada pelos sintomas

1. Humor expansivo/ elevado

Como tem estado seu humor nesta última semana?

Você tem se sentido mais alegre, otimista ou autoconfiante? Há razão para se sentir assim? É mais do que seu habitual?

Você tem estado tão alegre que as outras pessoas acham que você não está no seu normal?

Houve algum momento em que você riu de coisas que normalmente não te deixariam alegre? Sentiu-se mais brincalhão/brincalhona? Fez brincadeiras que as pessoas acharam de mau gosto?

0- Ausente

1- Leve ou possivelmente elevado quando questionado

2- Elevação subjetiva bem definida; otimista, autoconfiante; alegre; apropriado ao conteúdo

3- Elevado, inapropriado ao contexto: jocoso

4- Eufórico: riso inapropriado; cantando

2. Aumento da energia e atividade motora

Como tem estado sua energia nesta última semana? Você teve momentos em que se sentiu com energia em excesso? Sentiuse inquieto(a) ou agitado(a)? Você tem estado mais ativo(a) que o usual? Sente vontade de fazer várias coisas ao mesmo tempo?

0 - Ausente

1- Aumento subjetivo

2- Animado: aumento de gesticulação

3- Energia excessiva; às vezes, hiperativo: inquieto/impaciente (pode ser acalmado)

4- Excitação motora; hiperatividade contínua (não pode ser acalmado)

\section{Interesse sexual}

Você tem estado muito paquerador(a), feito piadas sobre sexo? Você tem sentido mais interesse ou desejo sexual do que o habitual? Tem estado mais ativo(a) sexualmente do que o habitual? Tem tido algum tipo de comportamento sexual que não era habitual antes? Alguém reclamou do seu comportamento sexual na última semana?

O-Normal; sem aumento

1- Leve ou possivelmente aumentado

2- Aumento subjetivo bem definido quando questionado

3- Conteúdo sexual espontâneo; discorre sobre assuntos sexuais; hipersexualizado segundo autorrelato

4- Atos sexuais evidentes (direcionados a pacientes, equipe ou entrevistador) 


\section{Sono}

Quantas horas por noite você tem dormido? Quantas horas a menos tem dormido que o habitual? Mesmo assim você se sente descansado(a) e bem-disposto(a)?

0- Não relata diminuição do sono

1- Dorme menos do que o habitual (até uma hora a menos)

2- Dorme menos do que o habitual (por uma hora ou mais)

3- Relata diminuição da necessidade de sono

4- Nega necessidade de sono

5. Irritabilidade

Aconteceu algo que tenha feito você se sentir irritado(a) nesta última semana? Se sim, isto te irritou mais que o usual? Como você demonstrou sua raiva? Discutiu, agrediu alguém ou quebrou objetos? Se não, mesmo sem ter acontecido algo, você tem se sentido mais irritado?

0 - Ausente

2- Aumento subjetivo

4- Irritável em alguns momentos durante a entrevista; episódios recentes de raiva ou importunação na enfermaria

6- Frequentemente irritável durante a entrevista

8- Hostil, não cooperativo; entrevista impossível

6. Discurso (velocidade e quantidade)

Na última semana, você tem estado mais falante que seu normal? As pessoas comentam que você está tagarela? Elas demonstram dificuldade em acompanhar o que você fala ou se queixam de que você não as deixa falar? Uma vez que você começa a falar, tem tido dificuldade em parar?

O- Sem aumento

2- Sente-se mais falante

4- Aumento da velocidade ou quantidade em alguns momentos, prolixo em alguns momentos

6- Aumento consistente da velocidade e quantidade; difícil interromper

8- Pressão de discurso, ininterruptível, discurso contínuo.

7. Distúrbio de linguagem-pensamento

Na última semana, você notou que seus pensamentos estão mais rápidos do que o habitual? Seu raciocínio tem estado especialmente claro ou aguçado? Acontece de você se distrair facilmente, passando rapidamente de um pensamento a outro e perdendo o fio da meada?

0 - Ausente

1- Circunstancial; leve distraibilidade; pensamentos rápidos

2- Distraído; perde intenção do pensamento; muda de assunto frequentemente; pensamentos acelerados

3- Fuga de ideias; tangencialidade; difícil para acompanhar; rimando, ecolalia

4- Incoerente; comunicação impossível

8. Conteúdo

Nesta última semana, você tem tido novas ideias ou projetos para a sua vida?(Quais?)Você tem se sentido com algum talento ou habilidade especial? Você teve alguma experiência religiosa incomum? Você tem tido ideias ou pensamentos que não fazem sentido para as outras pessoas? Você tem percebido coisas ou coincidências que as pessoas não percebem? Tem tido sensações de que estão falando de você ou tentando te prejudicar?

O- Normal

2.-Planos questionáveis, novos interesses

4- Projetos especiais, hiper-religioso 
6- Ideias grandiosas ou paranoides; ideias de referência

8- Delírios; alucinações

9. Comportamento disrruptivo-agressivo

Como você tem se relacionado com as pessoas nesta última semana? Às vezes, você fala alto, reclama ou se torna sarcástico(a) com as pessoas? Você brigou com alguém ou quebrou coisas na última semana?

0 - Ausente, cooperativo

2- Sarcástico; fala alto às vezes, vigilante

4- Querelante; faz ameaças na enfermaria

6- Ameaça entrevistador; grita; entrevista difícil.

8- Agressivo; destrutivo; entrevista impossível

\section{Aparência}

O quanto cuidou de sua aparência nesta última semana? Alguém achou você malvestido(a) ou arrumado(a) demais? Você escolheu roupas com cores que não está habituado a usar? Usou mais acessórios ou maquiagem do que de costume?

O- Traje e cuidados pessoais apropriados

1- Um pouco descuidado

2- Desleixado, moderadamente desalinhado, trajes exagerados.

3- Desalinhado, parcialmente trajado, maquiagem extravagante

4- Completamente descuidado, enfeitado, vestes bizarras

\section{Insight}

Analisando a última semana, você acha que seu comportamento(jeito de agir) tem estado diferente do seu habitual? Estas coisas aconteceram porque você estava eufórico(a)? Como você interpreta o fato de (exemplificar com possíveis sintomas apresentados)? Você acha que precisa de tratamento?

O. Presente; admite doença; concorda com necessidade de tratamento

1- Possivelmente doente

2- Admite mudanças de comportamento, mas nega doença

3- Admite possível mudança de comportamento, mas nega doença

4- Nega qualquer mudança de comportamento 
Folha de Respostas-SIGH-D-17 e YMRS

SIGH-D

\begin{tabular}{|c|c|c|c|c|c|}
\hline 1 & 0 & 1 & 2 & 3 & 4 \\
\hline 2 & 0 & 1 & 2 & 3 & 4 \\
\hline 3 & 0 & 1 & 2 & 3 & 4 \\
\hline 4 & 0 & 1 & 2 & & \\
\hline 5 & 0 & 1 & 2 & & \\
\hline 6 & 0 & 1 & 2 & & \\
\hline 7 & 0 & 1 & 2 & 3 & 4 \\
\hline 8 & 0 & 1 & 2 & 3 & 4 \\
\hline 9 & 0 & 1 & 2 & 3 & 4 \\
\hline 10 & 0 & 1 & 2 & 3 & 4 \\
\hline 11 & 0 & 1 & 2 & 3 & 4 \\
\hline 12 & 0 & 1 & 2 & & \\
\hline 13 & 0 & 1 & 2 & & \\
\hline 14 & 0 & 1 & 2 & & \\
\hline 15 & 0 & 1 & 2 & 3 & 4 \\
\hline 16 & 0 & 1 & 2 & & \\
\hline 17 & 0 & 1 & 2 & & \\
\hline
\end{tabular}

YMRS

\begin{tabular}{|c|c|c|c|c|c|c|}
\hline 1 & 0 & 1 & 2 & 3 & 4 & 8 \\
\hline 2 & 0 & 1 & 2 & 3 & 4 & 8 \\
\hline 3 & 0 & 1 & 2 & 3 & 4 & 8 \\
\hline 4 & 0 & 1 & 2 & 3 & 4 & 8 \\
\hline 5 & 0 & 1 & 2 & 3 & 4 & 8 \\
\hline 6 & 0 & 1 & 2 & 3 & 4 & 8 \\
\hline 7 & 0 & 1 & 2 & 3 & 4 & 8 \\
\hline 8 & 0 & 1 & 2 & 3 & 4 & 8 \\
\hline 9 & 0 & 1 & 2 & 3 & 4 & 8 \\
\hline 10 & 0 & 1 & 2 & 3 & 4 & 8 \\
\hline 11 & 0 & 1 & 2 & 3 & 4 & 8 \\
\hline
\end{tabular}




\section{EMBU-P (AUTOAPLICÁVEL)}

\section{RESPONDA APENAS SE VOCÊ TIVER FILHOS}

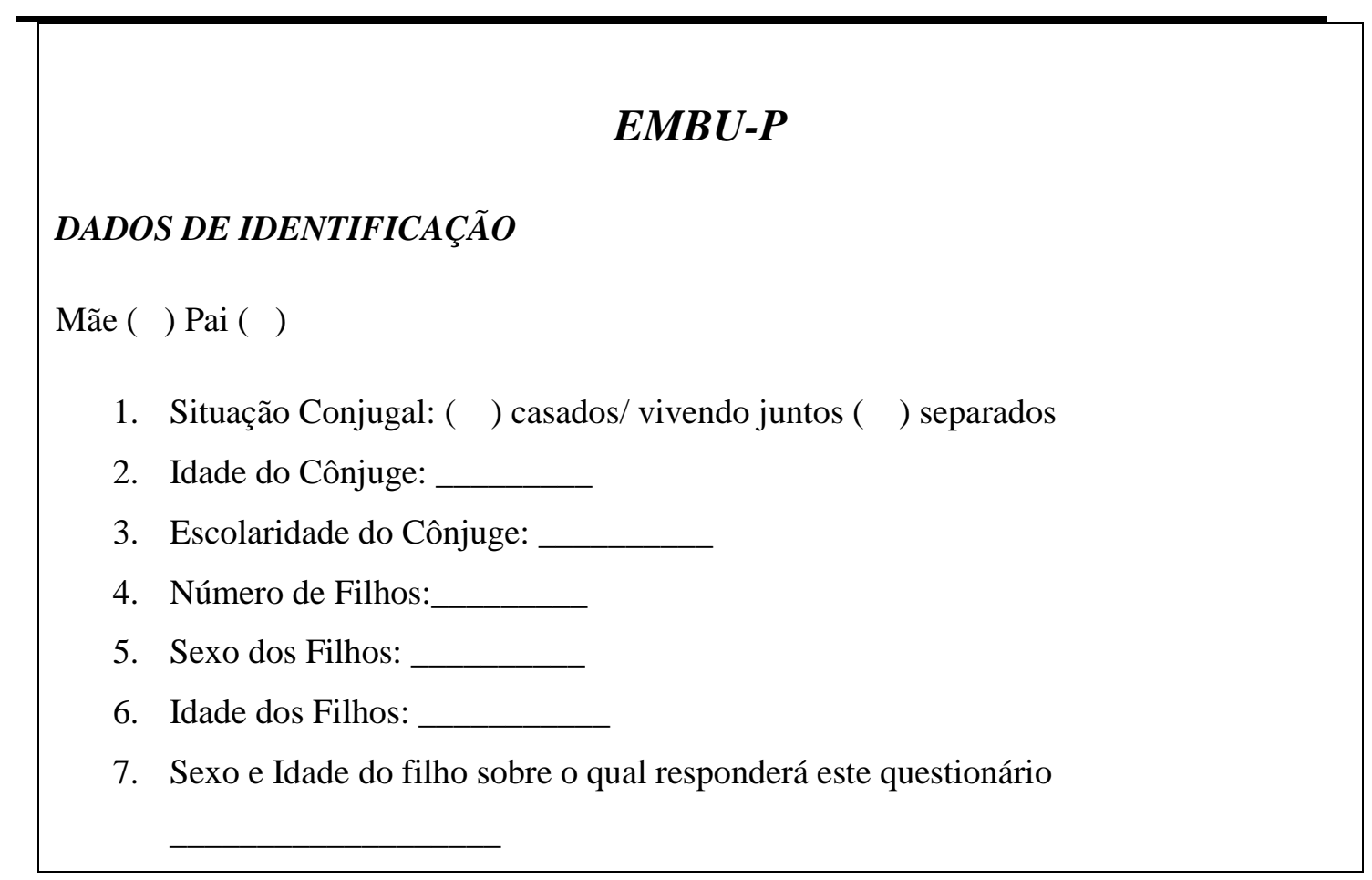




\section{PARTE I}

\section{ENTREVISTA}

$\mathrm{Na}$ continuação, encontrarão uma série de frases. Primeiramente, escolham um filho sobre o qual responderão este questionário; depois, leiam cada uma delas com atenção e marquem com um círculo a alternativa que vocês acreditam ser a mais apropriada.

1. Significa que acontece SEMPRE.

2. Significa que acontece ALGUMAS VEZES.

3. Significa que NUNCA acontece.

\begin{tabular}{|lccc|}
\hline & Sempre & $\begin{array}{c}\text { Algumas } \\
\text { Vezes }\end{array}$ & Nunca \\
\hline $\begin{array}{l}\text { 2. Vocês têm demonstrado com palavras e gestos que } \\
\text { gostam de seu filho? }\end{array}$ & 1 & 2 & 3 \\
\hline $\begin{array}{l}\text { 3. Acreditam que seu filho se sente o mais mimado em } \\
\text { comparação aos irmãos? }\end{array}$ & 1 & 2 & 3 \\
\hline $\begin{array}{l}\text { 6. Vocês castigam seu filho mesmo quando ele comete } \\
\text { pequenos erros? }\end{array}$ & 1 & 2 & 3 \\
\hline $\begin{array}{l}\text { 7. Vocês tentam influenciar seu filho para que ele seja uma } \\
\text { pessoa importante? }\end{array}$ & 1 & 2 & 3 \\
\hline $\begin{array}{l}\text { 9. Vocês desejam que o seu filho seja diferente em algum } \\
\text { aspecto? }\end{array}$ & 1 & 2 & 3 \\
\hline $\begin{array}{l}\text { 12. Vocês são muito severos com seu filho? } \\
\text { 13. Se seu filho fizer uma "arte", ele pode consertar a } \\
\text { situação frente a vocês pedindo-lhes desculpas? }\end{array}$ & 1 & 2 & 3 \\
\hline $\begin{array}{l}\text { 14. Vocês gostariam de decidir como o seu filho deve } \\
\text { vestir-se ou que aparência deve ter? }\end{array}$ & 1 & 2 & 3 \\
\hline $\begin{array}{l}\text { 17. Seu filho é tratado injustamente em comparação a seus } \\
\text { irmãos? }\end{array}$ & 1 & 2 & 3 \\
\hline $\begin{array}{l}\text { 18. Por medo de que lhe aconteça algo, vocês proíbem que } \\
\text { seu filho faça coisas que os outros jovens de mesma idade } \\
\text { podem fazer? }\end{array}$ & 1 & 2 & 3 \\
\hline $\begin{array}{l}\text { 19. Vocês xingam ou batem em seu filho na presença de } \\
\text { outras pessoas? }\end{array}$ & 1 & 2 & 3 \\
\hline $\begin{array}{l}\text { 20. Vocês se preocupam em saber o que seu filho faz } \\
\text { quando não está em casa? }\end{array}$ & 1 & 2 & 3 \\
\hline $\begin{array}{l}\text { 21. Vocês acham que seu filho tem a sensação de se sentir } \\
\text { compreendido e animado por vocês quando as coisas vão } \\
\text { mal para ele? }\end{array}$ & 1 & 2 & 3 \\
\hline $\begin{array}{l}\text { 22. Vocês se preocupam excessivamente com a saúde de } \\
\text { seu filho? }\end{array}$ & 1 & 2 & 3 \\
\hline 23. Vocês batem em seu filho mais do que ele merece? & 1 & 2 & 3 \\
\hline $\begin{array}{l}\text { 24. Vocês ficam irritados se seu filho não ajuda nas tarefas } \\
\text { de casa tanto quanto vocês gostariam? }\end{array}$ & 1 & 2 & 3 \\
\hline $\begin{array}{l}\text { 25. Vocês se entristecem quando seu filho faz algo errado } \\
\text { a ponto dele sentir-se culpado pelo que fez? }\end{array}$ & 1 & 2 & 3 \\
\hline
\end{tabular}




\begin{tabular}{|c|c|c|c|}
\hline $\begin{array}{l}\text { 28. Vocês contam coisas, diante de outras pessoas, sobre } \\
\text { aquilo que seu filho tenha dito ou feito, fazendo com que } \\
\text { ele se sinta envergonhado? }\end{array}$ & 1 & 2 & 3 \\
\hline $\begin{array}{l}\text { 29. Vocês acham que o seu filho sente que vocês gostam } \\
\text { menos dele do que dos outros irmãos? }\end{array}$ & 1 & 2 & 3 \\
\hline $\begin{array}{l}\text { 31. Demonstram ao seu filho interesse de que ele tire boas } \\
\text { notas? }\end{array}$ & 1 & 2 & 3 \\
\hline $\begin{array}{l}\text { 32. Vocês acham que o seu filho se sente ajudado por } \\
\text { vocês quando ele enfrenta uma tarefa difícil? }\end{array}$ & 1 & 2 & 3 \\
\hline $\begin{array}{l}\text { 35. Vocês dizem ao seu filho: "Com a idade que tens não } \\
\text { deverias te comportar desta forma?" }\end{array}$ & 1 & 2 & 3 \\
\hline $\begin{array}{l}\text { 37. Quando vocês estão tristes, acham que seu filho se } \\
\text { sente culpado por vocês se sentirem assim? }\end{array}$ & 1 & 2 & 3 \\
\hline $\begin{array}{l}\text { 38. Vocês tentam estimular seu filho para que ele seja o } \\
\text { melhor? }\end{array}$ & 1 & 2 & 3 \\
\hline 39. Vocês demonstram que estão satisfeitos com seu filho? & 1 & 2 & 3 \\
\hline $\begin{array}{l}\text { 40. Vocês confiam no seu filho a tal ponto de permitir que } \\
\text { ele atue por sua própria responsabilidade? }\end{array}$ & 1 & 2 & 3 \\
\hline 41. Vocês respeitam a opinião do seu filho? & 1 & 2 & 3 \\
\hline $\begin{array}{l}\text { 42. Vocês desejam falar com seu filho sobre os pequenos } \\
\text { segredos dele? }\end{array}$ & 1 & 2 & 3 \\
\hline $\begin{array}{l}\text { 43. Vocês dão a sensação ao seu filho de quererem estar } \\
\text { ao lado dele? }\end{array}$ & 1 & 2 & 3 \\
\hline $\begin{array}{l}\text { 44. Seu filho pensa que vocês são "pão duros e chatos" } \\
\text { com ele? }\end{array}$ & 1 & 2 & 3 \\
\hline $\begin{array}{l}\text { 46. Quando seu filho volta para casa, sempre tem que dar } \\
\text { explicações a vocês sobre o que ele estava fazendo? }\end{array}$ & 1 & 2 & 3 \\
\hline $\begin{array}{l}\text { 47. Vocês estimulam a adolescência de seu filho para que } \\
\text { seja interessante e atrativa (por exemplo, dando-lhes bons } \\
\text { livros para ler, animando-o a sair em excursões etc.)? }\end{array}$ & 1 & 2 & 3 \\
\hline $\begin{array}{l}\text { 48. Vocês elogiam frequentemente os comportamentos de } \\
\text { seu filho? }\end{array}$ & 1 & 2 & 3 \\
\hline \multirow[t]{2}{*}{$\begin{array}{l}\text { 49. Vocês dizem a seu filho coisas como esta: "Assim é } \\
\text { que agradeces tudo o que nós temos feito por ti e todos os } \\
\text { sacrifícios que fazemos pelo teu bem"? }\end{array}$} & 1 & 2 & 3 \\
\hline & Sempre & $\begin{array}{l}\text { Algumas } \\
\text { Vezes }\end{array}$ & Nunca \\
\hline $\begin{array}{l}\text { 54. Quando seu filho está triste, ele pode buscar ajuda e } \\
\text { compreensão em vocês? }\end{array}$ & 1 & 2 & 3 \\
\hline $\begin{array}{l}\text { 57. Vocês dizem ao seu filho que não estão de acordo com } \\
\text { a forma como ele se comporta em casa? }\end{array}$ & 1 & 2 & 3 \\
\hline $\begin{array}{l}\text { 60. Vocês se interessam pelo tipo de amigos com quem } \\
\text { seu filho anda? }\end{array}$ & 1 & 2 & 3 \\
\hline $\begin{array}{l}\text { 61. De todos os seus filhos, é neste que vocês colocam a } \\
\text { culpa quando acontece alguma coisa? }\end{array}$ & 1 & 2 & 3 \\
\hline 63. Vocês são bruscos com seu filho? & 1 & 2 & 3 \\
\hline $\begin{array}{l}\text { 64. Vocês castigam seu filho com dureza, inclusive por } \\
\text { coisas que não têm importância? }\end{array}$ & 1 & 2 & 3 \\
\hline 65. Vocês batem em seu filho sem motivo? & 1 & 2 & 3 \\
\hline $\begin{array}{l}\text { 66. Vocês acham que seu filho gostaria que vocês se } \\
\text { preocupassem menos com as coisas que ele faz? }\end{array}$ & 1 & 2 & 3 \\
\hline $\begin{array}{l}\text { 67. Vocês participam ativamente nas diversões e nos } \\
\text { hobbies de seu filho? }\end{array}$ & 1 & 2 & 3 \\
\hline 68. Vocês batem em seu filho? & 1 & 2 & 3 \\
\hline
\end{tabular}




\begin{tabular}{|llll|}
\hline $\begin{array}{l}\text { 69. Seu filho pode ir onde quiser sem que vocês se } \\
\text { preocupem demasiadamente com isso? }\end{array}$ & 1 & 2 & 3 \\
\hline $\begin{array}{l}\text { 70. Vocês impõem a seu filho limitações fortes ao que ele } \\
\text { pode ou não pode fazer e o obrigam a respeitá-los } \\
\text { rigorosamente? }\end{array}$ & 1 & 2 & 3 \\
\hline $\begin{array}{l}\text { 71. Vocês tratam seu filho de modo que ele se sinta } \\
\text { envergonhado? }\end{array}$ & 1 & 2 & 3 \\
\hline $\begin{array}{l}\text { 72. Vocês deixam seus outros filhos terem coisas que este } \\
\text { filho não pode ter? }\end{array}$ & 1 & 2 & 3 \\
\hline $\begin{array}{l}\text { 73. Vocês têm um medo exagerado de que aconteça algo a } \\
\text { seu filho? }\end{array}$ & 1 & 2 & 3 \\
\hline $\begin{array}{l}\text { 74. Vocês sentem que existe carinho e ternura entre seu } \\
\text { filho e vocês? }\end{array}$ & 1 & 2 & 3 \\
\hline $\begin{array}{l}\text { 78. Vocês se sentem orgulhosos de seu filho quando } \\
\text { consegue fazer algo que ele se propôs fazer? }\end{array}$ & 1 & 2 & 3 \\
\hline $\begin{array}{l}79 . \text { Vocês demonstram preferência por este filho em } \\
\text { comparação aos demais? }\end{array}$ & 1 & 2 & 3 \\
\hline $\begin{array}{l}\text { 81. Vocês manifestam que estão satisfeitos com o seu filho } \\
\text { he fazendo carinho (abraçando etc.)? }\end{array}$ & 1 & 2 & 3 \\
\hline
\end{tabular}




\section{PARTE II}

Por favor, escolham uma marcando com um $x$.

Vocês se consideram, em relação à educação, dos seus filhos.

( ) Muito coerentes na aplicação das normas e princípios educativos.

( ) Coerentes, ao longo do tempo, na aplicação desses princípios educativos.

( ) Bastante incoerentes.

( ) Muito incoerentes pois modificam esses princípios todos os dias.

Qual a opinião que vocês julgam que seu filho tem com relação à educação dada por vocês a ele?

( ) Muito severa, às vezes chegando até a aterrorizar.

( ) Em geral, severa.

( ) Não muito severa.

( ) Nada severa, permitindo que ele faça o que tiver vontade. 


\section{EMBU-S (AUTOAPLICÁVEL)}

\section{$E M B U-S$}

Vivi com meus pais até a idade de: anos.

Meu pai ainda vive $\square$ Morreu quando eu tinha anos.

Minha mãe ainda vive $\square$ Morreu quando eu tinha anos.

Meus pais se separaram quando eu tinha anos.

Meus pais têm TB ou indícios de TB?

Fui criado por. desde que eu tinha. anos.

Tenho. .irmãos.

Tenho. irmãos mais velhos do que eu.

Tenho. ..filhos

Abaixo, há 25 perguntas relacionadas à sua infância. Antes de responder a este questionário, leia cuidadosamente as seguintes instruções:

Ainda que seja difícil recordar com exatidão o modo como seus pais o tratavam quando você era criança, a verdade é que cada um de nós tem uma ideia, mais ou menos precisa, das normas básicas ou dos princípios nos quais se baseavam para educar-nos. Para responder a este questionário, é muito importante que você tente recordar o que sentia a respeito das atitudes que seus pais tinham com você. Como verá, cada pergunta tem várias alternativas e você deverá escolher aquela que reflete melhor tanto o comportamento do seu pai como o de sua mãe na sua educação quando você era criança. Marque com um "X" a alternativa mais apropriada para o seu caso.

Tenha o cuidado de não deixar questões não respondidas. Sabemos que algumas perguntas são impossíveis de responder se você não tem irmãos ou se foi criado por apenas um dos pais. Neste caso, deixe estas questões em branco. 
Para cada pergunta, por favor marque um " $\mathrm{X}$ " na resposta apropriada para o comportamento do seu pai e de sua mãe em relação a você. Leia cuidadosamente até o fim cada pergunta e julgue qual das possíveis respostas se aplica a você. Responda separadamente para seu pai e sua mãe.

A seguir, damos um exemplo do modo como você deve responder ao questionário.

\section{Exemplo:}

\begin{tabular}{|l|l|l|l|l|l|}
\hline \multirow{2}{*}{ Seus pais costumavam bater em você? } & Pai & 1 & 2 & 3 & 4 \\
\cline { 2 - 6 } & Mãe & 1 & 2 & 3 & 4 \\
\hline \multirow{2}{*}{ Seus pais eram carinhosos com você? } & Pai & 1 & 2 & 3 & 4 \\
\cline { 2 - 6 } & Mãe & 1 & 2 & 3 & 4 \\
\hline
\end{tabular}

1 Não, nunca.

$2 \mathrm{Sim}$, às vezes.

3 Sim, frequentemente.

4 Sim, sempre.

1. Seus pais ficavam aborrecidos com você e não lhe diziam os motivos?

2. Seus pais o elogiavam?

3. Você desejava que seus pais se preocupassem menos com as coisas que você estava fazendo?

4. Seus pais lhe batiam mais do que você merecia?

5. Quando você voltava para casa tinha que explicar a seus pais o Pai que estivera fazendo?

6. Você acha que seus pais tentavam tornar sua adolescência estimulante, interessante, instrutiva (por exemplo: dando-lhe bons livros para ler, incentivando-o a sair para passear, levandoo a clubes)?

7. Seus pais o criticavam na frente dos outros dizendo que você era preguiçoso e inútil?

8. Seus pais o proibiam de fazer coisas que outras crianças faziam por terem medo de que alguma coisa lhe acontecesse?

9. Seus pais o pressionavam para que se tornasse o melhor?

10. Seus pais pareciam ficar tristes, ou de alguma maneira mostravam que você tinha se comportado mal, de forma que você se sentisse culpado?

11. Você acha que seus pais tinham um medo exagerado de que algo lhe acontecesse?

12. Se para você as coisas iam mal, você sentia que seus pais procuravam encorajá-lo e confortá-lo?

\begin{tabular}{|l|l|l|l|l|}
\hline Pai & 1 & 2 & 3 & 4 \\
\hline Mãe & 1 & 2 & 3 & 4 \\
\hline Pai & 1 & 2 & 3 & 4 \\
\hline Mãe & 1 & 2 & 3 & 4 \\
\hline Pai & 1 & 2 & 3 & 4 \\
\hline Mãe & 1 & 2 & 3 & 4 \\
\hline Pai & 1 & 2 & 3 & 4 \\
\hline Mãe & 1 & 2 & 3 & 4 \\
\hline Pai & 1 & 2 & 3 & 4 \\
\hline Mãe & 1 & 2 & 3 & 4 \\
\hline Pai & 1 & 2 & 3 & 4 \\
\hline Mãe & 1 & 2 & 3 & 4 \\
\hline Pai & 1 & 2 & 3 & 4 \\
\hline Mãe & 1 & 2 & 3 & 4 \\
\hline Pai & 1 & 2 & 3 & 4 \\
\hline Mãe & 1 & 2 & 3 & 4 \\
\hline Pai & 1 & 2 & 3 & 4 \\
\hline Mãe & 1 & 2 & 3 & 4 \\
\hline Pai & 1 & 2 & 3 & 4 \\
\hline Mãe & 1 & 2 & 3 & 4 \\
\hline Pai & 1 & 2 & 3 & 4 \\
\hline Mãe & 1 & 2 & 3 & 4 \\
\hline Pai & 1 & 2 & 3 & 4 \\
\hline Mãe & 1 & 2 & 3 & 4 \\
\hline
\end{tabular}


13. Você era tratado como "ovelha negra" ou como "bode expiatório" da família?

14. Seus pais demonstravam, com palavras e gestos, que gostavam de você?

15. Você sentia que seus pais gostavam mais de seus irmãos do que de você?

16. Seus pais o tratavam de um modo que o fazia sentir-se envergonhado?

17. Você podia ir onde gostava sem que seus pais ficassem muito Pai preocupados?

18. Você sentia que seus pais interferiam em tudo o que você fazia?

19. Você sentia que havia calor e ternura entre você e seus pais?

20. Seus pais costumavam colocar regras claras sobre o que você $\mathrm{P}$ podia e o que não podia fazer e as seguiam rigorosamente?

21. Seus pais o castigavam com severidade, mesmo por coisas sem importância?

22. Seus pais costumavam decidir sobre como você deveria se vestir ou que aparência deveria ter?

23. Você sentia que seus pais ficavam orgulhosos quando você obtinha êxito em alguma coisa pela qual havia se empenhado?

\begin{tabular}{|l|l|l|l|l|}
\hline Pai & 1 & 2 & 3 & 4 \\
\hline Mãe & 1 & 2 & 3 & 4 \\
\hline Pai & 1 & 2 & 3 & 4 \\
\hline Mãe & 1 & 2 & 3 & 4 \\
\hline Pai & 1 & 2 & 3 & 4 \\
\hline Mãe & 1 & 2 & 3 & 4 \\
\hline Pai & 1 & 2 & 3 & 4 \\
\hline Mãe & 1 & 2 & 3 & 4 \\
\hline Pai & 1 & 2 & 3 & 4 \\
\hline Mãe & 1 & 2 & 3 & 4 \\
\hline Pai & 1 & 2 & 3 & 4 \\
\hline Mãe & 1 & 2 & 3 & 4 \\
\hline Pai & 1 & 2 & 3 & 4 \\
\hline Mãe & 1 & 2 & 3 & 4 \\
\hline Pai & 1 & 2 & 3 & 4 \\
\hline Mãe & 1 & 2 & 3 & 4 \\
\hline Pai & 1 & 2 & 3 & 4 \\
\hline Mãe & 1 & 2 & 3 & 4 \\
\hline Pai & 1 & 2 & 3 & 4 \\
\hline Mãe & 1 & 2 & 3 & 4 \\
\hline Pai & 1 & 2 & 3 & 4 \\
\hline Mãe & 1 & 2 & 3 & 4 \\
\hline
\end{tabular}

1 Não, nunca.

$2 \mathrm{Sim}$, às vezes.

3 Sim, frequentemente.

4 Sim, sempre. 
SDQ (AUTOAPLICÁVEL)

\section{Questionário de Capacidades e Dificuldades (SDQ-Por)}

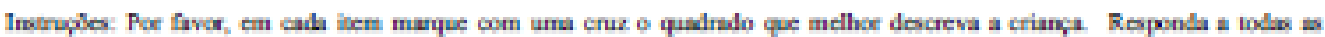

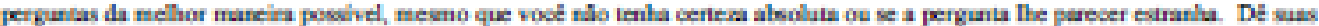
ropostas oom buse no coenportamenbo da crianca sos âlimas seis meses.

None Aa Crianca

Masculano/Fentain:

Data de Nascinate

Mrír ou mevas

Talas tordadeiro Verdadeire

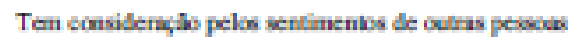

$\square \quad \square \quad \square$

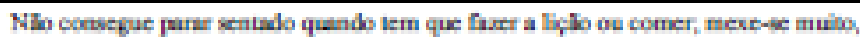

esturrando an coibus, derrulende coivas

Muitas veres se quatixa de doe de callega, dar de barriza os enjón

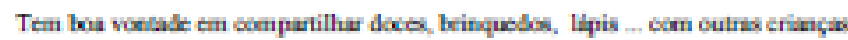

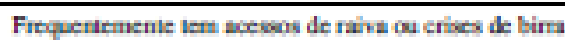

É soludria, prefert briscar sariaho

Geralneate é obediente e fax nomalmente o que cos alulwos late polen

Tem muitas preccupapdes, maitas veres parece preocupado cont mbe

$\square \quad \square \quad \square$

Tenta ser atencioso se alguem parese nagnabs, aflito ou se sentindo mal

Esti senpre ayituda, balascando as permas eu mexendo as miks

Tem jelo menos un boen antigo oe amige

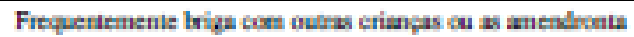

Frequentemenle parece triste, desarimadb ou choros.

Em garal, é querids per ousas criança

Facilmente perde a coticentrapio

Fiea inseguso qaando tem que faner alguma coiju pela pritseira ver, facilmente pende a confanca on si mesme

$\square \quad \square \quad \square$

É gentil cont criascas mais novas

$\square \quad \square \quad \square$

Frequentemente exgana cu mente

Oubas criancas 'pegant no pe' ou aloententam-n.

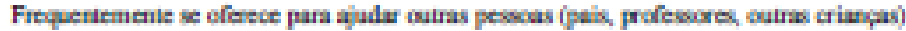

Pensa nas coibus antes de fanf-las

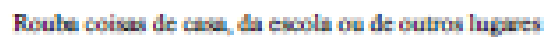

Se da melhor com alulacs bo que cont outras crianças

Tem muibs medok, mosuda-se facilmerae

Completa as uefias que contopa, ten bea concenteracilo

$\begin{array}{lll}\square & \square & \square \\ \square & \square & \square\end{array}$

$\square \quad \square \quad \square$

$\square \quad \square \quad \square$

$\square \quad \square$

$\square \quad \square \quad \square$

$\square \quad \square \quad \square$

$\square \quad \square \quad \square$

$\square \quad \square \quad \square$

$\square \quad \square \quad \square$

$\square \quad \square$

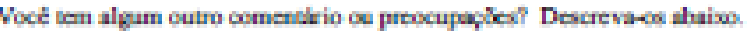




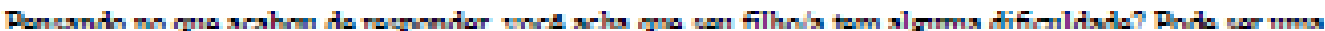

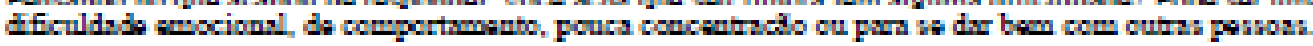

\begin{tabular}{|c|c|c|c|}
\hline MEo & $\begin{array}{l}\text { Sim- } \\
\text { Taquans: } \\
\text { deferiludos }\end{array}$ & $\begin{array}{l}\text { Sim- } \\
\text { bunulus. } \\
\text { bam definds: }\end{array}$ & Sim- \\
\hline
\end{tabular}

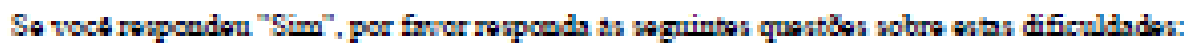

- Hi quato trmpo estan difculdades ovistem?

$\begin{array}{llll}\text { Manos do } & 1-5 & 6-12 & \text { Mais do } \\ 1 \text { mog } & \text { mono } & \text { mose } & 1 \text { ano } \\ \prod & \square & \square & \square\end{array}$

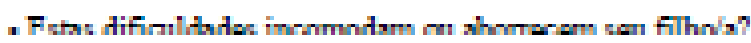

$\begin{array}{llll}\text { Nada } & \text { Un } & \text { Mais } \\ \square & \square & \text { Muito } & \text { Gos mnito } \\ \square & \square & \square\end{array}$

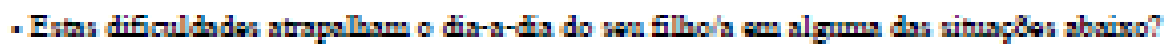

\begin{tabular}{|c|c|c|c|c|}
\hline & Nada & $\begin{array}{l}\text { The: } \\
\text { poues }\end{array}$ & Minito & $\begin{array}{l}\text { Mas } \\
\text { quat muito }\end{array}$ \\
\hline ГTA-A-TITA FM CASA & $\square$ & $\square$ & $\square$ & $\square$ \\
\hline AWIZADES & $\square$ & $\square$ & $\square$ & $\square$ \\
\hline 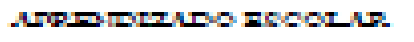 & $\square$ & $\square$ & $\square$ & $\square$ \\
\hline 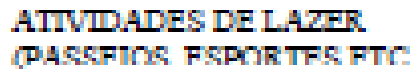 & $\square$ & $\square$ & $\square$ & $\square$ \\
\hline
\end{tabular}

- Eutra dificuldadoa dín um poso para woca ou para a familia cono um todón

$\begin{array}{llll}\text { Nada } & \text { Um } & \text { Mris } \\ \square & \square & \text { Muito } & \text { qou monito } \\ \square & \square & \square\end{array}$

Noma complato (pm lots de forma)

Data

Mhapailouro (arpecifipa) : 
Escalas de Exigência e Responsividade Parentais -para ser respondida por um dos pais do sujeito da pesquisa sobre a época do filho adolescente. Avô ( ) Avó ( )

\section{Escala de Exigência}

Até que ponto o(a) senhor(a) TENTAVA saber...

1. Onde ele ia à noite?
( ) Não tentava
( ) Tentava pouco
( ) Tentava bastante

2. O que ele fazia com seu tempo livre?
( ) Não tentava
( ) Tentava pouco
( ) Tentava bastante

3. Onde ele estava quando não estava na escola?
( ) Não tentava
( ) Tentava pouco
( ) Tentava bastante

Até que ponto o(a) senhor(a) REALMENTE sabia...

4. Onde seu filho ia à noite?
( ) Não sabia
( )Sabia pouco
( )Sabia bastante

5. O que seu filho fazia com seu tempo livre?
( ) Não sabia
( )Sabia pouco
( )Sabia bastante

6. Onde seu filho estava quando não estava na escola?
( ) Não sabia
( )Sabia pouco
( )Sabia bastante

\section{Escala de Responsividade}

A respeito de seu filho, como considera que ele responderia aos seguintes itens:

7. Podia contar com ajuda dos meus pais caso eu tivesse algum tipo de problema.
( )Quase nunca
( ) Às vezes
( ) Geralmente

8. Meus pais me incentivam a dar o melhor de mim em qualquer coisa que eu fazia.
( )Quase nunca
( ) Às vezes
( ) Geralmente

9. Meus pais me incentivam a pensar de forma independente.
( )Quase nunca
( ) Às vezes
( )Geralmente

10. Meus pais me ajudavam nos trabalhos da escola se tivesse alguma coisa que eu não entendia.
( )Quase nunca
( ) Às vezes
( )Geralmente

11. Quando queriam que eu fizesse alguma coisa, me explicavam o porquê. 
( )Quase nunca ( ) Às vezes ( )Geralmente

12. Quando tirava uma boa nota na escola, com que frequência seus pais te elogiavam?

( )Quase nunca ( )Às vezes ( )Geralmente

13. Quando tirava uma nota baixa na escola, com que frequência seus pais te encorajam a se esforçar mais?

( )Quase nunca ( ) Às vezes ( )Geralmente

14. Seus pais realmente sabiam quem eram seus amigos.

( ) Não sabiam ( )Sabiam pouco ( )Sabiam bastante

15. Com que frequência seus pais passavam tempo conversando contigo?

( )Quase nunca ( ) Às vezes ( )Quase sempre

16. Com que frequência você e seus pais se reuniam para fazerem juntos alguma coisa agradável?

( )Quase nunca ( ) Às vezes ( )Quase sempre 


\section{MDQ - Questionário de Transtorno do Humor - para ser respondido pelo} mesmo avô que respondeu às Escalas de Exigência e Responsividade

Já ocorreu algum período na sua vida em que seu jeito de ser mudou? E que...

\begin{tabular}{|c|c|}
\hline $\begin{array}{l}1 \text {... você se sentia tão bem ou tão para cima a ponto das outras pessoas } \\
\text { pensarem que você não estava no seu jeito normal, ou você estava tão para } \\
\text { cima a ponto de se envolver em problemas? }\end{array}$ & Sim $\square$ Não $\square$ \\
\hline $\begin{array}{l}2 \ldots \text { você ficava tão irritado a ponto de gritar com as pessoas ou começava } \\
\text { brigas ou discussões? }\end{array}$ & Sim $\square$ Não $\square$ \\
\hline 3 ... você se sentia muito mais confiante em você mesmo do que o normal? & $\operatorname{Sim} \square$ Não $\square$ \\
\hline 4 ...você dormia menos que de costume e nem sequer sentia falta do sono? & $\operatorname{Sim} \square$ Não $\square$ \\
\hline 5 ...você falava muito mais ou falava mais rápido que o seu normal? & $\operatorname{Sim} \square$ Não $\square$ \\
\hline $\begin{array}{l}6 \text {...os pensamentos corriam rapidamente em sua cabeça ou você não } \\
\text { conseguia acalmar sua mente? }\end{array}$ & $\operatorname{Sim} \square$ Não $\square$ \\
\hline $\begin{array}{l}7 \text {... você se distraía com tanta facilidade com as coisas ao seu redor a ponto } \\
\text { de ter dificuldade em manter a concentração ou o foco em uma atividade? }\end{array}$ & Sim $\square$ Não $\square$ \\
\hline 8 ...você se sentia com muito mais energia que o seu normal? & Sim $\square$ Não $\square$ \\
\hline $\begin{array}{l}9 \text {...você ficava muito mais ativo ou fazia muito mais coisas que o seu } \\
\text { normal? }\end{array}$ & $\operatorname{Sim} \square$ Não $\square$ \\
\hline $\begin{array}{l}10 \text {...você ficava mais dado com as pessoas e mais expansivo que o seu } \\
\text { normal, por exemplo, telefonava para os amigos no meio da noite? }\end{array}$ & Sim $\square$ Não $\square$ \\
\hline 11 ...você ficava mais interessado em sexo que o normal? & Sim $\square$ Não $\square$ \\
\hline $\begin{array}{l}12 \text {...você fazia coisas que não eram comuns para você ou que faziam outras } \\
\text { pessoas pensarem que você era exagerado, bobo ou se arriscava mais? }\end{array}$ & $\operatorname{Sim} \square$ Não $\square$ \\
\hline 13 ... gastar dinheiro causava problemas para você ou para sua família? & $\operatorname{Sim} \square$ Não $\square$ \\
\hline $\begin{array}{l}\text { Se você marcou SIM em mais de uma das perguntas acima: } \\
\text { Várias delas ocorreram durante o mesmo período de tempo? Por favor, } \\
\text { circule apenas uma resposta. }\end{array}$ & Sim $\square$ Não $\square$ \\
\hline $\begin{array}{l}\text { Até que ponto o problema o afetou - como sentir-se incapaz de trabalhar, ter } \\
\text { dificuldades com a família, com dinheiro ou problemas com a justiça, } \\
\text { envolver-se em discussões ou brigas? Por favor, circule apenas uma resposta. }\end{array}$ & $\begin{array}{l}\text { Nenhum problema } \\
\text { Problema } \\
\text { pouco grave } \\
\text { Problema mais ou } \\
\text { menos grave } \\
\text { Problema } \\
\text { muito grave }\end{array}$ \\
\hline
\end{tabular}




\section{ANEXO D - Pontuação e Interpretação SDQ}

Os 25 itens do SDQ são compostos de cinco escalas com cinco itens cada. Mais ou menos verdadeiro é normalmente calculado como 1, enquanto falso e verdadeiro variam conforme o item, escala por escala. Para cada uma das cinco escalas, a pontuação pode variar de 0 a 10 se todos os cinco itens forem completados. O resultado de cada escala pode ser avaliado se ao menos três itens foram completados.

\section{Escala de Sintomas Emocionais}

\begin{tabular}{llcc}
\hline & Falso & $\begin{array}{c}\text { Mais ou menos } \\
\text { Verdadeiro }\end{array}$ & Verdadeiro \\
Muitas vezes queixa-se de dor de cabeça & 0 & 1 & 2 \\
muitas preocupações, muitas vezes parece preocupado & 0 & 1 & 2 \\
requentemente parece triste, deprimido ou choroso & 0 & 1 & 2 \\
ca nervoso quando enfrenta situações novas & 0 & 1 & 2 \\
\hline
\end{tabular}

\section{Escala de Problemas de Conduta}

\begin{tabular}{|c|c|c|c|}
\hline & Falso & $\begin{array}{l}\text { Mais ou menos } \\
\text { Verdadeiro }\end{array}$ & Verdadeiro \\
\hline Frequentemente tem acessos de raiva ou crises de birra & 0 & 1 & 2 \\
\hline Geralmente é obediente & 2 & 1 & 0 \\
\hline Frequentemente briga com outras crianças ou as amedronta & 0 & 1 & 2 \\
\hline Frequentemente mente ou engana & 0 & 1 & 2 \\
\hline Rouba coisas de casa, da escola ou de outros lugares & 0 & 1 & 2 \\
\hline
\end{tabular}

\section{Escala de Hiperatividade}

\begin{tabular}{llcc}
\hline & Falso & $\begin{array}{c}\text { Mais ou menos } \\
\text { Verdadeiro }\end{array}$ & Verdadeiro \\
Inquieto/a, hiperativo/a, não consegue ficar parado/a & 0 & 1 & 2 \\
Está constantemente irrequieto ou agitado & 0 & 1 & 2 \\
Distrai-se facilmente, perde a concentração & 0 & 1 & 2 \\
Pensa antes de agir & 2 & 1 & 0 \\
Completa as tarefas que começa, tem boa concentração & 2 & 1 & 0 \\
\hline
\end{tabular}




\section{Escala de Problemas de Relacionamento com os colegas}

\begin{tabular}{lccc}
\hline & Falso & $\begin{array}{c}\text { Mais ou menos } \\
\text { Verdadeiro }\end{array}$ & Verdadeiro \\
É solitário, prefere brincar sozinho & 0 & 1 & 2 \\
Tem pelo menos um/a bom/a amigo/a & 2 & 1 & 0 \\
Em geral, é querido por outras crianças & 2 & 1 & 0 \\
É perseguido ou atormentado por outras crianças & 0 & 1 & 2 \\
Relaciona-se melhor com adultos do que com outras crianças 0 & 1 & 2 \\
\hline
\end{tabular}

\section{Escala de Comportamento}

Prossocial

\begin{tabular}{llcc} 
& Falso & $\begin{array}{c}\text { Mais ou menos } \\
\text { Verdadeiro }\end{array}$ & Verdadeiro \\
Tem consideração pelos sentimentos de outras pessoas & 0 & 1 & 2 \\
Tem boa vontade em compartilhar & 0 & 1 & 2 \\
Mostra-se prestativo se alguém parece magoado & 0 & 1 & 2 \\
É gentil com crianças mais novas & 0 & 1 & 2 \\
Frequentemente se oferece para ajudar outras pessoas & 0 & 1 & 2 \\
\hline
\end{tabular}

A pontuação Total de Dificuldades é gerada pela soma dos resultados de todas as escalas exceto a escala de sociabilidade. $\mathrm{O}$ resultado pode variar de 0 a 40 . A pontuação geral pode ser considerada se ao menos 12 dos 20 itens relevantes foram completados.

A interpretação da pontuação dos sintomas e a definição de "caso" é feita a partir da Tabela 4.

Em um estudo em que a amostra seja de "alto risco", no qual os falsos positivos não são a nossa maior preocupação, os "casos" podem ser identificados pela "pontuação alta ou limítrofe" em uma das quatro escalas de dificuldades. Em estudo em que a amostra seja de "baixo risco", no qual o mais importante é reduzir a taxa de falsos positivos, os "casos" podem ser identificados através de "pontuação alta" em uma das quatro escalas de dificuldades. 
Tabela 4 - Interpretação da Pontuação - SDQ

\begin{tabular}{llll} 
& Normal & Limítrofe & Anormal__ \\
\cline { 2 - 4 } & & & \\
Pontuação Total das Dificuldades & $0-13$ & $14-16$ & $17-40$ \\
Pontuação dos Sintomas Emocionais & $0-3$ & 4 & $5-10$ \\
Pontuação de Problemas de Conduta & $0-2$ & 3 & $4-10$ \\
Pontuação para Hiperatividade & $0-5$ & 6 & $7-10$ \\
Pontuação para Problemas com Colegas & $0-2$ & 3 & $4-10$ \\
Pontuação para Comportamento Prossocial & $6-10$ & 5 & $0-4$
\end{tabular}


ANEXO E -Análise descritiva da presença ou não de TB nos avós do grupo TBI e seus estilos parentais

Na Tabela a seguir, encontra-se também a distribuição de frequência dos avós diagnosticados ou não com TB e o seu respectivo estilo parental do grupo TBI. Observou-se que a maioria dos avós com TB apresentou um estilo parental autoritativo, e a maioria dos avós sem TB apresentou o estilo parental negligente.

Na Tabela seguinte, encontra-se a distribuição de frequência dos avós que responderam às escalas de Responsividade e Exigência, diagnosticados ou não com TB, do grupo TBI. Observou-se uma distribuição bem equilibrada: 53\% não preencheram critério para TB e $47 \%$ preencheram critério para TB segundo MDQ.

Tabela 14 - Distribuição de frequência dos avós diagnosticados ou não com TB e seu respectivo estilo parental do grupo TBI

\begin{tabular}{lccc}
\hline & Avós Não TB & Avós TB & Total \\
\hline $\mathrm{n}(\%)$ & $9(53 \%)$ & $8(47 \%)$ & $17(100 \%)$ \\
Estilo Autoritativo & 0 & 3 & 3 \\
Estilo Autoritário & 2 & 1 & 3 \\
Estilo Indulgente & 2 & 1 & 3 \\
Estilo Negligente & 4 & 2 & 6 \\
Total & $9(53 \%)$ & $8(47 \%)$ & $17(100 \%)$ \\
\hline
\end{tabular}




\section{ANEXO F - Análise descritiva do estilo parental por idade dos avós}

$\mathrm{Na}$ Tabela a seguir, encontramos o resultado da distribuição de frequência dos estilos parentais por idade dos avós, que responderam às escalas de Responsividade e Exigência do grupo TBI.

Tabela 15 - Distribuição de frequência dos estilos parentais por idade dos avós do grupo TBI

\begin{tabular}{|c|c|c|c|c|c|}
\hline Idade & Estatística & $\begin{array}{c}\text { Estilo } \\
\text { Autoritativo }\end{array}$ & $\begin{array}{c}\text { Estilo } \\
\text { Autoritário }\end{array}$ & $\begin{array}{c}\text { Estilo } \\
\text { Indulgente }\end{array}$ & $\begin{array}{c}\text { Estilo } \\
\text { Negligente }\end{array}$ \\
\hline & $\mathrm{N}$ & 4 & 3 & 3 & 5 \\
\hline & Mean & 71.75 & 74.33 & 75.67 & 67.8 \\
\hline & Median & 74.5 & 80 & 83 & 67 \\
\hline & Standard deviation & 9.6 & 15.31 & 18.15 & 9.58 \\
\hline & Min & 58 & 57 & 55 & 57 \\
\hline & Max & 80 & 86 & 89 & 78 \\
\hline
\end{tabular}

Observou-se que os avós com média de idade mais avançada apresentaram o estilo parental indulgente (baixa exigência e alta responsividade) e os mais jovens, estilo negligente (baixa exigência e responsividade). Talvez, essa diferença seja um indicativo do fator geracional, uma vez que $\mathrm{SD}=18$ anos.

$\mathrm{Na}$ próxima Tabela, encontra-se a distribuição de frequência dos estilos parentais por idade dos avós do grupo controle saudável. Observou-se que os avós com idades mais avançada apresentaram um estilo parental negligente e os mais jovens, autoritativos; resultado diferente do grupo TBI (mais velhos, indulgentes; e mais novos, negligentes). 
Tabela 16 - Distribuição de frequência dos estilos parentais por idade dos avós do grupo controle

\begin{tabular}{llcccc}
\hline Idade & Estatística & $\begin{array}{c}\text { Estilo } \\
\text { Autoritativo }\end{array}$ & $\begin{array}{c}\text { Estilo } \\
\text { Autoritário }\end{array}$ & $\begin{array}{c}\text { Estilo } \\
\text { Indulgente }\end{array}$ & $\begin{array}{c}\text { Estilo } \\
\text { Negligente }\end{array}$ \\
\hline $\mathrm{N}$ & 3 & 0 & 1 & 1 \\
Mean & 68.33 & 0 & 72 & 79 \\
Median & 67 & 0 & 72 & 79 \\
Standard & 9.07 & 0 & 0 & 0 \\
deviation & & & & 79 \\
Min & 60 & 0 & 72 & 79 \\
Max & 78 & 0 & 72 & \\
\hline
\end{tabular}

Média de idade avós grupo controle $=73.1$ e SD=9. 


\section{ANEXO G- Análise descritiva dos estilos parentais dos avós (visão dos avós) por cuidado recebido dos pais (visão do sujeito).}

Na Tabela a seguir, observou-se que a percepção maior de rejeição paterna pelo sujeito, na visão do avô a criação foi no estilo autoritário ou indulgente. A percepção de menor rejeição paterna pelo sujeito, na visão do avô a criação foi no estilo negligente. A percepção de maior rejeição materna pelo sujeito, na visão do avô a criação foi no estilo autoritativo ou indulgente. A percepção de menor rejeição materna pelo sujeito, na visão do avô a criação foi no estilo indulgente ou negligente.

A percepção de menor calor emocional paterno pelo sujeito, na visão do avô a criação foi no estilo indulgente. A percepção de menor calor emocional materno pelo sujeito, na visão do avô a criação foi no estilo negligente. A percepção de maior calor emocional paterno e materno pelo sujeito, na visão do avô a criação foi no estilo autoritativo.

A percepção de menor superproteção paterna e materna pelo sujeito, na visão do avô a criação foi no estilo negligente. A percepção de maior superproteção paterna pelo sujeito, na visão do avô a criação foi no estilo autoritativo. A percepção de maior superproteção materna pelo sujeito, na visão do avô a criação foi no estilo indulgente. 
Tabela 17 - Distribuição de frequência dos estilos parentais por Embu-S do grupo TBI

\begin{tabular}{|c|c|c|c|c|c|}
\hline & Estatística & $\begin{array}{c}\text { Estilo } \\
\text { Autoritativo }\end{array}$ & $\begin{array}{c}\text { Estilo } \\
\text { Autoritário }\end{array}$ & $\begin{array}{c}\text { Estilo } \\
\text { Indulgente }\end{array}$ & $\begin{array}{c}\text { Estilo } \\
\text { Negligente }\end{array}$ \\
\hline PairejectionEMBUS & $\mathrm{N}$ & 4 & 4 & 3 & 6 \\
\hline PairejectionEMBUS & Mean & 13.75 & 15.75 & 17 & 11.5 \\
\hline PairejectionEMBUS & Median & 14 & 15.5 & 13 & 9.5 \\
\hline PairejectionEMBUS & $\begin{array}{l}\text { Standard } \\
\text { deviation }\end{array}$ & 5.12 & 7.63 & 9.64 & 6.22 \\
\hline PairejectionEMBUS & Min & 8 & 7 & 10 & 6 \\
\hline PairejectionEMBUS & Max & 19 & 25 & 28 & 22 \\
\hline PaiemotionalwarmthEMBUS & $\mathrm{N}$ & 4 & 4 & 3 & 6 \\
\hline PaiemotionalwarmthEMBUS & Mean & 16.25 & 14 & 13 & 13.17 \\
\hline PaiemotionalwarmthEMBUS & Median & 19 & 14 & 9 & 14 \\
\hline PaiemotionalwarmthEMBUS & $\begin{array}{l}\text { Standard } \\
\text { deviation }\end{array}$ & 6.9 & 4.4 & 6.93 & 5.12 \\
\hline PaiemotionalwarmthEMBUS & Min & 6 & 9 & 9 & 7 \\
\hline PaiemotionalwarmthEMBUS & Max & 21 & 19 & 21 & 18 \\
\hline PaioverprotectionEMBUS & $\mathrm{N}$ & 4 & 4 & 3 & 6 \\
\hline PaioverprotectionEMBUS & Mean & 18.75 & 22 & 19 & 18 \\
\hline PaioverprotectionEMBUS & Median & 18.5 & 22.5 & 21 & 16.5 \\
\hline PaioverprotectionEMBUS & $\begin{array}{l}\text { Standard } \\
\text { deviation }\end{array}$ & 2.5 & 4.97 & 5.29 & 6.23 \\
\hline PaioverprotectionEMBUS & Min & 16 & 16 & 13 & 12 \\
\hline PaioverprotectionEMBUS & $\operatorname{Max}$ & 22 & 27 & 23 & 30 \\
\hline MaerejectionEMBUS & $\mathrm{N}$ & 4 & 4 & 3 & 6 \\
\hline MaerejectionEMBUS & Mean & 13.25 & 13.5 & 15.33 & 12.17 \\
\hline MaerejectionEMBUS & Median & 14 & 12 & 9 & 9.5 \\
\hline MaerejectionEMBUS & $\begin{array}{l}\text { Standard } \\
\text { deviation }\end{array}$ & 5.19 & 6.81 & 10.97 & 6.49 \\
\hline MaerejectionEMBUS & Min & 7 & 7 & 9 & 7 \\
\hline MaerejectionEMBUS & Max & 18 & 23 & 28 & 22 \\
\hline MaeemotionalwarmthEMBUS & $\mathrm{N}$ & 4 & 4 & 3 & 6 \\
\hline MaeemotionalwarmthEMBUS & Mean & 16.25 & 12.75 & 15.67 & 11.33 \\
\hline MaeemotionalwarmthEMBUS & Median & 19 & 13.5 & 17 & 9 \\
\hline MaeemotionalwarmthEMBUS & $\begin{array}{l}\text { Standard } \\
\text { deviation }\end{array}$ & 6.9 & 4.35 & 6.11 & 5.24 \\
\hline MaeemotionalwarmthEMBUS & Min & 6 & 7 & 9 & 7 \\
\hline MaeemotionalwarmthEMBUS & Max & 21 & 17 & 21 & 18 \\
\hline MaeoverprotectiomEMBUS & $\mathrm{N}$ & 4 & 4 & 3 & 6 \\
\hline MaeoverprotectiomEMBUS & Mean & 18.75 & 17.75 & 21.33 & 17.67 \\
\hline MaeoverprotectiomEMBUS & Median & 18.5 & 17 & 22 & 16.5 \\
\hline MaeoverprotectiomEMBUS & $\begin{array}{l}\text { Standard } \\
\text { deviation }\end{array}$ & 2.5 & 3.1 & 2.08 & 6.35 \\
\hline MaeoverprotectiomEMBUS & Min & 16 & 15 & 19 & 12 \\
\hline MaeoverprotectiomEMBUS & $\operatorname{Max}$ & 22 & 22 & 23 & 30 \\
\hline
\end{tabular}


Na próxima Tabela, encontra-se o resultado da distribuição de frequência dos estilos parentais dos avós (visão dos avós) por cuidado recebido dos pais (visão do sujeito); ou seja, visões diferentes (avô e sujeito) sobre a mesma relação (como sujeito foi criado na infância e adolescência) no grupo controle saudável.

Observou-se que a percepção de rejeição parental (pai e mãe) mais alta pelo sujeito, na visão do avô a criação foi no estilo negligente. A percepção de rejeição parental mais baixa pelo sujeito, na visão do avô a criação foi no estilo indulgente. A percepção de calor emocional parental mais alto pelo sujeito, na visão do avô a criação foi no estilo indulgente. A percepção calor emocional parental mais baixo pelo sujeito, na visão do avô a criação foi no estilo negligente. A percepção superproteção parental mais alta pelo sujeito, na visão do avô a criação foi no estilo indulgente. E a percepção de superproteção mais baixa pelo sujeito, na visão do avô a criação foi nos estilos autoritativo e negligente. 
Tabela 18 - Distribuição de frequência dos estilos parentais por Embu-S do grupo controle saudável

\begin{tabular}{|c|c|c|c|c|c|}
\hline & Estatística & $\begin{array}{c}\text { Estilo } \\
\text { Autoritativo }\end{array}$ & $\begin{array}{c}\text { Estilo } \\
\text { Autoritário } \\
\end{array}$ & $\begin{array}{c}\text { Estilo } \\
\text { Indulgente }\end{array}$ & $\begin{array}{c}\text { Estilo } \\
\text { Negligente } \\
\end{array}$ \\
\hline PairejectionEMBUS & $\mathrm{N}$ & 3 & 0 & 1 & 1 \\
\hline PairejectionEMBUS & Mean & 10 & NA & 7 & 13 \\
\hline PairejectionEMBUS & Median & 10 & NA & 7 & 13 \\
\hline PairejectionEMBUS & $\begin{array}{l}\text { Standard } \\
\text { deviation }\end{array}$ & 3 & NA & 0 & 0 \\
\hline PaiemotionalwarmthEMBUS & $\mathrm{N}$ & 3 & 0 & 1 & 1 \\
\hline PaiemotionalwarmthEMBUS & Mean & 19.67 & NA & 23 & 14 \\
\hline PaiemotionalwarmthEMBUS & Median & 18 & NA & 23 & 14 \\
\hline PaiemotionalwarmthEMBUS & $\begin{array}{l}\text { Standard } \\
\text { deviation }\end{array}$ & 2.89 & NA & 0 & 0 \\
\hline PaiemotionalwarmthEMBUS & Min & 18 & NA & 23 & 14 \\
\hline PaiemotionalwarmthEMBUS & Max & 23 & NA & 23 & 14 \\
\hline PaioverprotectionEMBUS & $\mathrm{N}$ & 3 & 0 & 1 & 1 \\
\hline PaioverprotectionEMBUS & Mean & 21 & NA & 23 & 18 \\
\hline PaioverprotectionEMBUS & Median & 17 & NA & 23 & 18 \\
\hline PaioverprotectionEMBUS & $\begin{array}{l}\text { Standard } \\
\text { deviation }\end{array}$ & 7.81 & NA & 0 & 0 \\
\hline PaioverprotectionEMBUS & Min & 16 & NA & 23 & 18 \\
\hline PaioverprotectionEMBUS & Max & 30 & NA & 23 & 18 \\
\hline MaerejectionEMBUS & $\mathrm{N}$ & 3 & 0 & 1 & 1 \\
\hline MaerejectionEMBUS & Mean & 8.67 & NA & 7 & 14 \\
\hline MaerejectionEMBUS & Median & 8 & NA & 7 & 14 \\
\hline MaerejectionEMBUS & $\begin{array}{l}\text { Standard } \\
\text { deviation }\end{array}$ & 2.08 & NA & 0 & 0 \\
\hline MaerejectionEMBUS & Min & 7 & NA & 7 & 14 \\
\hline MaerejectionEMBUS & $\operatorname{Max}$ & 11 & NA & 7 & 14 \\
\hline MaeemotionalwarmthEMBUS & $\mathrm{N}$ & 3 & 0 & 1 & 1 \\
\hline MaeemotionalwarmthEMBUS & Mean & 19 & NA & 23 & 14 \\
\hline MaeemotionalwarmthEMBUS & Median & 19 & NA & 23 & 14 \\
\hline MaeemotionalwarmthEMBUS & $\begin{array}{l}\text { Standard } \\
\text { deviation }\end{array}$ & 4 & NA & 0 & 0 \\
\hline MaeemotionalwarmthEMBUS & Min & 15 & NA & 23 & 14 \\
\hline MaeemotionalwarmthEMBUS & Max & 23 & NA & 23 & 14 \\
\hline MaeoverprotectiomEMBUS & $\mathrm{N}$ & 3 & 0 & 1 & 1 \\
\hline MaeoverprotectiomEMBUS & Mean & 17.67 & NA & 23 & 18 \\
\hline MaeoverprotectiomEMBUS & Median & 17 & NA & 23 & 18 \\
\hline MaeoverprotectiomEMBUS & $\begin{array}{l}\text { Standard } \\
\text { deviation }\end{array}$ & 2.08 & NA & 0 & 0 \\
\hline MaeoverprotectiomEMBUS & Min & 16 & NA & 23 & 18 \\
\hline MaeoverprotectiomEMBUS & $\operatorname{Max}$ & 20 & NA & 23 & 18 \\
\hline
\end{tabular}

